\title{
RESEARCH MEMORANDUM
}

This is a working paper. It may be expanded, modified, or withdrawn at any time.

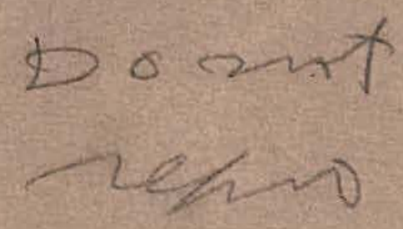




\section{DISCLAIMER}

This report was prepared as an account of work sponsored by an agency of the United States Government. Neither the United States Government nor any agency Thereof, nor any of their employees, makes any warranty, express or implied, or assumes any legal liability or responsibility for the accuracy, completeness, or usefulness of any information, apparatus, product, or process disclosed, or represents that its use would not infringe privately owned rights. Reference herein to any specific commercial product, process, or service by trade name, trademark, manufacturer, or otherwise does not necessarily constitute or imply its endorsement, recommendation, or favoring by the United States Government or any agency thereof. The views and opinions of authors expressed herein do not necessarily state or reflect those of the United States Government or any agency thereof. 


\section{DISCLAIMER}

Portions of this document may be illegible in electronic image products. Images are produced from the best available original document. 
Prepared Under Contract

with

U. 8. Atomic Enerisy Conmission Contract No. AT(29-1)-1477

$A E(U-351)$

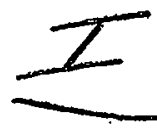

RESEARCH MEMORANDUM

POINT SOURCE EXPLOSION IN AIR

Harold L. Brode

$\mathrm{RM}-1824-\mathrm{AEC}$

ASTIA Document Number AD 133030

December 3, 1956

Assigned to

This is a working paper. It may be expanded, modified, or withdrown at any time.

LEGAL NOTICE

Thle report was prepared as an account of Govorsment aponsored work. Nelther the valtod States, nor the Commination, nor any porson acuags on behall of the Commieston:

A. Makces any warranty or representa ion, expresaed or implied, whis respect to tho accu-

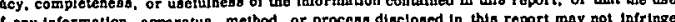

B. Acsumes any linbuluce with respect to the use of or for damages reaulting trom the of any information, apparatug, method, or process disclosed in thes report.

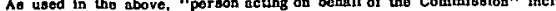
ployes or contractor of the commaston, or omployeo of such cont

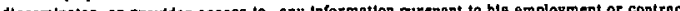
with the Comminsion, or his employment with such contractor. 


\section{II}

$\leftrightarrow$

5100070 Los Alamos Scientific Laboratory, (20 copies)

Attn: Carson Mark

B. Freeman

Document Section ( 18 copies)

5100121 UCRL, Iivermore (10 copies)

Attn: H. York

M. M. Mills

II. Brown

J. Foster

R. Christian

D. Beckstead

Information Division (4 coples)
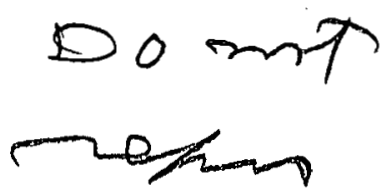


\begin{abstract}
Uolng a high speed JOHNNIAC computer and a program which allows the solution of the partial differential equations governing hydrodynamic motion In spherical geometry, the problem of the blast wave from a point source in alr has been carried out. The first section of the report describe the methods and the equation of state for air. The second section covers the results of the particular solution for a point source, giving shock values of pressure, density, particle velocity, temperature and dynamic pressure as functions of the shock radius and of the peak overpressure. The time histories of the same varlables are given for a number of distances from the source, as well as values of the durations of positive phases and Impulses from overpressure and from dynamic pressure.
\end{abstract}

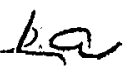




\section{CONTENTS}

\section{Section}

I. INTRODUCTION............................. 1

II. EQUATIONS OF MOTION AND STATE.................

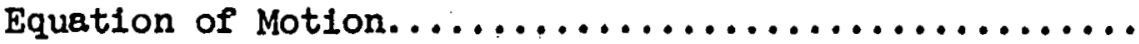

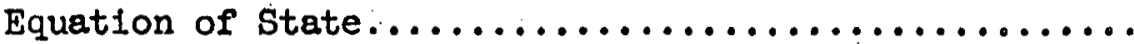

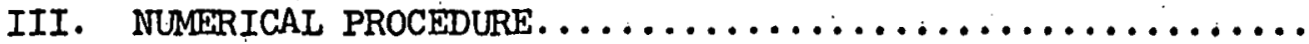

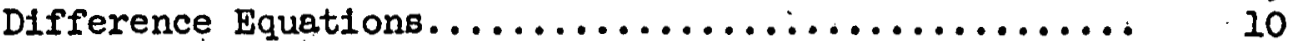

Distribution of Space Points.................. 12

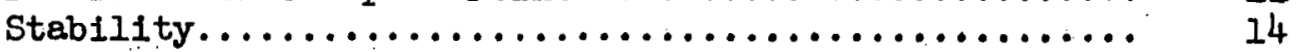

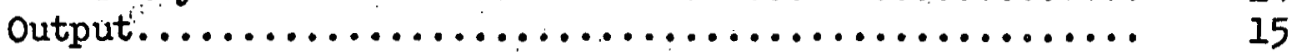

The Rankine-Hugoniot Conditions................ 17

Scaling and Numerical Significance............. 18

IV. POINT SOURCE IN AIR......................... 21

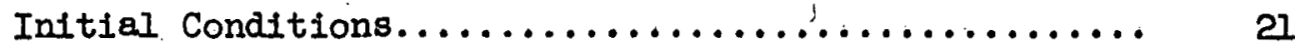

Shock Front Behavior......................... 2l

Variation of Blast Parameters with Shock Overpressure. $\quad 24$

Variation of Impulses with Distance.............. 27

Kinetic and Internal Energies as Functions of Time.... 27

Pressures as Functions of Time................. 28

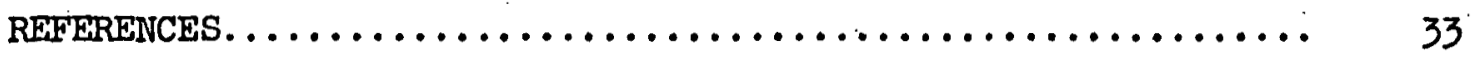

TABLE I - Shock Values for Flgures 13 thru 46............. 35 


\section{INIRODUCTION}

The blast wave from an instantaneous release of enersy at a point has been solved numertcally in considerable detall for an 1deal gas ${ }^{(1)}$. The same source in real air will result in a blast that is different In a number of important ways. This paper is a report on a calculation of the point source explosion in real air. The method is similar to that used in previous problems, (1) relying on the basic technique of the artificial viscosity (2), but the equation of state of air makes it a technically more complicated problem:

The first portions of this paper will deal with the deta1ls of the method and of the equation of state fits since much of this information 1s of general usefulness and does not appear elsewhere. The differential equations, the corresponding difference equations, and the computation procedures all are described so as to be useful both in evaluating the various problems that have been run and in setting up simflar problems where desired. The fits to the equation of state were obtained empirically through a series of tedious plottings of data in different forms and with many guesses and adjustments of parameters. The resulting fit over the two thermodynamic variables is qutte sat1sfactory however and represents a conventent analytical expression for the equation of atate of alr over the ent1re range of pressures and densities necessary to treat shocks of arbitrary strength in alr at standard sea level conditions to conditions at sixty thousand feet or better. The f1t as given here does not Include correctlons for the more recently accepted blading energy of the nitrogen molecule. Bubsequent calculations did use an improved fit which corrected for this difference and also included some further reflnements. (3) 


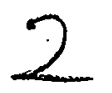

The remaining sections of th1s report present a summary of calculational results for the blast from a point source in air This 1s a rather classic problem in that two numerical solutions already exist for a point source In an ideal gas $(1,4)$ and several analytical solutions exist under the IImitations of a strong shock and an 1deal gas $(5,6,7)$. A comparison between these ideal gas results and the results for real air 18 therefore interesting. The point source is not a physically sensible beginning, of course, since in the reglons of very high pressures and temperatures other phenomena will play an important role (e.g., radiation transport).: Some of the subsequent problems that have been carried out are based on more realistic initial conditions $(3)$, but the point source problems have the advantage of a simple flow field lnvolving only one shock wave at the same time possessing the most sallent features of other more complex spherical blast wave problems.

The summary given in this report includes most of the results of analysis of the numerical data, including the behavior of the varlous shock parameters, the time dependences of overpressures, particle velocity, density, temperature, and dynamic pressure at a series of distances from the source, and including the behavior of such integral qualities as the positive and negative impulses of overpressure and dynamic pressure. Time of shock arrival, durations of posttive and negative phases of pressure and velocity, balance of energy between kinetic and internal all are iliustrated. For most applications this data 18 sufficiently detalled and complete so that Purther reference to the numerical results 18 unnecessary, however, for those cases where further information about gradients and values of pressure; velocity and density within the flow fleld at varlous times 18 desired, a complete set of plots of these variables as functions of the radius are avallable in a supplement to this paper $(8)$. 


\section{EQUATIONS OF MOTION AND STATE}

\section{EQUATION OF MOTION}

The equations of motion are expressed in a Lagrangean form whth the independent varlables being the time $(t)$ and a mass coordinate $(x)$ where $X$ is defined as $X=p_{1}{ }^{3} / 3$ and $p_{1}$ 1s the initial density of the gas and $r_{0}$ its inftial position. The hydrodyantc equations may then be written as follows:

$$
\begin{aligned}
& \frac{1}{\rho}=R^{2} \frac{\partial R}{\partial X}, \\
& \text { conservation of mass; } \\
& \frac{\partial u}{\partial t}=-R^{2} \frac{\partial P}{\partial X} \\
& \text { conservation of momentum; } \\
& \frac{\partial E}{\partial t}=\frac{P}{\rho^{2}} \frac{\partial \rho}{\partial t}, \\
& \text { conservation of energy; } \\
& \mathbf{P}(\mathrm{E}, \mathrm{p}), \\
& \text { caloric equation of state; } \\
& \mathbf{T}(E, \rho) \\
& \text { thermal equation of state; } \\
& u=\frac{\partial R}{\partial t}, \\
& \text { definition of particle velocity: . }
\end{aligned}
$$

It. Is conventent to reduce these equations to a dimensionless set which then may be applied to any initial total energy (v) and any Inttial preshock conditions $\left(P_{0}, P_{0}, F_{0}, E_{0}\right)$.

For this we define

$$
\begin{aligned}
& \alpha^{3}=\frac{w}{P_{0}}, \\
& \delta=\frac{p_{0}}{\rho_{0} E_{0}}=\left(y_{0}-1\right)=0.4,
\end{aligned}
$$


RM-1824-AEC

$12-3-56$

$$
\begin{aligned}
& f \\
& \quad=\frac{c_{0}^{2} \rho_{0}}{P_{0}}=\tau_{0}=i .4 .
\end{aligned}
$$

Bubstituting the following varlables

$$
\begin{aligned}
\pi & =P / p_{0} \\
\eta & =\rho / \rho_{0} \\
B & =u / c_{0} \\
\epsilon & =E / s_{0} \\
\theta & =T / T_{0} \\
\lambda & =R / \alpha \\
x & =x / \rho_{0} \alpha^{3}=\frac{\eta_{1} \lambda_{0}^{3}}{3}=\frac{1}{3} \frac{\rho_{1} r_{0}^{3}}{p_{0} \alpha^{3}} \\
\therefore & =r_{0} / \alpha \\
\tau & =t C_{0} / \alpha
\end{aligned}
$$

the equations of motion become

$$
\begin{aligned}
& \frac{1}{\eta}=\lambda^{2} \frac{\partial \lambda}{\partial x}=\frac{1}{3} \frac{\partial \lambda^{3}}{\partial x} \\
& \frac{\partial \beta}{\partial \tau}=-\frac{1}{r_{0}} \lambda^{2} \frac{\partial \pi}{\partial x} \\
& \frac{\partial \epsilon}{\partial \tau}=\delta \frac{\pi}{\eta^{2}} \frac{\partial \eta}{\partial \tau} \\
& \frac{\partial \lambda}{\partial \tau}=\beta
\end{aligned}
$$


It w1ll be conrenlent to write the equations of state in st1ll Bnother form:

$$
\theta=s(z, \eta), \therefore \quad \text { where } z=\pi / \eta
$$

and

$$
\varepsilon=\delta 2\left(\frac{\mu-1}{2}\right) ; \quad \mu(z, \eta) .
$$

\section{EQUATION OF STATE}

The quant1ties $s(z, \eta), \mu(z, \eta)$ are then derived from equation of state data as some analytical or tabular functions. These two f1ts are not entirely independent. In order to satisfy the second law of thermo-. dynamics a reciprocity relation exists whlch places a constraint on these functions. For purely hydrodynamical considerations, however, there is no need to observe this restraint since the thermal equation 18 superpluous to the equation of motion. In such cases where the temperature is coupled to the hydrodynamics, e.g. as by radiation, heat conduction, or heat diffusion, it would be necessary to observe the reciprocity restriction. Consequently, the following derivation points to an approximation which makes such a congtraint less difficult to comply with in fitting the equation of atate data analytically.

Choosing as our independent varlables $z=\pi / \eta$, and $\eta$ the second law In the form

$$
d s=\frac{D q}{T}=\frac{d E+p d v}{T}, \text { where } v=\frac{1}{\rho},
$$

becomes 


$$
\begin{gathered}
\frac{\rho_{0} T_{0}}{\dot{P}_{0}} a_{\theta}=\frac{1}{2 S(z, \eta)}\left\{\left(\frac{\partial \mu}{\partial \eta}\right)_{z} a_{\eta}+\left[\left(\frac{\partial \mu}{\partial z}\right)_{\eta}+\frac{\mu-1}{z}\right] d z\right\}-\frac{d \eta}{\eta S} \\
\left.\left.=\left[\frac{1}{2 S} \frac{\partial \mu}{\partial \eta}\right)_{z}-\frac{1}{\eta \delta}\right] a_{\eta}+\frac{1}{2 \delta}\left[\frac{\partial \mu}{\partial z}\right)_{\eta}+\frac{\mu-1}{z}\right] d z,
\end{gathered}
$$

and the reciprocity relation $1 \mathrm{~s}$

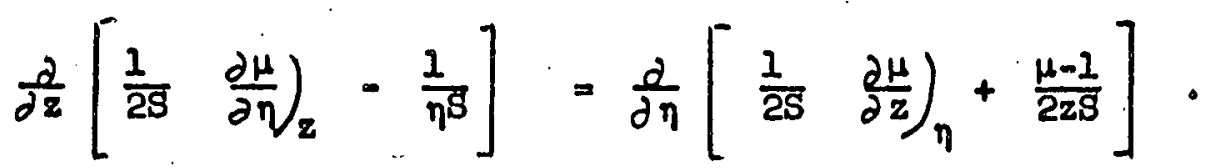

To within $10 \%$ in the density range of interest the function 8 can represent the thermal properties of alr as a function of $t$ alone (Independent of $\eta$ ). Furthermore, the function $\beta$ can fit the caloric properties to the same accuracy with the form

$$
\mu=\mu_{0}(z)+\mu_{1}(z) \ln \eta
$$

In this case, then, the reciprocity relation requires that

$$
\mu_{1}(z)=\frac{2 z s^{\prime}}{s+z s^{\prime}}
$$

The equation of state of alr data were taken from references 9, 10 and 11 and fitted prior to the publication of the later information of references 12 and 13. Subsequent problems were carried out with a fit corrected to these latter dats.

These functions as first fitted are the following:

$$
\begin{aligned}
\quad B(z) & =\frac{485}{1000+z^{2}}+\frac{3860+z}{7500+16.5 z} \\
\mu_{0}(z) & =1+\frac{17+3 z}{3+z}+\frac{800(z-1)}{2000+z^{2}}+\frac{2725 z}{16 \times 10^{4}+z^{2}}+\frac{45,000 z}{16 \times 10^{6}+z^{2}}
\end{aligned}
$$


$R M-1824-A E C$
$12-3-56$
$-7-$

$$
z S^{\prime}=z\left(\frac{d S}{d z}\right)=-\frac{2(485) z^{2}}{\left(1000+z^{2}\right)^{2}}-\frac{(16.5 \times 3860-7500) z}{(7500+16.5 z)^{2}}
$$

It will now be convenient to rewrite the energy conservation equation (13)

$$
\frac{\partial \xi}{\partial \tau}=\varepsilon \frac{\pi}{\eta} \frac{\partial \eta}{\partial \tau}=\delta=\frac{\partial \xi}{\partial \tau},
$$

In terms of $z$ and $\eta$ which after some algebra may be written

$$
\frac{\partial z}{\partial \tau}=\frac{\left(2-\mu_{1}\right) z}{\mu-1+z\left(\mu_{0}+\mu_{1} \xi\right)} \quad \frac{\partial \xi}{\partial \tau},
$$

where $\xi=$ ln $\eta$. 
THIS PAGE

\section{WAS INTENTIONALLY LEFT BLANK}


III. NTMPRICAL PROCEDURE

In order to solve the set of partial differential equations (11), (12), (14), and (25), we resort to the progressive solution (from a time $\tau$ to a new time $\tau+\Delta \tau$ ) of a set of difference equations which in the Iimt of Infinftesimal differences converges to the desired differential equations. Before such a scheme is workable, however, several condtions must be carefully met.

(1). The difference equations, besides converging in the 11mtt to the differential equations, should approximate them to as high an order in the difference quantities $(\Delta x$ and $\Delta \tau$ ) as is practicable, since we strive to reproduce numerically the solution throughout several thousand time steps.

(2) Stability of the numerical procedure must be guaranteed, 1.e. an upper bound dependent on some of the variables must be imposed on the size of time increments $(\Delta \tau)$ used.

(3) Discontinuities as arise in shock fronts must be avolded. To this end the artificial viscosity technique of Von Neumann and Richtmyer (2) is employed.

(4) Economy of computation must be balanced with the desire for numerlcal accuracy and detail, 1.e. the problem must be completable in a reasonable number of machine hours and yet contain as much detall as possible or as 1s necessary. 
DIFFERENCE EQUATIONS

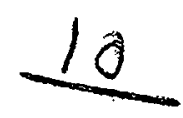

The following set of difference equations was chosen with the above conditions in mind. A space grid defined by $\Delta x_{l+1 / 2}$ between polnts $\left(l\right.$ and $l+1$ ) is carried with the variables $\beta_{l}$ and $\lambda_{l}$ defined at $l$-points and the variables $\pi_{\ell-1 / 2}, \quad \ell-1 / 2, z_{\ell-1 / 2}, \eta_{\ell-1 / 2}$ defined at the half-l points. An additional variable 18 introduced which is the artificial viscosity $(\xi) .^{*}$ For conventence this is sometimes carried as $\sigma=\xi / \eta$. Time is indicated in units of $\Delta \tau$ as $\tau=n \Delta \tau$.

$\beta_{\ell}^{n+l / 2}=\beta_{\ell}^{n-1 / 2}-k_{l}\left(\lambda_{\ell}^{n}\right)^{2} \frac{\Delta \tau}{\Delta x_{l}}\left[\pi_{l+1 / 2}^{n} \pi_{\ell-1 / 2}^{n}+\xi_{l+1 / 2}^{n-1 / 2}-\xi_{l-1 / 2}^{n-1 / 2}\right]$, where $\Delta x_{l}=\frac{1}{2}\left(\Delta x_{\ell+1 / 2}+\Delta x_{l-1 / 2}\right)$ and $k_{1}=\gamma_{0}^{-1}$

$\lambda_{\ell}^{n+1}=\lambda_{\ell}^{n}+\beta_{\ell}^{n+1 / 2} \Delta \tau$,

$\sigma_{l-1 / 2}^{n+1 / 2}=k_{2}\left(\beta_{l}^{n+1 / 2}-\beta_{l-1}^{n+l / 2}\right)^{2}$ for $\beta_{l-1}>\beta_{l}$,

and $\quad \sigma_{l-1 / 2}^{n+1 / 2}=0$ for $\beta_{l} \geqslant \beta_{l-1}$,

$$
\mathrm{k}_{2}=\cdot \frac{9}{2}\left(\gamma_{0}+1\right) \gamma_{0}\left(\frac{\mathrm{m}}{3 \pi}\right)^{2} \simeq 6 \text { for } \mathrm{m}=6 .^{* *}
$$

$\eta_{l-1 / 2}^{n+1}=\frac{3 \cdot \Delta x \ell-1 / 2}{\left(\lambda_{l}^{n+1}-\lambda_{l-1}^{n+1}\right)\left[\left(\lambda_{l}^{n+1}\right)^{2}+\lambda_{l}^{n+1} \lambda_{l-1}^{n+1}+\left(\lambda_{l-1}^{n+1}\right)^{2}\right]}$

\footnotetext{
*Th1s v1scosity is discussed more fully in references (1) and (2). * The number $m$ represents the number of space points over which a shock is spread; $1 . e$., for $m=6$ the variables will rise from pre-shock conditions to shock values in a space of approximately six l-points.
} 
$\xi_{\ell-1 / 2}^{n+1}=1 \mathrm{n} \eta_{\ell-1 / 2}^{n+1}$

$$
z_{l-1 / 2}^{n+1}=\frac{(A+B \xi+C \Delta \xi)^{*} z_{l-1 / 2}^{n}+2 \sigma_{l-1 / 2}^{n+1 / 2} \Delta \xi}{(A+B \xi-C \Delta \xi)^{*}}
$$

where $(A+B \xi \pm C \Delta \xi)^{*}$ is flrat computed with

$$
z_{l-1 / 2}^{n}, \xi_{l-1 / 2}^{n}, \Delta \xi_{i}=\xi_{l-1 / 2}^{n+1}-\xi_{l-1 / 2}^{n}
$$

With this a new value of $z$ is obtained and the above quantities can be recomputed with

$$
z_{l-1 / 2}^{n+1 / 2}, \xi_{l-1 / 2}^{n+1 / 2}, \Delta \xi=\xi_{l-1 / 2}^{n+1}-\xi_{l-1 / 2}^{n}
$$

This single iteration leaves us. With an accuracy of the same order 88 In the other difference equations, namely good to second order in $\Delta \tau$ or $\Delta x$. The other variables may then be computed in terms of these preceding ones.

$$
\begin{aligned}
& \pi_{l-1 / 2}^{n+1}=\eta_{l-1 / 2}^{n+1} z_{l-1 / 2}^{n+1}, \\
& \int_{l-1 / 2}^{n+1 / 2}=\left(\frac{\eta_{l-1 / 2}^{n+1}+\eta_{l-1 / 2}^{n}}{2}\right)^{\sigma_{l-1 / 2}^{n+1 / 2}} .
\end{aligned}
$$

And some not needed in the computation are also worth noting.

$$
\begin{aligned}
& \varepsilon_{\ell-1 / 2}^{n+1}=\delta z_{\ell-1 / 2}^{n+1}\left(\frac{\mu_{l-1 / 2}^{n+1}-1}{2}\right), \\
& \theta_{\ell-1 / 2}^{n+1}=z_{\ell-1 / 2}^{n+1} \delta_{\ell-1 / 2}^{n+l},
\end{aligned}
$$


$\mathrm{RM}-1824-\mathrm{AEC}$

$12-3-56$

-12 -

12

$$
q_{l-1 / 2}^{n+1 / 2}=\left(\beta_{l}^{n+1 / 2}+\beta_{l-1}^{n+1 / 2}\right)\left|\beta_{l}^{n+1 / 2}+\beta_{l-1}^{n+l / 2}\right|
$$

DISTRIBUTION OF SPACE POINTS

As the shock waves or hydrodynamical disturbances advance through undisturbed material more space points must be computed over in the numerical procedure. The machine memory 18 limited, however, and for high speed computation it 18 desirable to carry a more or less fixed number of space points. Accordingly, the following scheme 18 particularly appropriate for spherical shock wave problems.

As the shock begins to. move the last zone (at $l=I$ ) a new zone Is invented in front of it and a zone further back is eliminated.

When $\beta_{L}$ is greater than zero (or some mall constant) the following arithmetic is accomplished.

$\Delta r \quad=2^{-\frac{k}{15}} \cdot \lambda_{I-1}$

or $\Delta r \quad=k_{16}$

$\lambda_{I_{i}}=\lambda_{L-I}+\Delta r$

$\Delta x_{L-1 / 2}=\Delta r \eta_{I}\left(\lambda_{I} \lambda_{L-1}+\frac{\Delta r^{2}}{3}\right)$

$\xi_{L-1 / 2}=\beta_{L}=0$

$z_{L-1 / 2}=z_{I}$

$\eta_{I-1 / 2}=\eta_{I} \quad\left(e . g, z_{I}=\eta_{I}=\pi_{I}=1.0\right)$

$\xi_{I}=0$

$$
\begin{aligned}
& \pi_{I-1 / 2}=\pi_{I} \\
& \xi_{I-I / 2}=\xi_{I}
\end{aligned}
$$


After the new zone 18 1nvented one prevlous zone 18 to be eliminated. Th1s zone is determined as follows:

Beginning at some point near the origin called $l_{0}$ the varlables at $l_{0}+1$ and $l_{0}+2$ are comblned with

$$
\begin{aligned}
& \Delta x^{\prime} \ell_{0}+1 / 2=\Delta x_{l_{0}}+1 / 2+\Delta x_{l}+3 / 2, \\
& u^{\prime} \ell_{0}+1=u_{l_{0}}+2, \\
& \lambda^{\prime} \ell_{0}+1=\lambda_{\ell}+2
\end{aligned}
$$

and with

$$
2 l_{0}+1 / 2, \xi^{\prime} \ell_{0}+1 / 2, \xi^{\prime} l_{0}+1 / 2, \eta^{\prime} l_{0}+1 / 2, \pi^{\prime} l_{0}+1 / 2
$$

computed by

$$
z_{\ell_{0}+1 / 2}=\frac{z_{\ell_{0}+1 / 2} \Delta x_{\ell_{0}+1 / 2}+z_{\ell_{0}+3 / 2} \Delta x_{\ell_{0}+3 / 2}}{\Delta x_{\ell_{0}+1 / 2}+\Delta x_{\ell_{0}+3 / 2}} .
$$

After thss, all the data at $\ell_{0}+3$ and greater $l$ are shuffled down one $l$ value.

Provlded $\ell_{0}+1$ is not larger than some flxed $l$-value near the front, $l_{0} 18$ Increased by one for the next zone doubling. If $l_{0}+118$ too big, then $l_{0}$ is reset to some value $l_{\infty}$ which in turn 18 determined by the smallest $l$-value for which

$$
\lambda_{\ell+1}-\lambda_{l}<2^{-k_{17}} \lambda_{L}\left(\text { e.g., } k_{L 7}=5\right) .
$$

In order to avold doubling some zones near the origin, however, it is 


$$
14
$$

also arranged that $l_{\text {oo }}>l_{\text {op }}$ where $l_{\text {op }}$ defines the zones not to be doubled.

\section{STABILITY}

There are two different conditions on stablilty to be satisfied, one, the usual Courant condition on the sound speed and mesh opeed, the other, a diffusion-type term due to the artificial viscosity. These conditions impose the followlng restrictions:

$$
\begin{aligned}
& \Omega\left.=\left[\frac{\lambda^{4} \pi \eta}{(\Delta x)^{2}}\right]_{\max }(\Delta \tau)^{2}=\frac{2}{(\Delta \lambda)^{2}}\right]_{\max }(\Delta \tau)^{2}<1 \\
& \Sigma\left.\left.=\frac{4 \lambda^{2} \zeta \Delta \tau}{\gamma_{0}\left|\frac{\partial u}{\partial x}\right|(\Delta x)^{2}}\right]_{\max }=\frac{4 \zeta \Delta \tau}{\gamma \Delta u \rho \Delta \lambda}=K_{12} \frac{\Delta u}{\Delta \lambda}\right]_{\max } \tau<<1 \\
&\left.K_{12}=\frac{K_{2}}{\gamma_{0}}=\frac{2\left(\gamma_{0}+1\right) M^{2}}{(3.1416)^{2}}=17.5 \text { (for } M=6\right)
\end{aligned}
$$

Since the second condition is generally the more stringent, we arrange to change $\Delta \tau$ on the basis of

$$
\begin{aligned}
& \Delta \tau=\frac{2 / 3}{\left.k_{12} \frac{\Delta u}{\Delta \lambda}\right|_{\max }}=\frac{2 / 3 \Delta \tau}{\sum}, \\
& \text { where } \Delta u=u_{\ell}^{n+1 / 2}-u_{\ell-1}^{n+1 / 2} \text { and } \Delta \lambda=\lambda_{\ell}^{n+l}-\lambda_{l-1}^{n+l} .
\end{aligned}
$$

If this value of $\Delta \tau$ satisfies the flrst condition (Eq. 46) then the $\Delta \tau$ 1s changed. However, this will be attempted or tested only at certain Intervals which correspond to the times when we expect to print out the list of varlables. 
OUTPUT

It was planned to store in the electrostat1c memory all the varlables used in the computation plus some which are only desired at the time of printing.

Varlable

$B_{l}^{n+1 / 2}$

$\lambda_{\ell}^{n+1}$

$\Delta x_{\ell-1 / 2}$

$\zeta^{n+1}$

$\zeta_{\ell-1 / 2}^{n+1}$

$q^{n+1 / 2}$

$q_{l-1 / 2}$

$n+1$

$\eta_{l-1 / 2}^{n+1}$

$\pi_{\ell-1 / 2}^{n+1}$

$\lambda_{\ell-1 / 2}^{n+1}$

$\theta_{\ell-1 / 2}^{n+1}$

$\varepsilon_{l-1 / 2}^{n+1}$

${ }^{n+1}$

$\mathrm{z}_{\ell-1 / 2}^{n+1}$

$\sum_{\ell-1 / 2}^{n+1}$

$\sigma_{l-1 / 2}^{n+1}$
Carried in Compute Print (no. of diglts)

yes

уев $\quad 6(+8180)$

yes

yes

$7(+81 g n)$

yes

yes

$7(+\operatorname{sign})$

yes

yes

$7(+8180)$

no

yes $7(+\operatorname{sign})$

yes

yes

6 (no s1gn)

yes

yes

7 (no sign)

no

yes

7 (no sign)

yes

yes

7 (no slgn)

yes

yes

7 (no sign) yes

yes

yes no

no

no 
Not all these varlables need to be carrled for the computation, nor are they all important for the print-out, but as the problems attempted with this code may become more detalled and may include more variables, this extravagance may be cashed in on and the superfluous space re-assigned In a tighter code.

It $\mathbf{1 1 1}$ be desirable to display several 'constants' and characterlstic numbers at the time of output, also.

$$
\begin{aligned}
& \Delta \tau=\text { time increment (previous or current) } \\
& \tau=\text { time }=\sum_{1=1}^{n} \Delta \tau_{1} \\
& \text { n }=\text { number of cycles of } \Delta \tau \text { (time steps) } \\
& \text { m = number of space zones (untt for each added zone) } \\
& l_{0}=l \text { point for doubling } \\
& l_{00}=\text { last restart } l \text {-value for doubling } \\
& l_{\text {op : }}=\text { minimum allowed for doubling } \\
& \left.\Omega=\text { Courant stabll1ty }=\frac{z}{(\Delta \lambda)^{2}}\right]_{\max } \Delta \tau^{2} \\
& \left.\sum \equiv \text { viscosity stability }=\frac{K_{12} \Delta u}{\Delta \lambda}\right)_{\max } \Delta \tau \\
& E \quad \equiv \text { net 1nternal energy } k_{13} \sum_{l=1}^{L}\left(\varepsilon_{l-1 / 2}^{n+l}-\frac{1}{\eta_{l-1 / 2}^{n+l}}\right) \Delta x_{l-1 / 2} \\
& \mathrm{k}_{13}=4 \pi / \delta=31.416
\end{aligned}
$$




$$
\begin{aligned}
K & \equiv k_{14} \cdot \sum_{l=1}^{L} q_{l-1 / 2} \Delta x_{l-1 / 2}=\text { total k1net1c energy } k_{14}=\frac{\pi}{2} r \\
W & \equiv K+E=\text { total energy (normalized) } \\
& =\text { unity (1f all 1s well.) } \\
N & =\text { output number }
\end{aligned}
$$

THE RANKINE-HUGONIOT CONDITIONS

In the unfts of this paper the general shock conditions (expressing conservation of mass, momentum and energy) may be written as

$$
\begin{aligned}
\frac{\beta_{B}}{B} & =1-\frac{1}{\eta_{s}}, \\
B^{2} & =\frac{\pi_{s}-1}{\gamma_{1}} \frac{\eta_{s}}{\eta_{s}^{-1}} \text {, or } \beta_{s}^{2}=\left(\frac{\eta_{s}-1}{\eta_{s}}\right)\left(\frac{\pi_{s}-1}{\gamma_{1}}\right), \\
1+\pi_{s} & =\frac{2}{\left(\gamma_{I}-1\right)} \frac{\eta_{s}}{\eta_{s}^{-1}}\left(\epsilon_{B}-1\right) \text {, or } B^{2}=\frac{\pi_{s}^{2}-1}{\epsilon_{s}^{-1}}\left(\frac{\gamma_{I}-1}{2 \gamma_{1}}\right)
\end{aligned}
$$

where

$$
\begin{aligned}
& B=\frac{\bigsqcup}{C_{1}} \quad \beta_{s}=\frac{u_{s}}{C_{1}} \quad c_{1}{ }^{2}=\frac{P_{1} \gamma_{1}}{\rho_{1}} \\
& E_{1}=\frac{P_{1}}{\rho_{1}\left(\gamma_{1}-1\right)} \quad \epsilon_{s}=\frac{E_{s}}{E_{1}} \quad \pi_{s}=\frac{P_{s}}{P_{1}} \quad \eta_{s}=\frac{\rho_{s}}{\rho_{1}}
\end{aligned}
$$

These expressions are useful in establishing the scaing of velocities and densities for certain shock pressures, (one needs also to refer to the equation of state to determine a relation between $\left.\pi_{B}, \eta_{g}, \epsilon_{8}\right)$. Some maximum velocities and densities are listed for the following shock pressures: 


\begin{tabular}{ccccc} 
& \multicolumn{1}{c}{$/ 8$} & & & \\
$\pi_{B}$ & $\beta_{B}$ & $B$ & $\eta_{B}$ & $\epsilon_{B}$ \\
\hline $6 \times 10^{6}$ & 1800 & 2380 & 4.1 & $.905 \times 10^{6}$ \\
$10^{4}$ & 252 & 283 & 9 & 1780 \\
200 & 11.3 & 12.6 & 9.4 & 37 \\
10 & 2.17 & 2.95 & 3.8 & 2.7 \\
2 & 0.523 & 1.36 & 1.625 & 1.23 \\
\hline
\end{tabular}

SCALING AND NUMERICAL SIGNIFICANCE

The equation of state fits are intended to be valld for all temperatures above normal, and for densities from twenty times normal to less than one hundredth normal. However, radiation pressure and energy are not included In the current forms, so that for near normal densities we shall be restricted to temperatures less than a thousand times normal.

In a fixed-point code," as was used here, all numbers must be carried as fractions of the largest allowed value of that varlable. As a consequence, variables that have a large range cannot be carried to many places at the small end of the range and every reasonable device must be used to restrict the range of variables or of any terms in the computations. Also, where a number elther grows or decreases with time during the calculation, it is wise to stop and re-scale some of the variables and some parts of the computations.

Ideally, each problem that is concelved should be accompanted by a set of scaling rules for the variables and computations which are specially tallored to give maximum olgnificance. 
For scaling purposes it was found convenfent to write the equation of state 1n terms of $z^{-1} \equiv Y$, for whlch the varlous functions in Equation 31 become

$$
\begin{aligned}
& B_{1}=\frac{4}{5}\left[\frac{485 Y}{1+1000 Y^{2}}+\frac{(3860 Y+1)}{Y(16.5+7500 Y)}\right] \\
& B_{3}=\frac{485\left(1000 Y^{2}-1\right) Y^{2}}{\left(1+1000 Y^{2}\right)^{2}}+\frac{7500 Y(3860 Y+1)+(7500 Y+165)}{(16.5+7500 Y)^{2}} \\
& c_{1}=-\frac{2}{5}\left[\frac{2(485) Y^{2}}{\left(1+1000 Y^{2}\right)^{2}}+\frac{(16.5 \times 3860-7500) Y}{(16.5+7500 Y)^{2}}\right] \text {, } \\
& B_{2}=-2 Y^{3}\left[\frac{485\left(3000 Y^{2}-1\right)}{\left(1000 Y^{2}+1\right)^{3}}+\frac{7500(16.5 \times 3860-7500)}{(16.5+7500 Y)^{3}}\right], \\
& A=\frac{51 Y^{2}+18 Y+3}{(3 Y+1)^{2}}+\frac{800 Y^{2}[1+2000(2-Y) Y]}{\left(2000 Y^{2}+1\right)^{2}}, \\
& +\frac{8.72 \times 10^{8} Y^{3}}{\left(16 \times 10^{4} Y^{2}+1\right)^{2}}+\frac{1.44 \times 10^{12} Y^{3}}{\left(16 \times 10^{6} Y^{2}+1\right)^{2}}=4_{0}-1+24_{0} \\
& \mu_{0}-1=\frac{17 Y+3}{3 Y+I}+\frac{800 Y(1-Y)}{2000 Y^{2}+1}+\frac{2725 Y}{16 \times 10^{4} Y^{2}+1}+\frac{45,000 Y}{16 \times 10^{6} Y^{2}+1} \text {, } \\
& B=\frac{B_{1} B_{2}}{B_{3}^{2}}=\mu_{1}+z \mu^{\prime} \\
& C=1-\frac{C_{1}}{B_{3}},
\end{aligned}
$$

where $A, B$ and $C$ are as used in the energy equation (Equation 31 ). 
THIS PAGE

WAS INTENTIONALLY

LEFT BLANK 


\section{POITPT BOURCE IN AIR}

INITIAL CONDITIONS

The analytical solutions to the point source problem $(5,7)$ are restricted to an 1deal gas and a strong shock, and so do not lend themselves immediately to use as inftial conditions for an alr problem. In a sea level atmosphere the equation of otate 18 falrly well characterized along the Hugonlot by a constant gamms of 1.25 between 4000 atmos and 40,000 atmos shock pressure, so that an approximate inftial state 1s attalned by using the strong shock solution for this gamma at a shock pressure of 4500 atmos. Von Neumann's solution was used in this case (5) with a modified front to adjust to the artificlal viscosity requirement of a smeared shock front.

\section{SHOCK FRONT BEHAVIOR}

The shock overpressure $\left(\Delta p_{s}=\pi_{s}-1\right)$ as a function of the shock radius $\left(\lambda_{8}\right)$ is shown in Flgure 1 on a log-log scale. For comparison the peak overpressure for the 1deal gas case is also Indicated (broken Iine). The two curves can be made to colncide over most of their range by reducing the radius at each pressure on the ldeal gas curve by a factor of 0.843 . This reduction corresponds to an effective energy reduction to 60 percent of the total, 1.e., the real air case appears to be only 60 percent as efficlent as the 1deal gas blast insofar as peak overpressures are concerned. The discrepancy lies in the much larger amount of work that is done on the h1gh temperature air in dissociation and fontzation. The temperatures are st1ll high. In the reglons near the origin long after the shock is gone, and so that enersy 18 not fed back Into the blast very quickly and adds 
little to the subsequent history. It 18 interesting to compare the peak overpressures from a bare spherlcal charge of TNT (dashed curve in F1gure 1) wth these two point source curves. The early decay rate of the point source curves in the strong shock region 18 like the Inverse cube of the radius; but the early part of the HE curve $1 \mathrm{~s}$ more l1ke the 1nverse f1rst power of the radius since the source in that case is a falrly low temperature, high density gas which acts more like a plston. At later stages the decay increases as the plston energy 18 exhausted, but at the larger distances the TNI curve looks more like the ldeal gas curve since there is not the concentration of energy left near the origin in a high temperature sphere.

Beyond a lambda of 4 or below a peak overpressure of 0.05 atmos the point source real air curve is not reliable, since beyond this point the lack of significant figures and computing accuracy ${ }^{*}$ allowed the total energy to deviate from unity: At this late stage all the air except that in the hot Interior can be treated as ideal gas so the last part of the problem was remun using just an ideal gas equation of state, but accounting for the energy beld in the hot Inner region by arbitrarily reducing the total energy to 0.6 , thus giving the same overpressures at the point of start of the 1deal gas extension. This extension was not entirely satisfactory, however, both because of inaccuracies in the then small overpressures and velocities and.

\footnotetext{
*Perhaps the most serious inaccuracy in the computation in the late part of this problem 18 in the use of the approximation that zone volumes are proportional to $\lambda^{2} \Delta \lambda$ rather than to $(\lambda+\Delta \lambda)^{3}-\lambda^{3}$. Equation 29 indicates the latter form since it was used in subsequent problems and 1 s the more correct. In this problem, however, the approximate form was used since it was not originalily planned to allow zones near the origin to increase to a point where this approximation would not be valid, 1.e., to where $\Delta \lambda$ is no longer small relative to $\lambda$ over most of the energy-containing volume.
} 
because all the work energy was not yet out of the hot Interior where the alr was st1ll far from ldeal gas.

The 1deal gas extension calculation is shown In F1gure 1 as a dotted IIne. Since the time when thlis calculation was completed, some more accurate calculations have been carried at, giving results that are more rellable in the lower pressure reglon. These are reported on in RM-1825.

The peak dynamic pressure $\left(\gamma \eta \beta^{2} / 2\right)$ is shown as a function of shock radius in Figure 2. Here again both the original air calculation and the ideal gas extension calculation are of little value beyond a radius of about four. Pressures are shown in units of $P_{0}, 1_{. e}$, in atmospheres.

The peak particle velocity $\left(u / c_{0}\right)$, actually the peak particle Mach number, 18 shown in Figure 3 as a function of the shock radius. The shock compression (the shock overdensity) $\left(\eta_{\mathrm{s}}-1\right)$ is shown as a function. of shock radius in F1gure 4. Where the shock is strong, the density rat1o at the shock 1s given by $(y+1) /(\gamma-1)$, and it is evident from the early compression values (equal to $2 /(\gamma-1)$ for strong shocks) that the gamm is fairly small. As the shock decreases in strength the compression beglns to fall about like the inverse three halves power of the shock radius, much as the peak particle velocity does.

Figure 5 shows the shock temperature $\left(\mathrm{T} / \mathrm{T}_{0}-1\right.$ or temperature above freeting in untts of the absolute freezing temperature of water) as a function of shock radius. The shock temperature does not ride as high as the pressure for two reasons, one 18 the increased density in the shock, and the other is the fact that the non-1deal gas features of alr further depress the temperature relative to the pressure. 


\section{4}

The relation between shock radius $\left(\lambda_{\theta}\right)$ and shock arrival time $\left(t_{B}\right)$ 18 shown in Figure 6, where the t1me at the polnt where the calculation was begun was computed from the strong shock analytical solution that was used for inttial conditions (used a gamno of 1.25). The 1deal gas extension shows a sudden jump to a larger radius, indlcating that the arbitrary reduction of the energy to $81 x$-tenths was not correct for the time of arrival, although It was satisfactory for the peak overpressure-shock radius relation.

\section{VARIATION OF BLAST PARAMETERS WITH SHOCK OVERPRESSURE}

A number of variables are shown in Figure 7 as functions of the shock overpressure. The peak particle velocity can be seen to go from about a square-root dependence on the peak overpressure at high pressures to a linear dependence at low peak overpressures. The shock density ratio and the shock temperature (better shown in FIgures 4 and 5) approach unity at low pressures, but at no point as rapidly as the pressure does. The duration of the positive pressure phase $\left(D_{\Delta p}^{+}\right)$has a distinct minimum around four atmos pressure and rises slowly toward a constant at lower overpressures. The positive velocity duration $\left(\mathrm{D}_{Q}^{+}\right)$which must be greater than the positive pressure duration for inertial reasons, has less of a minfmum and epproaches the same limit as the positive pressure duration for very low overpressure. The negative phase durations $\left(D_{\Delta p}^{-}\right.$and $\left.D_{Q}^{-}\right)$are very similar to each other and nearly constant at around untty over the whole range of shock overpressure.

The positive impulse of overpressure $\left(I_{\Delta p}^{+}\right)$is defined as the integral over the positive phase of the overpressure.

$$
I_{\Delta p}^{+}=\int_{\tau}^{D_{a p}^{+}+\tau_{s}} \Delta p d \tau
$$


Figure 7 indicates that the overpressure impulse at high pressures varies about like the cube root of the overpressure, while at the low pressure end it varies more like the flrst power of the overpressure. Although the strong shock analytical solution would predict a sixth root dependence, such a dependence is not'valid since a considerable part of the Impulse comes at late times when the shock is no longer a strong shock, and the after-flow which is determining the tall of the Impulse at close-in points Is then characteristic of a weaker shock.

The negative overpressure impulse $\left(I_{\Delta p}^{-}\right)$, which is the absolute value of the integral of the overpressure In the negative phase (1.e. the "underpressure"), is seen to be nearly constant at the high overpressure end and to be dropping off about like the first power of the overpressure at the low pressure end.

$$
I_{\Delta p}^{-}=\int_{\tau_{s}+D_{\Delta p}^{+}}^{\tau_{s}+D_{\Delta p}^{+}+D_{\Delta p}^{-}} d \Delta d \tau .
$$

Figure 8 has the peak dynamic pressure $\left(Q_{8}\right)$ and the dynamlc Impulse $\left(I_{Q}^{+}\right)$indicated as functions of the shock overpressure. The usual relation from the Hugoniot conditions specifies that the peak dymamic pressure be releted to the peak overpressure by the form

$$
Q_{s}=\frac{\Delta p_{s}{ }^{2}+\Delta p_{s}(7-5 \gamma) / 2}{(\gamma-1)\left(7+\Delta p_{s}\right)}
$$

where gamma 18 defined by the relation between pressure, density and internal energy for air $(\gamma=p / \rho E-1)$, and ranges in value between 1.4 and 1.18 for shocks in sea level alr.' Disregarding the varlation of $\gamma$ - 1 , this relation 
Indicates a dependence at h1gh overpressures on the f1rat power of the shock overpressures. The varlations of the curve, then, at the high end are due to varlations in $\gamma$. At the lower pressures the $\gamma$ 18 very close to constant at $7 / 5$ ths, and the formula reduces to

$$
Q_{B}=\frac{5 \Delta p_{B}^{2}}{2\left(7+\Delta p_{s}\right)}, \text { for } \Delta p_{B}<10
$$

For small $\Delta p_{8}$ this expression is nearly quadratic in $\Delta p_{8}$, as the $Q_{8}$ curve in Figure 8 indicates.

The positive dynamie 1mpulse $\left(I_{Q}^{+}\right)$1s defined as

$$
I_{Q}^{+}=\int_{\tau_{B}}^{\tau_{B}+D_{Q}^{+}} Q d \tau
$$

Figure 8 indicates that the dynomic impulse increases exceedingly I1ttle as the shock pressure increases above about 10 atmos, and in fact the dynamic impulse appears to be proportional to the sixth root of the peak overpressure at high overpressures. At low peak overpressure, on the other hand, the dynamlc impulse seems to be nearly proportional to the square of the peak overpressure. An approximate expression then 18

$$
I_{Q}^{+} \simeq \frac{6.7^{8} \Delta p^{2}}{(1.4+\Delta p)^{11 / 6}}
$$

Also shown on Figure 8 is the time of arrival. "The nearly stralghtIine nature of this curve suggests a simple relation:

$$
\left(\tau_{B}\right)^{1.14} \Delta p_{B}=0.200, \quad \text { or } \tau^{8} \Delta p_{B}^{7}=1.28 \times 10^{-5}
$$

wh1ch 1s approximately valid over the entire range of shock overpressures. 


\section{VARIATION OF TMPULSES WITH DISTANCE}

Positive 1mpulses as functions of the distance from the source are Bhown In Flgure 9. Here again some simple approximat1ons are obvious from the straight-1ine character of parts of these curves. The positive overpressure Impulse 18 given well over 1ts ent1re range by the expression

$$
\lambda I_{\Delta p}^{+}=0.0322
$$

The positive dynemic pressure 1mpulse decreases like the Inverse square root of the radial distance in the close-in region, but falrly sharply at around a lambda of 0.3 it changes to a rate of decrease proportional to the inverse five halves power of the radius. This latter decay rate is true out to two orders of magnitude on lambda or down five more orders of magnitude in 1mpulse. An approximate expression which exhibits these features is the following:

$$
I_{Q}^{+}=\frac{A}{\sqrt{\lambda}\left(B+\lambda^{2}\right)} \cdot \frac{0.004}{\sqrt{\lambda}\left(0.089+\lambda^{2}\right)}
$$

Th1s expression is low by as much as thirty five percent near the inflection point $(\lambda \sim 0.36)$ but is much better than that on either side and goes quite exactly to the curve of Figure 9 at elther extreme. For a better fit (at all $\lambda^{\prime} \theta$ ) a correctlon term can be added.

$$
I_{Q}^{+}=\frac{0.004}{\sqrt{\lambda}\left(0.089+\lambda^{2}\right)}+\frac{0.000314 \lambda}{0.00231+\lambda^{5}}
$$

KINETIC AND INTERNAL ENERGIES AS FUNCTIONS OF TIME

At any Instant of time a certain fraction of the energy appears as ordered kinetic motion and the balance is in the form of Internal energy 
of the gas. It 18 interesting to note how these quantities (defined in Equations 50 and 51) vary with time. As Equation 50 indicates, the 1nternal energy considered is just the total internal energy in the blast wave minus the internal energy possessed Inftially by the unshocked air now engulfed, 1.e., the net Internal energy above that of normal air. F1gure 10 is a time plot of these quant1ties $\mathrm{K}$ (kinetic energy) and $\mathrm{E}$ (Internal energy) as a function of time. In the strong shock for an 1deal gas of gamma of 1.25 about one quarter of the energy is in kinetic energy, while in a weak shock the kinetic energy tends to zero.

\section{PRESSURES AS FUNCTIONS OF TIME}

The negative overpressure phase has a very constant duration, and in the close-1n regions it has also a constant minimum value. Figure 11 shows the negative overpressure duration, the mintmur overpressure, and the negative overpressure impulse as functions of the distance from the source. Beyond the region of the residual hot gasses, 1.e. beyond a radius of about 0.3 the minimum overpressure and the negative impulse begin to decrease about proportional to the inverse of the distance. The apparent proportionality between the negative orerpressure impulse and the minimum negative overpressure may be expressed by the following approximate relation:

$$
I_{\Delta p}^{-} \cong-0.55 \Delta p_{\min } \cong \frac{1}{2} \Delta p_{\min } D_{\Delta p}^{-}
$$

The factor of a half may be considered a kind of form factor, since the negative phases do in fact have very simllar shapes and nearly the same durations. The shape of the negative phase for overpressure 18 given approximately by the form 


$$
\Delta p=14 \Delta p_{m i n} t(1-t) e^{-4 t}
$$

where $t$ 10 measured from the onset of the negat1ve phase.

The mintmum negative dynamlc pressure, 1.e., the maximum inward drected dynamic pressure in the negative phase of the velocities rises very sharply in the close-in region (where the alr 18 left considerably heated) $(\lambda<0.3)$ to a maximum of about $2 \times 10^{-3}$ at a radius of about a half. Beyond that point 1 t decreases in absolute value at a rate asymptotically proportional to the radius squared. Flgure 12 11lustrates this rapid rise and fall of the maximum inward dynamic pressure and also the corresponding inward dymantc impulse. Much like the negative overpressure phase, the negative velocity phases follow olmilar time historles at all points, and having also a nearly constant duration the maximum Inward dynamic pressure and the resulting impulse are nearly proportional.

$$
I_{Q}^{-}=0.38 Q_{\min } \text {. }
$$

Such blast parameters as the overpressure, the dynamic pressure, the alr density, the temperature and the particle velocity are given as functions of the time after shock arrival in Figures $13-46$. The first ten (F1gures 13 - 23) are plotted on sem1-10g paper to 11lustrate the exponential nature of their decay. A simple exponential would be represented as a stralght line, but none of these are that simple. Actually, the overpressure is very easily fit with the sum of two exponentials, a sharp decaylng one for the earliest times and more lelsurely one for the remainder. If the overpressure f1t 18 to be made to pass through zero at the end of the positive phese, then a inear factor $\left(1-t / D_{\Delta p}^{+}\right)$may 
be included. At any of the time plots, a reasonable lit may be made with the form

$$
\Delta p=\Delta p_{s}:\left(a e^{-\alpha t}+b e^{-\beta t}\right) \cdot\left(1-t / D_{\Delta p}^{+}\right), \text {with } a+b=1
$$

Less preclsely but more generally the same form can be applled over the ent1re range of distances or of peak overpressures by taking the arbltrary constants in equation 78 to be the following:

$$
\begin{aligned}
\alpha & =\Delta p_{8}+1 / 2 \\
\beta & =70+10 \Delta p_{8} \\
a & =\left(1+0.16 \Delta p_{8}\right) /\left(1+\Delta p_{B}\right) \\
b & =\left(0.84 \Delta p_{8}\right) /\left(1+\Delta p_{8}\right)
\end{aligned}
$$

This form with these constants expressed in terms of the peak overpressure (as above) gives a fairly good fit to the overpressure at all levels, however, 1ts integral over time, which 1s the positive overpressure impulse, 1s lower than the actual numerical integral for the highest pressure levels, but 18 good to ten percent for peak overpressures less than thirty etmospheres.

A simliar exponential fit can be made for the dynamic pressure, using the sum of two exponential decays, but the dymamic pressure drops so rapidy with time that a single exponential fit to the initial decay rate together with a linear term to force the dynamic pressure to zero at the end of the positive phase works quite well.

$$
Q=Q_{s}\left(1-t / D_{Q}^{+}\right) e^{-\sigma t},
$$

where again $t$ is the time after time of arrival $\left(t=\tau-\tau_{8}\right)$, and $D_{Q}^{+}$is the 


$$
\begin{gathered}
\mathrm{RM}-1824-\mathrm{AEC} \\
12-3-56 \\
-32-
\end{gathered}
$$

duration of the positive velocity phase. This form can be made to agree fairly well over the whole range of pressure levels with the follow lng epproxfinating analytic form for the exponential coefficient:

$$
\sigma=14.5\left(\Delta \mathrm{p}_{8}\right)^{1.126}+7
$$

This form not only approximates the time dependence, of the dynamic pressure but also gives the dynamic Impulse to better than an order of magnitude.

Table 1 is a list of the shock values at the distances chosen for the time plots of Figures $13-46$. 
THIS PAGE

\section{WAS INTENTIONALLY \\ LEFT BLANK}




\section{REFTERENCES}

1. Brode, H. I., Journal of Applied Phys1cB, Volume 26, June 1955, pp. $766-775$.

2. Von Neumann, J., and R. D. Rlchtmyer, Journal of Applied Physics; Volume $2 i, 1950$, p. 232.

3. Brode, H. I., The Blast Wave in Air Resulting From a High Temperature, High Pressure Sphere of Alr, The RAND Corporation, RM-1825-AEC, December 3, 1956.

4. Von Neumanin, J. and H.H. Goldstine, Communications on Pure and Applied Mathemat1cs, Volume VIII, 1955, pp. $327-354$.

5. Von Neumann, J., and others, Shock Hydrodynamics and Blast Waves, LOB Alamos Scientific Labortory, AECD-2860, 1944.

6. Taylor, G.I., Proceedings of Róyal Soclety, Series A, Volume 201, March 1950, pp. 159-186. (Taylor fld not complete his analytical solution, but chose to integrate numerically after reducing the equations to ordinary differential ones by means of his similerity assumption. Von Neumann's solution - reference 5 - obtains completely analytic results as have the more recent efforts of others, e. 8., reference 7. )

7. Latter, R., Journal of Applied Phys1cs, Volume 26, August 1955, pp. $954-960$.

8. Brode, H. I., Space Plots of Pressure, Density and Particle Velocity for the Blast Wave from a Polnt Source in AIr (Supplement to RM-1824-AEC, The RAND Corporation, RM-1913-AEC, June 3, 1957.

9. Hirschfelder, J. 0 . and J. L. Magee, Thermodynamic Propertles of Alr at High Temperatures; Los Alamos Laboratory, IADC-122 (MDDC-590), January 1947.

10. Hirschfelder, J. 0 . and C. F. Curtiss; Thermodynamic Properties of

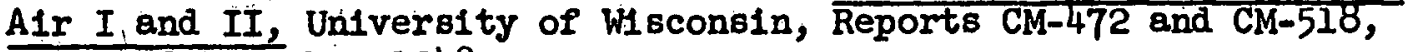
June and December 1948.

11. Krieger, F.J. and W. B White, The Composition and Thermodynamic Properties of Air at Temperatures from 500 to $80000 \mathrm{~K}$ and Pressures from 0.00001 to 100 Atmos, The RAND Corporation, Report R-149, April 1949. (out of print)

12. Gilmore, F. R., Equilibrium Composition and Thermodynamic Properties of A1r to $24,000 \%$, The RAID Corporation, RM-1543, August 1955. 
RM-1824-AEC

$12-3-56$

$-34-$

13. H1lsenrath, J., and C. W. Beckett, Thermodynamle Propert1es of Argon-free A1r, National Bureau of Standards, Report 3991, April 1955. 
Table 1

Shock Values for Figures 13 thru 46.

\begin{tabular}{|c|c|c|c|c|c|c|c|}
\hline $\begin{array}{l}\text { F18. } \\
\text { No. }\end{array}$ & $\lambda_{8}$ & $\Delta p_{8}$ & $\eta_{B}$ & $\beta_{B}$ & $\theta_{B}$ & $Q_{B}$ & $T_{8}$ \\
\hline 13 & .048644 & 900.1 & 8.402 & 27.33 & 50.06 & 4393. & $.0^{3} 66004$ \\
\hline 14 & .052857 & 698.6 & 9.112 & 23.459 & 39.88 & 3510. & $.0^{3} 81207$ \\
\hline 15 & .061134 & 452.1 & 10.079 & 18.70 & 28.52 & 2467 & $.0^{2} 117497$ \\
\hline 16 & .069561 & 297.2 & 9.669 & 15.12 & 22.65 & 2547. & $.0^{2} 163764$ \\
\hline 17 & .078376 & 202.7 & 8.941 & 12.07 & 18.51 & 911.8 & $.0^{2} 223367$ \\
\hline 18. & .097630 & 99.86 & $7 \cdot 360$ & 8.645 & 12.47 & 385.0 & $.0^{2} 391663$ \\
\hline 19 & .113408 & 69.88 & 6.864 & 6.872 & 9.736 & 226.9 & $.0^{2} .572371$ \\
\hline 20 & .124683 & 52.66 & 6.319 & 5.899 & 8.141 & 153.9 & $.0^{2} 724744$ \\
\hline 21 & .151996 & 30.61 . & 5.421 & 4.380 & 5.703. & 72.80 & .01182123 \\
\hline 22 & .175526 & 20.70 & 4.912 & 3.470 & 4.356 & 41.40 & .0167477 \\
\hline 23 & .197034 & 14.85 & 4.433 & 2.922 & 3.539 & 26.49 & .0221001 \\
\hline 24 & .223110 & 10.56 & 3.987 & 2.409 & 2.878 & 16.20 & .0297042 \\
\hline 25 & .254437 & 7.343 & 3.517 & 1.960 & 2.359 & 9.458 & .0403989 \\
\hline 26 & .296806 & 4.910 & 3.023 & 1.558 & 1.947 & 5.137 & .0574644 \\
\hline 27 & . 370999 & 3.034 & 2.489 & 1.136 & 1.616 & 2.451 & .0934767 \\
\hline 28 & .433672 & 2.021 & 2.107 & .8784 & 1.430 & 1.138 & .1293144 \\
\hline 29 & .494358 & 1.5012 & 1.8745 & . 72961 & 1.3309 & .69850 & .1686889 \\
\hline 30 & .609083 & .9873 & 1.614 & .5275 & 1.229 & .3144 & .2493437 \\
\hline 31. & .721279 & .7212 & 1.4650 & .40438 & 1.1724 & .16769 & .3353310 \\
\hline 32 & .880953 & .4970 & 1.331 & .3105 & 1.123 & .08983 & .46486489 \\
\hline 33 & 1.121718 & .3523 & 1.2391 & .22795 & 1.0891 & .045070 & .6793629 \\
\hline 34 & 1.328503 & .2679 & 1.1841 & .17939 & 1.0687 & .026674 & .8599936 \\
\hline 35 & 1.56402 & .20832 & 1.14459 & .13742 & 1.05364 & .015130 & 1.08110 \\
\hline 36 & 2.13397 & .13395 & 1.09387 & .091473 & 1.03663 & $.0^{2} 64069$ & 1.54872 \\
\hline 37 & 2.58061 & .20304 & 1.072531 & .072656 & 1.02845 & $.0^{2} 39632$ & 1.96674 \\
\hline 38 & 3.50446 & .068127 & 1.048193 & .047938 & 1.01902 & $.0^{2} 16862$ & 2.86984 \\
\hline 39 & 4.32976 & .051419 & 1.036459 & .036285 & 1.01443 & $.0^{3} 95522$ & 3.66868 \\
\hline 40 & 5.23119 & .041958 & 1.029791 & .029598 & 1.01181 & $.0^{3} 63150$ & 4.59842 \\
\hline 41 & 6.19689 & .034537 & 1.024548 & .024490 & 1.00975 & $.0^{3} 43014$ & 5.54919 \\
\hline 42 & $7 \cdot 54070$ & .027467 & 1.019543 & .019538 & 1.00777 & $.0^{3} 27244$ & 6.88027 \\
\hline 43 & 9.78855 & .020813 & 1.014822 & .014790 & 1.00590 & $.0^{3} 15539$ & 9.12267 \\
\hline 44 & 11.28682 & .017374 & 1.012379 & .012410 & 1.00493 & $.0^{3} 10914$ & 10.61940 \\
\hline 45 & 13.45330 & .013513 & 1.0096333 & $.0^{2} 97801$ & 1.00384 & $.0^{4} 67600$ & 12.78051 \\
\hline 46 & 14.12602 & .012659 & 1.0090260 & $.0^{2} 90091$ & 1.00360 & $.0^{4} 57328$ & 13.47936 \\
\hline
\end{tabular}




\section{THIS PAGE}

WAS INTENTIONALLY

LEFT BLANK 


\section{7}

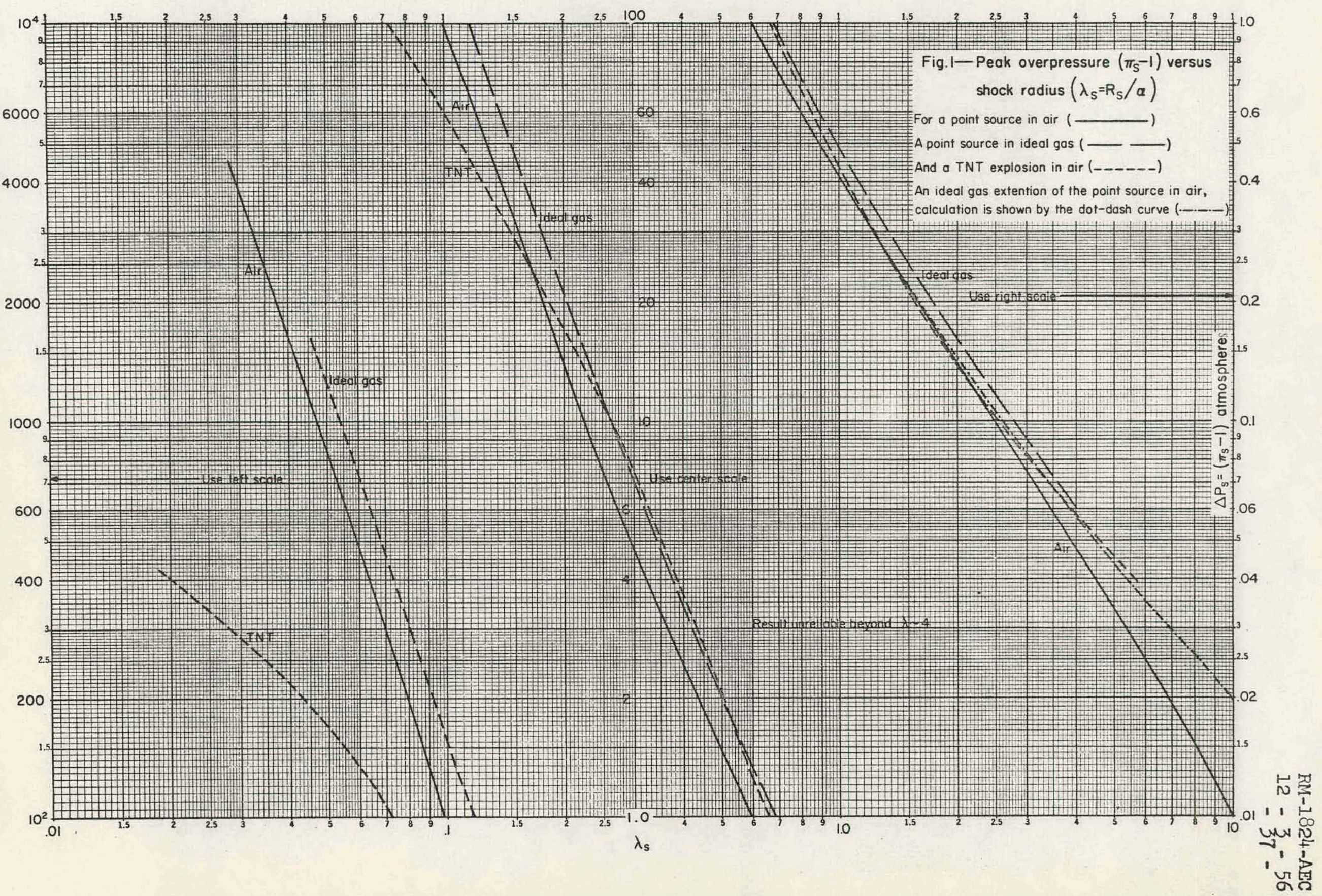




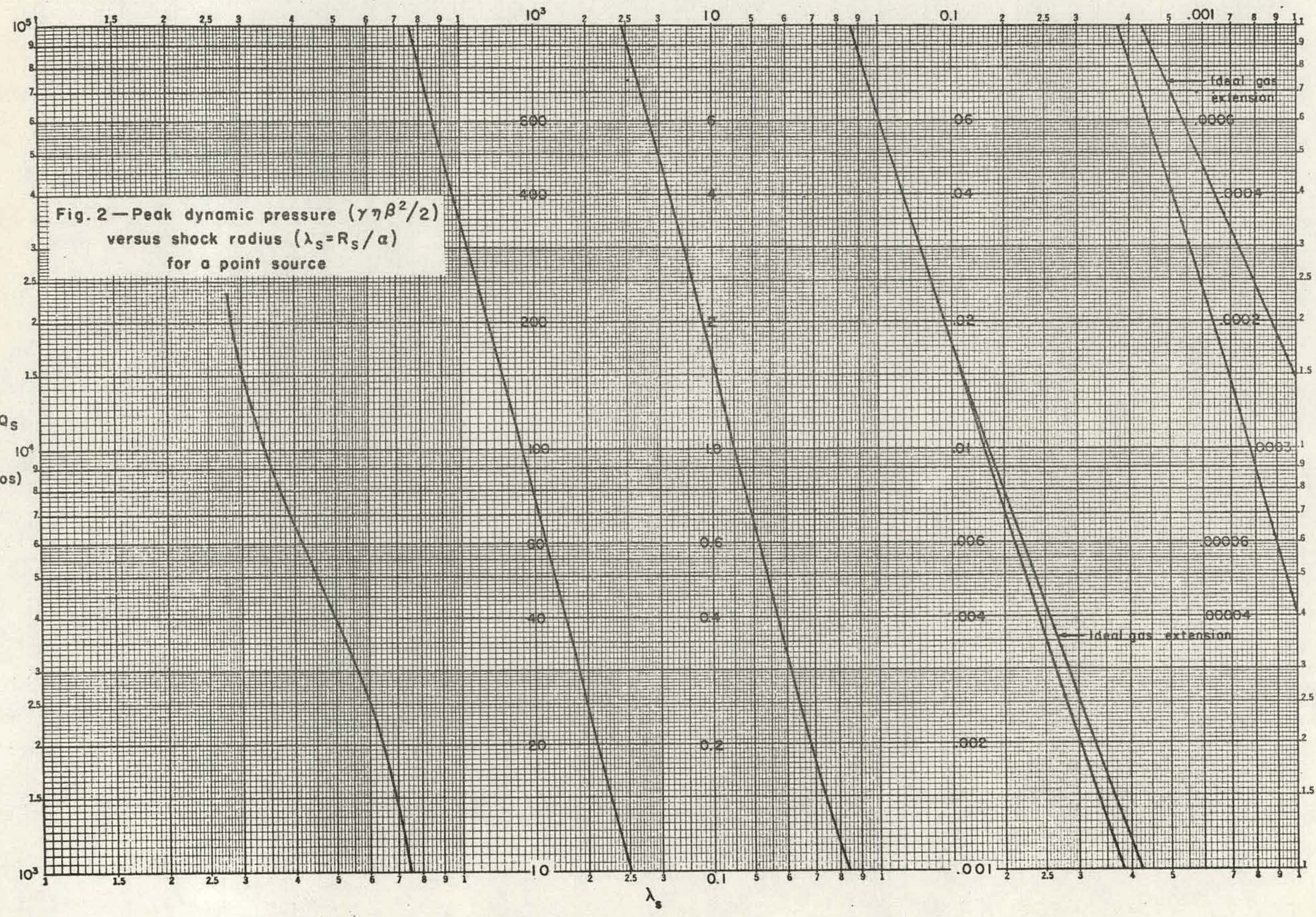

ूㅣㅇ 
(25

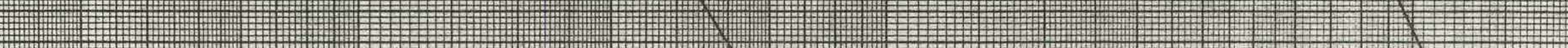

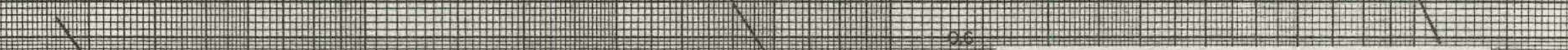
(O) ( Fig.3-Peak particle velocity versus shock radius $\left(\beta_{s}=u_{s} / c_{0}\right),\left(\lambda_{s}=r_{s} / \alpha\right)$ for a point radius

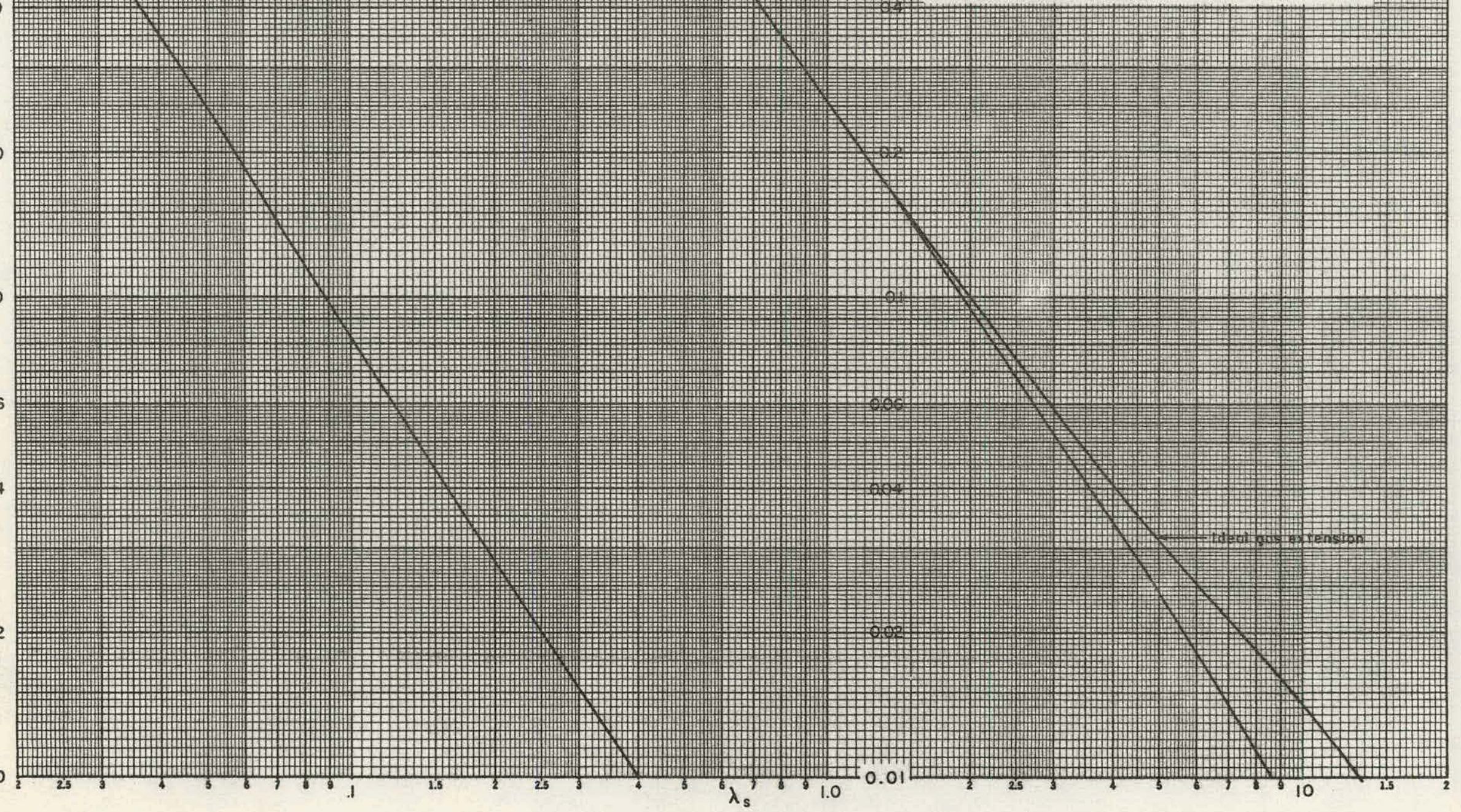




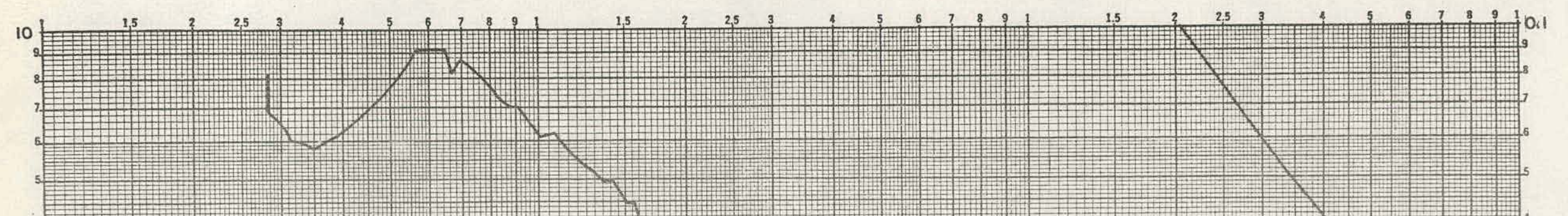

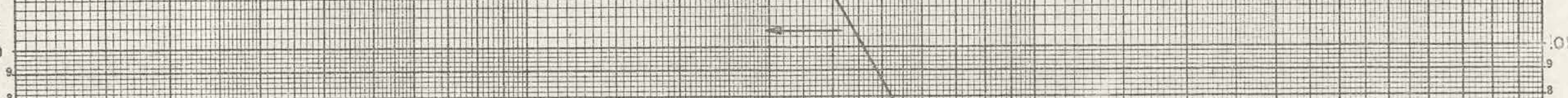
\begin{tabular}{|l|l|l|}
\hline &
\end{tabular}

2.5

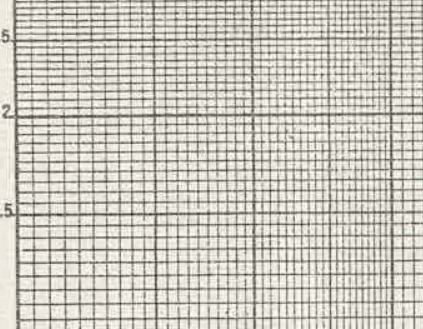

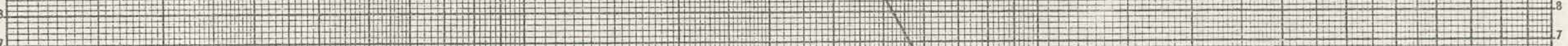

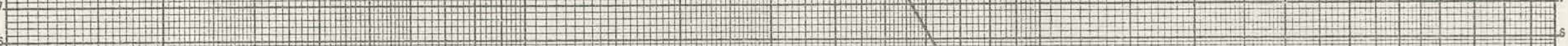

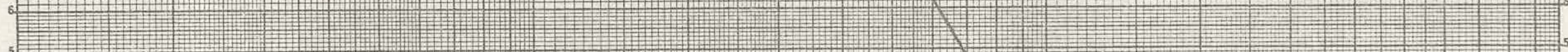

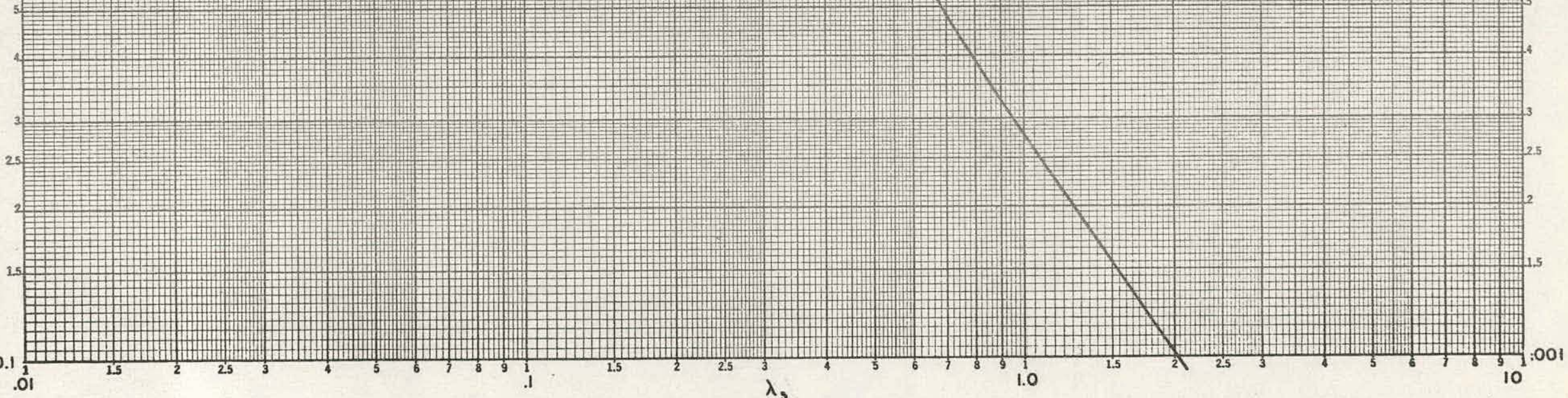




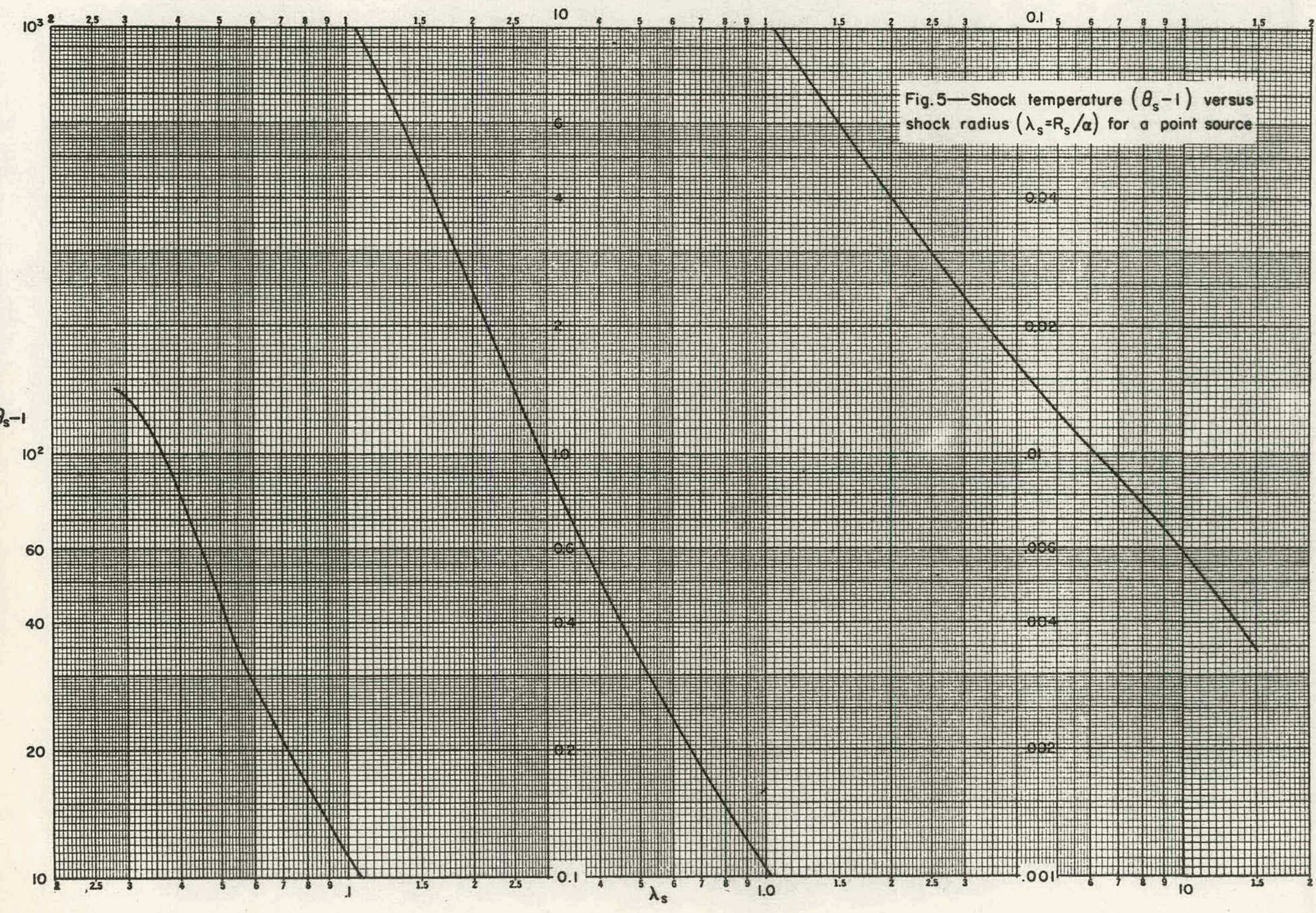




\section{2}

敌

15

茫点

ปूँ

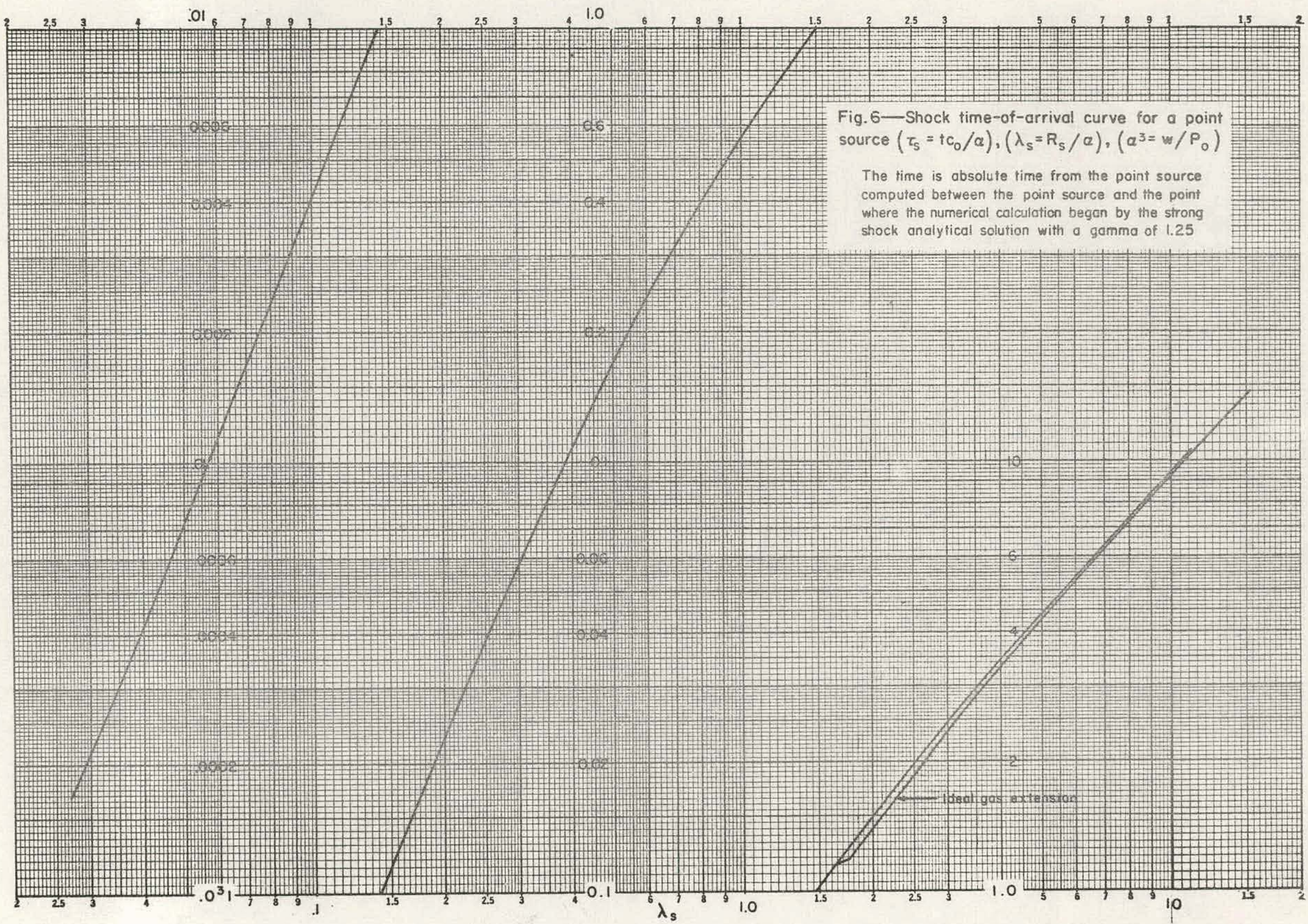

$r_{s}$ (abs) 


$$
43
$$

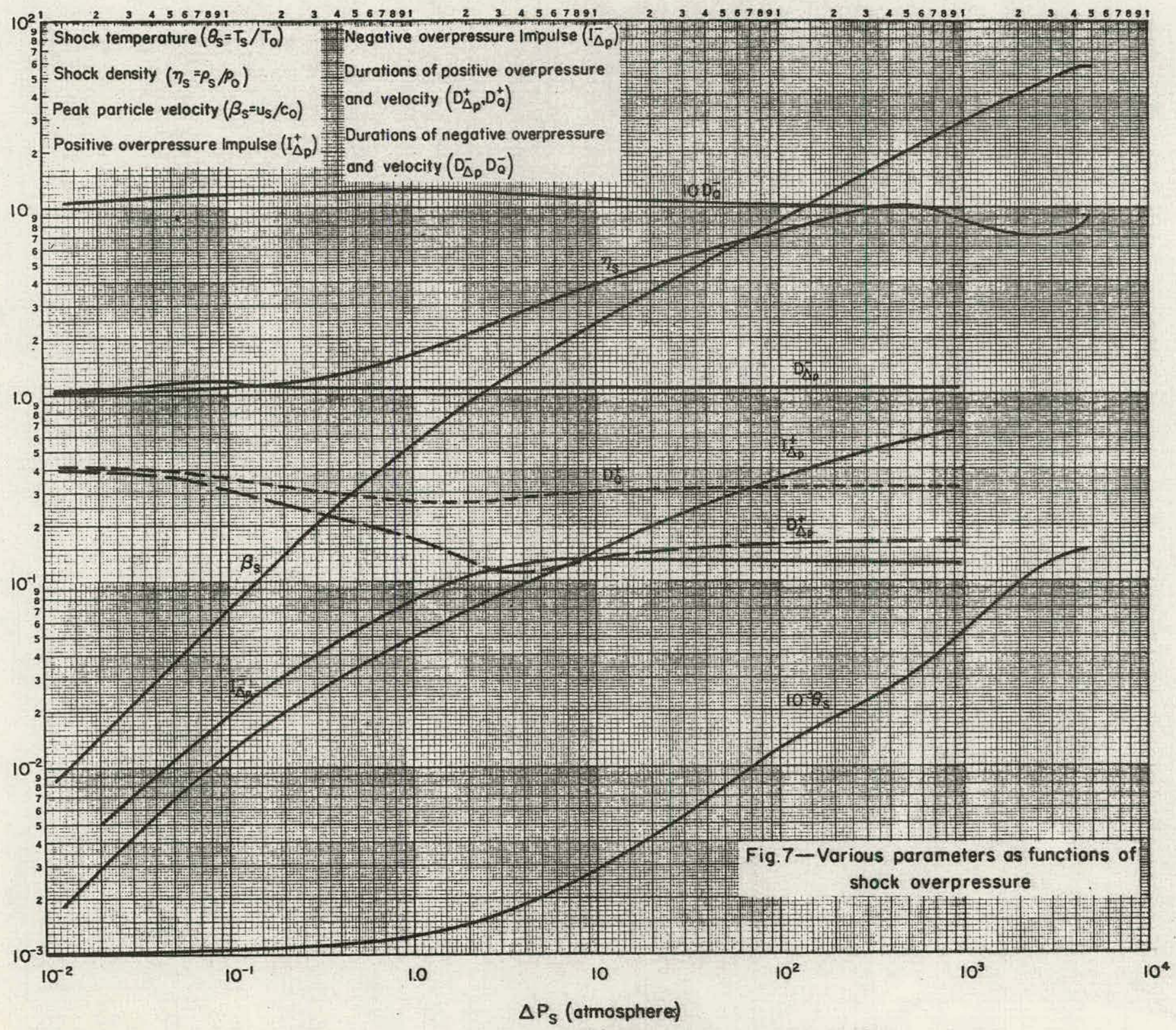

揢

1 . W 


\section{4}

占苧

${ }^{10^{6}}$ प

$10^{5}$

$10^{4}$

$10^{3}$

$10^{2}$

10

1.0

$10^{-1}$

$10^{-2}$

$10^{-3}$

$10^{-4}$ \begin{tabular}{|lll}
\hline 1 \\
\hline
\end{tabular}

\section{2}

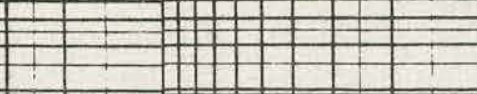

1 (1)

H

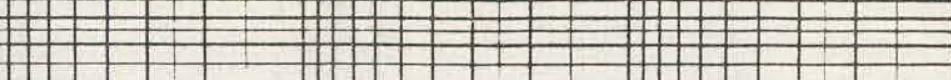

-

$n_{\text {H }}$ -

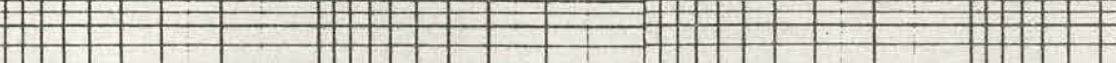

Fig. 8-Peak dynamic pressure $\left(Q_{s}\right)$, dynamic positive

impulse $\left(I_{a}^{+}\right)$, and time-of-shock-arrival $\left(\tau_{s}\right)$, versus shock

overpressure $\left(\Delta p_{s}\right)$, for a point source

7 2

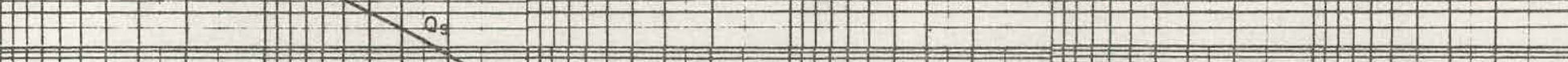
2

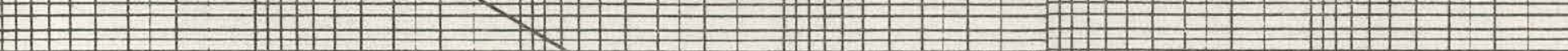

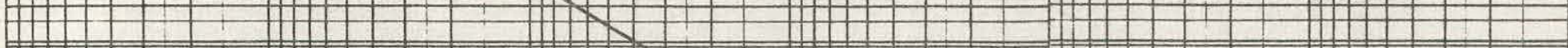

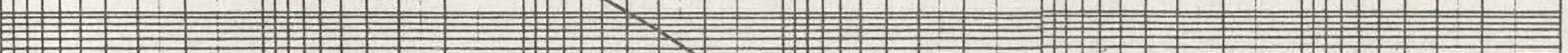
72
12

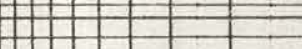
$02+\sqrt{1040}$

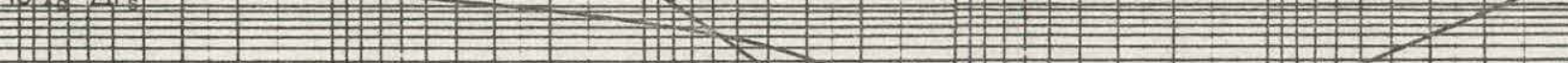

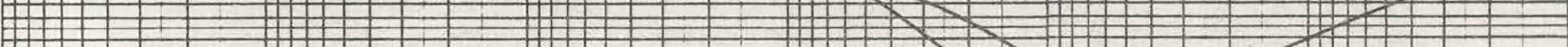

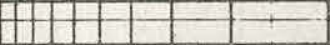

$\because \quad 10 \quad \square \quad \square \quad \square$

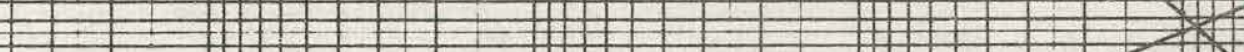
$+2+$

$4 \quad+2+101$ -

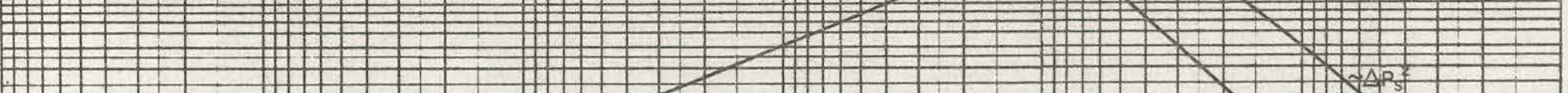

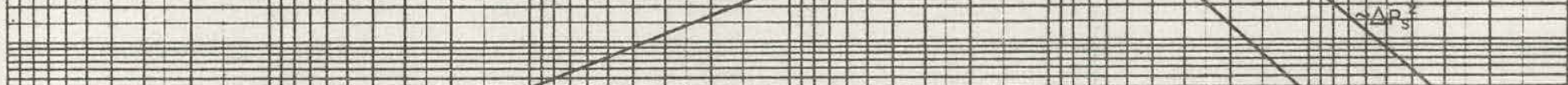
1 - 1 -

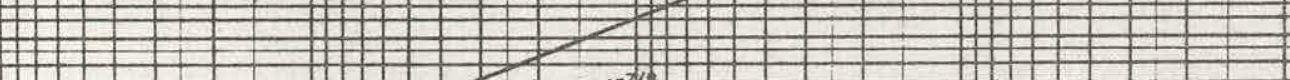

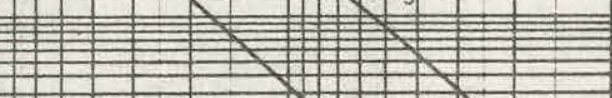

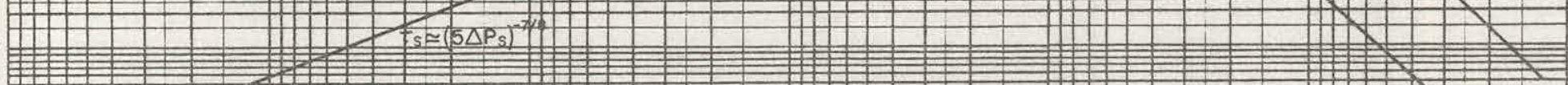
$101+20$

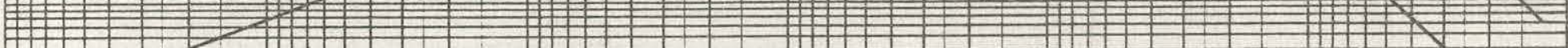

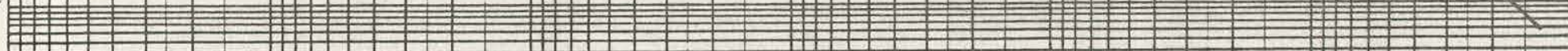
\begin{tabular}{ll}
\hline 2 \\
\hline
\end{tabular}

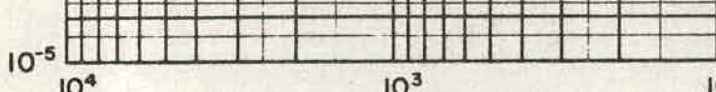




$$
45
$$

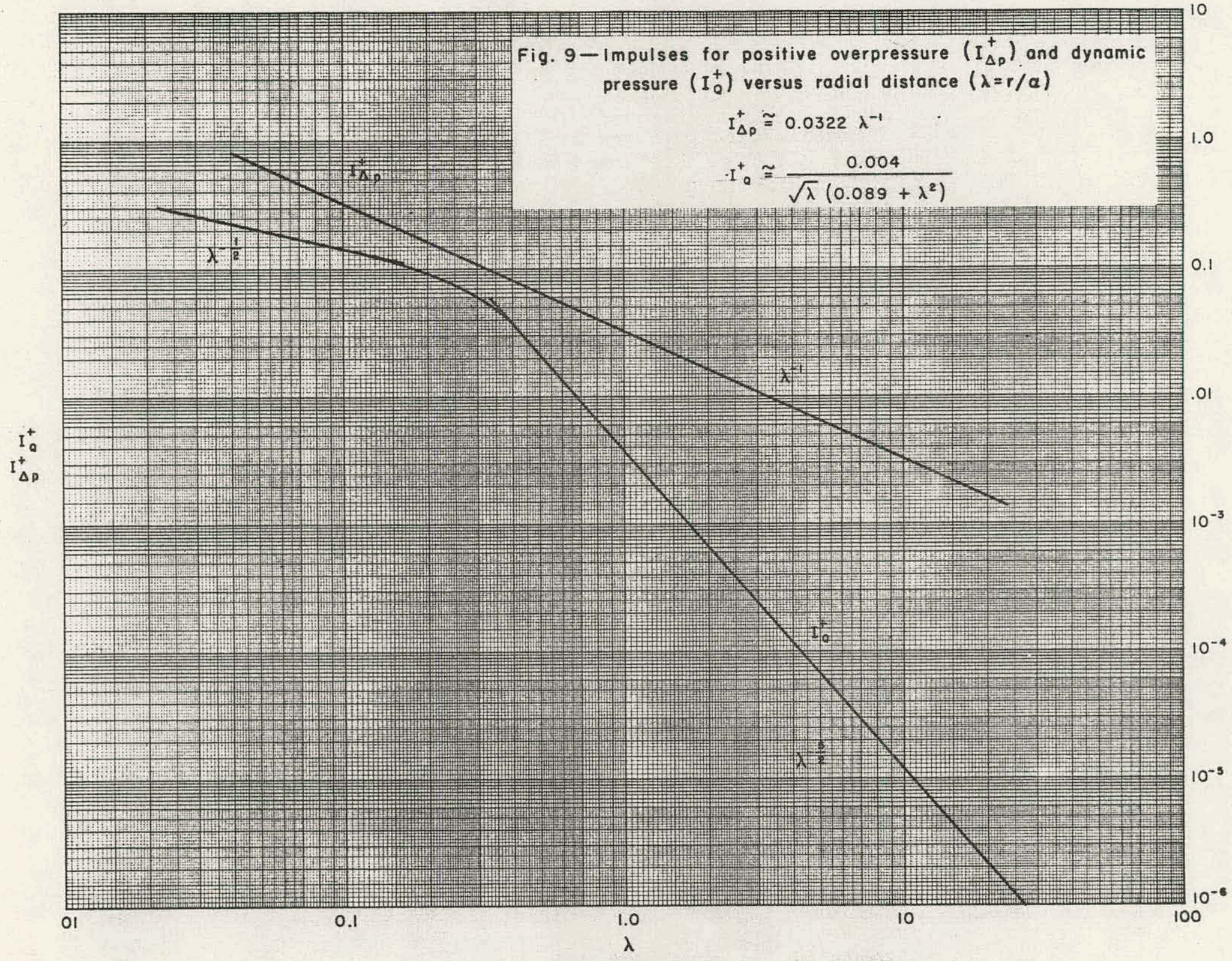


RM-1824-AEC

$12-3-56$

- 46 .

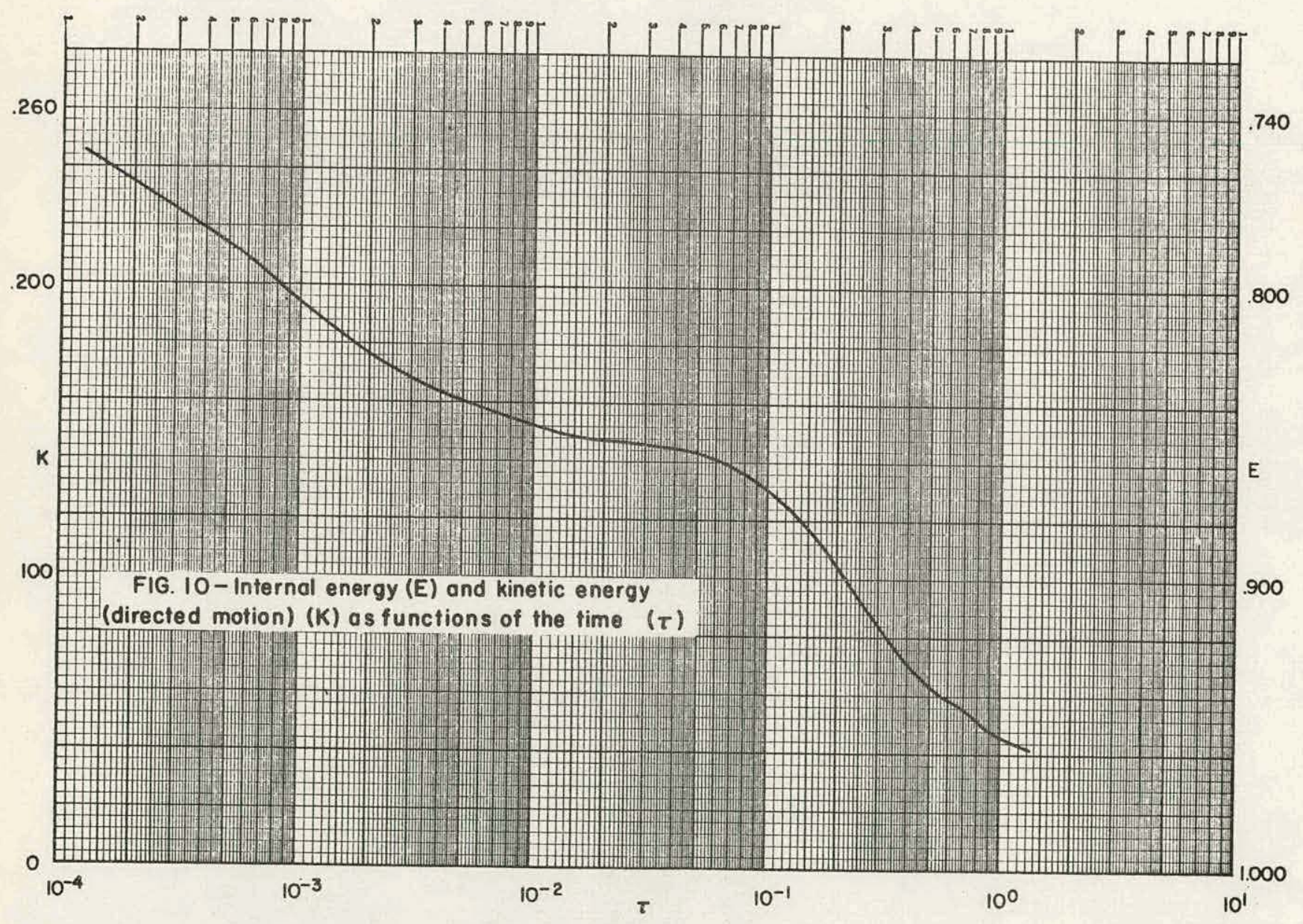




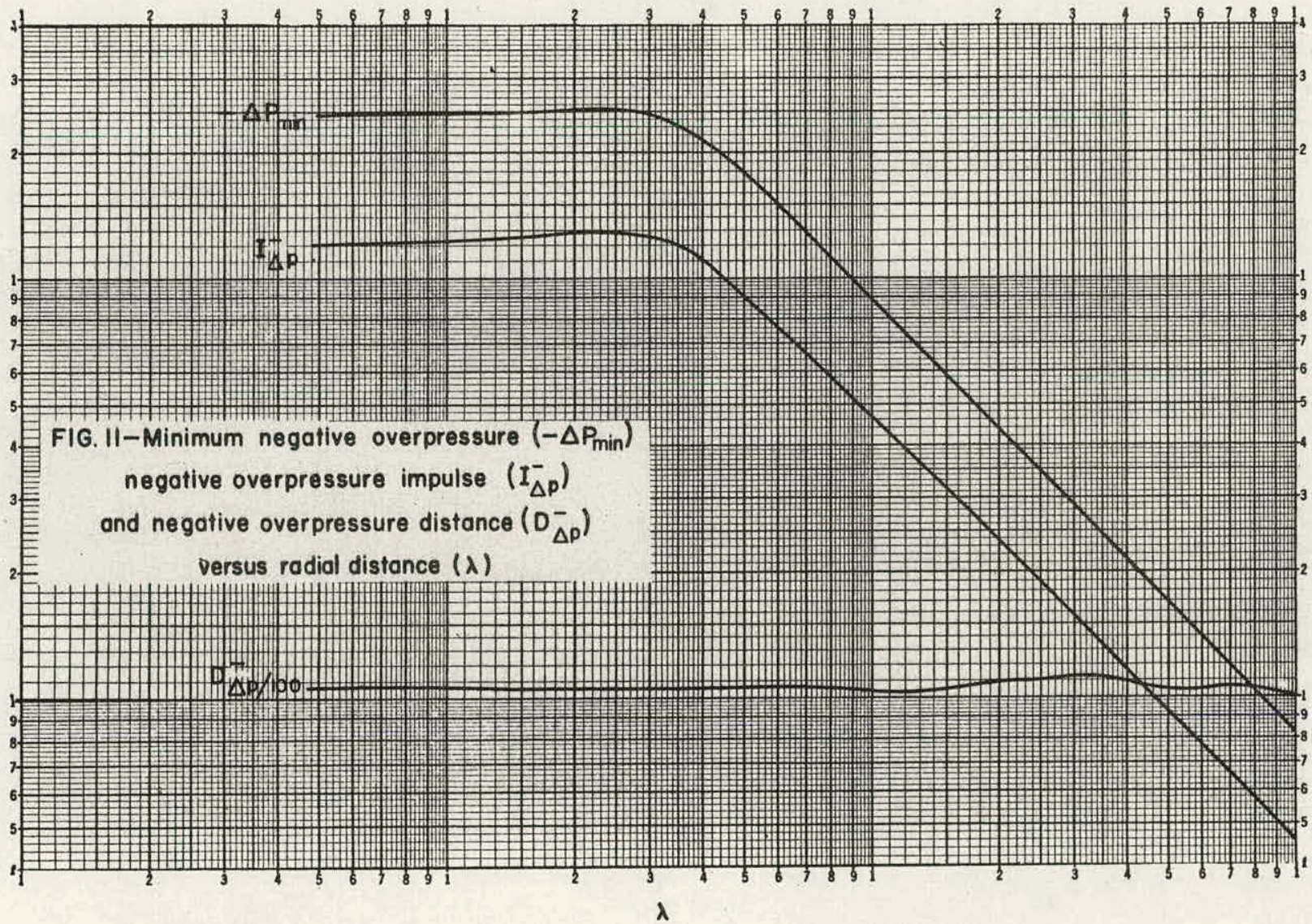




\section{$10^{-1}$}

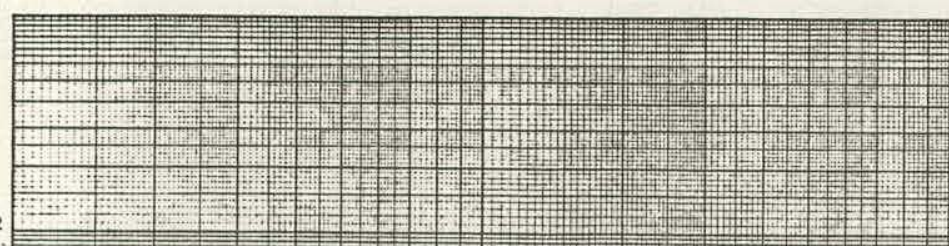

\begin{tabular}{|c|c|c|c|c|}
\hline \\
\hline
\end{tabular}

\#

+

Fig. 12 - Minimum negative dynamic pressure $(0$ )

or (maximum inward dynamic pressure), and dynamic impulse in negative phase $\left(\mathrm{I}_{a}^{-}\right)$versus radial distance $(\lambda)$

$1 \frac{1}{\infty}$

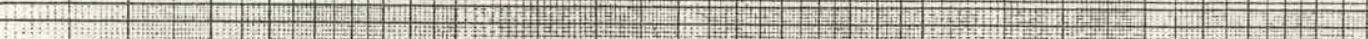

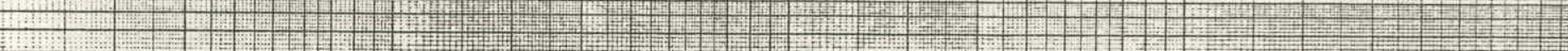
TH:

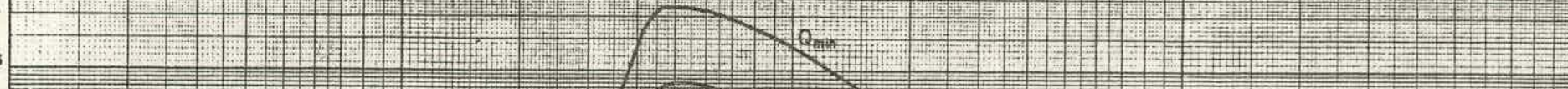

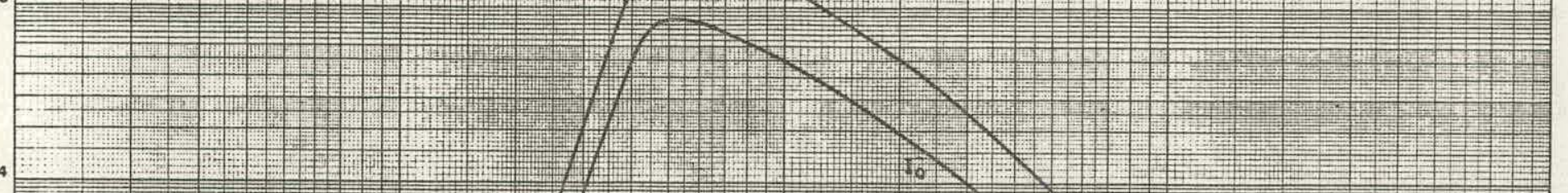

$10^{-4}$

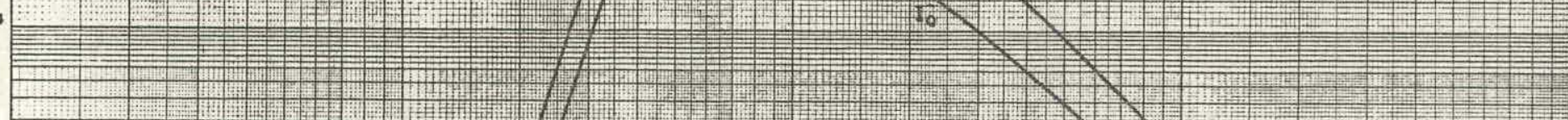

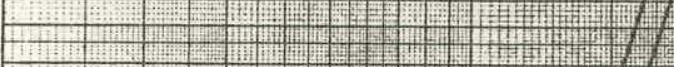

$10^{-5}$

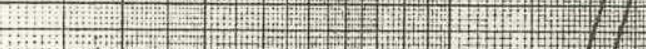

$0^{-5}$

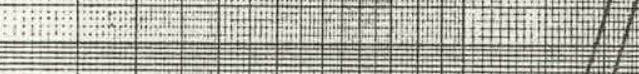

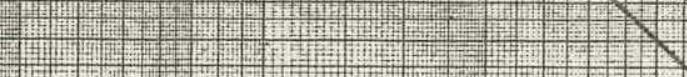

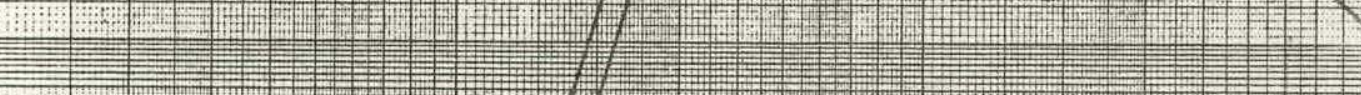

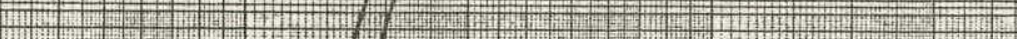

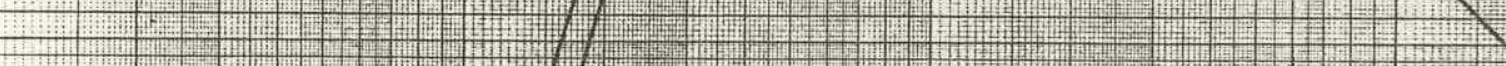

$10^{-6}$ -1: :

\section{|

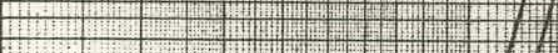

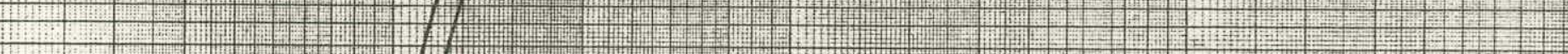 -

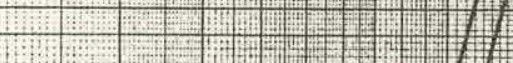 \\ (2)}

$10^{-7}$

F+2.+2

T L

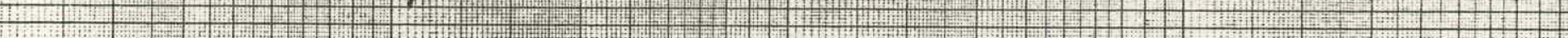

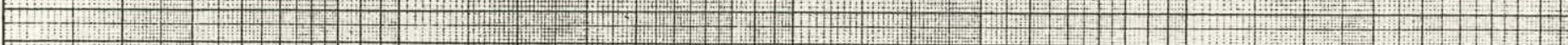

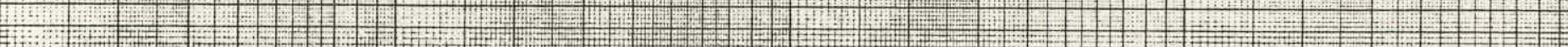

10 이
1.0
10 


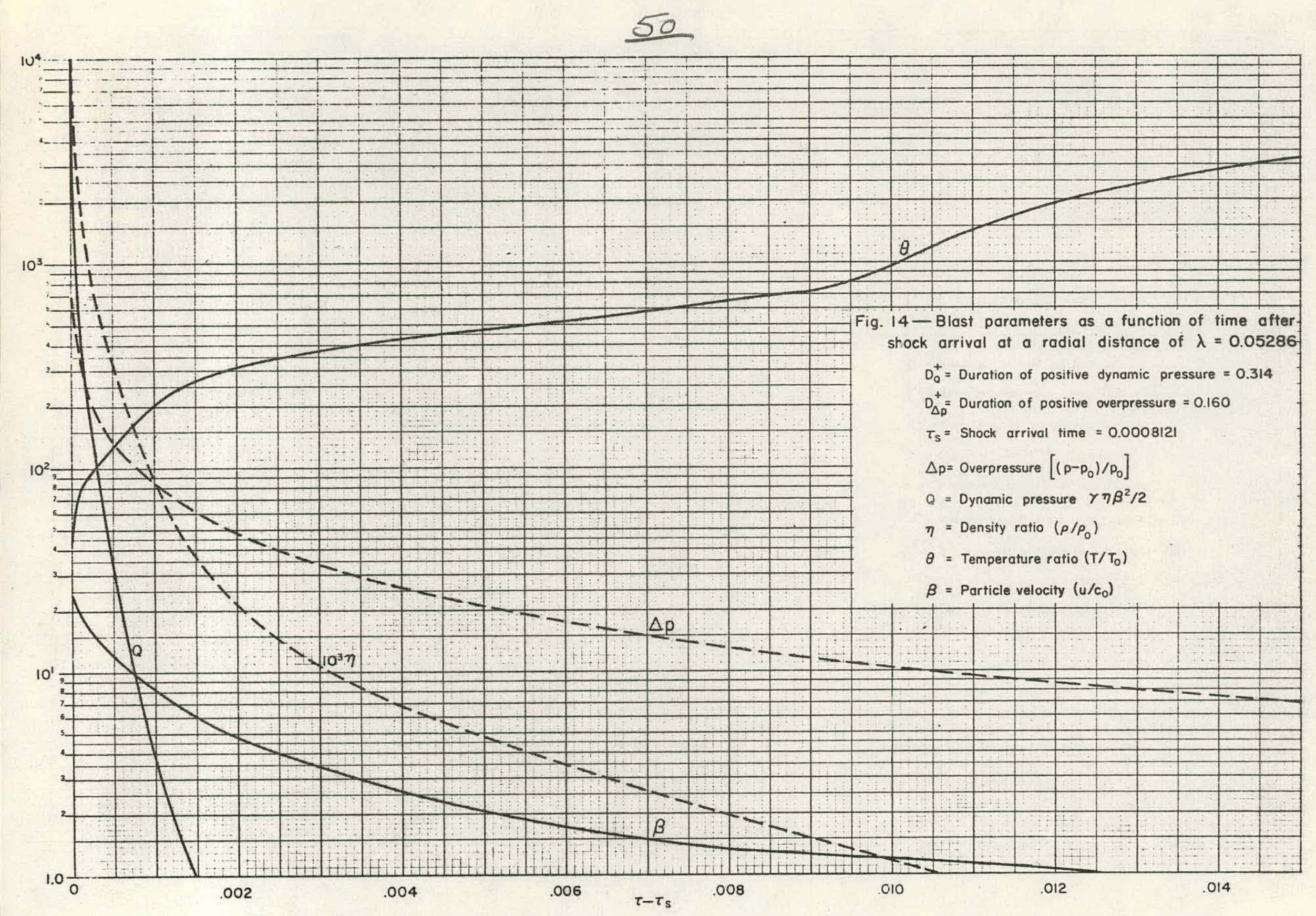




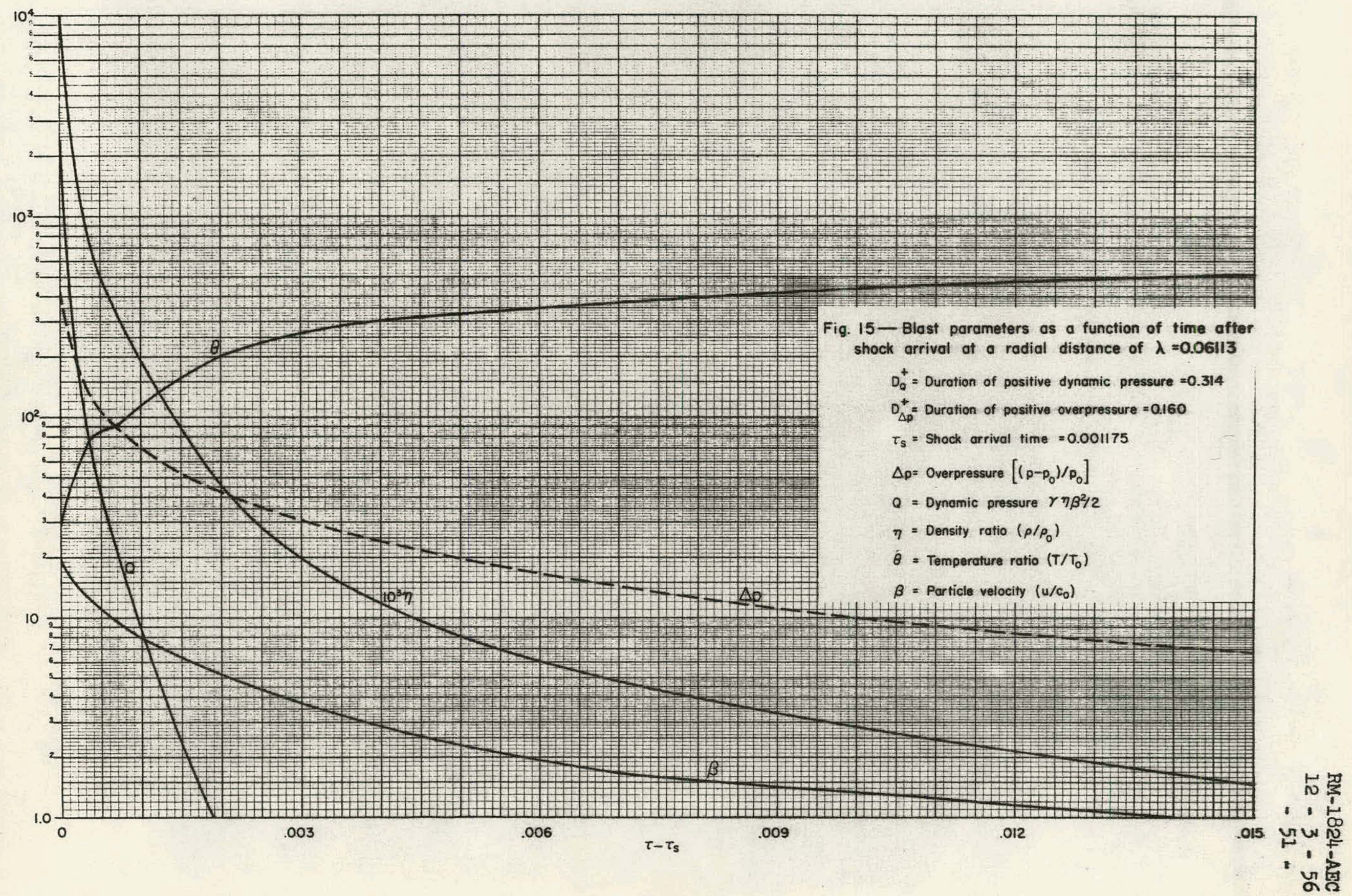




\section{2}

$10^{4}=$ Fig. 16-Blast parameters as a function of time after
shock arrival at a radial distance of $\lambda=0.06956$ $D_{a}^{+}=$Duration of positive dynamic pressure $=0.314$ $\mathrm{D}_{\Delta p}^{+}=$Duration of positive overpressure $=0.160$ $\tau_{\mathrm{S}}=$ Shock arrival time $=0.001638$

$\Delta p=$ Overpressure $\left[\left(p-p_{0}\right) / p_{0}\right]$

$Q=$ Dynamic pressure $\gamma \eta \beta / 2$

$\eta=$ Density ratio $\left(\rho / \rho_{0}\right)$

$\theta=$ Temperature ratio $\left(T / T_{0}\right)$

$\beta=$ Particle velocity $\left(u / c_{0}\right)$

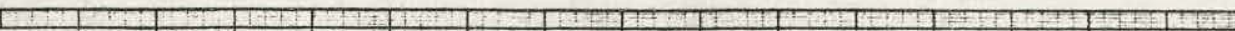

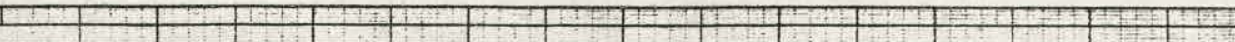

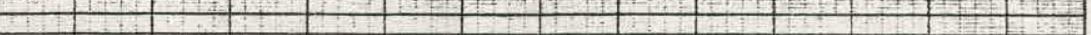

政

जू.

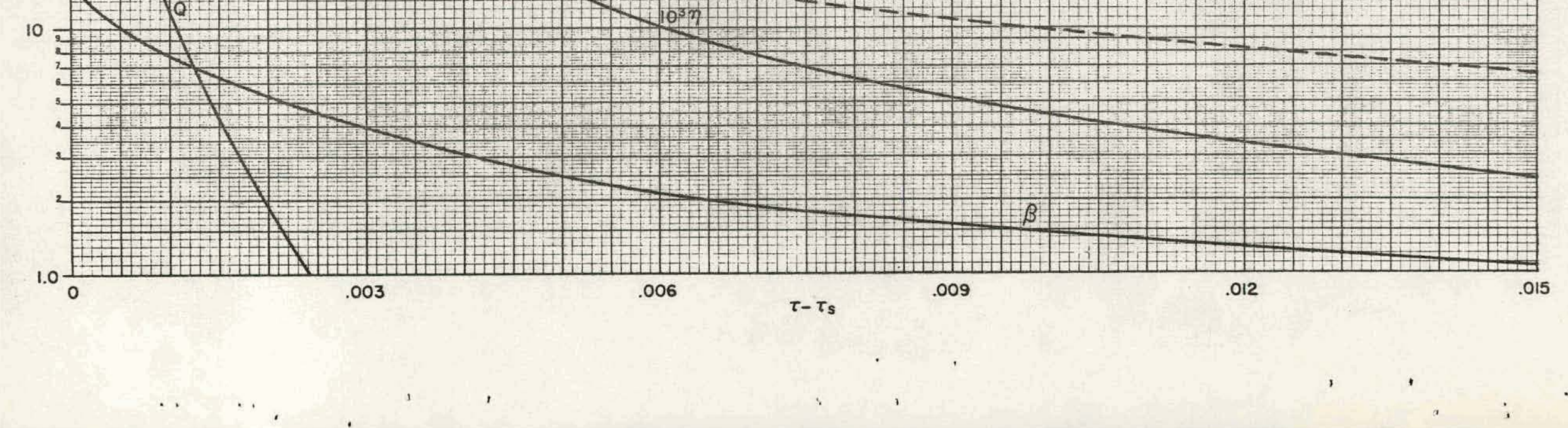


$10^{3}$

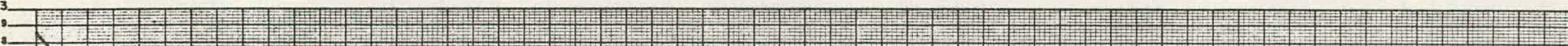

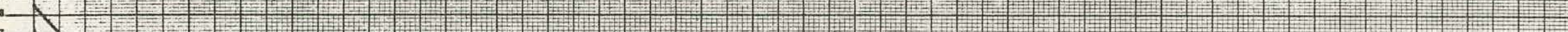
1

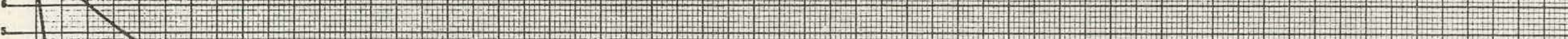

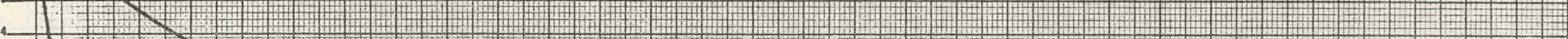

1

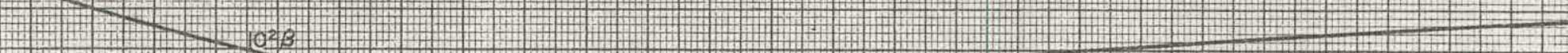

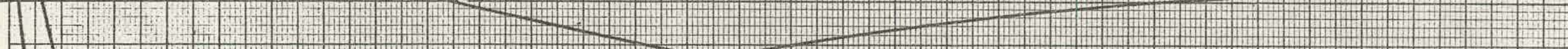
$\sqrt{ }$

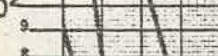
$4 \quad$ (1) A S

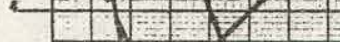

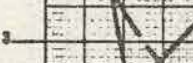

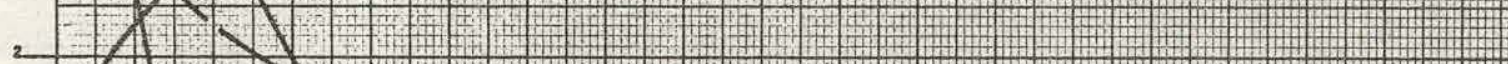

$(1)$ (Q)

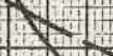

$$
\begin{gathered}
10 \frac{2}{2} \\
7 \\
6 \\
5 \\
5 \\
1.0 \\
0
\end{gathered}
$$

F

.015
18- Blast parameters as a function of time after shock arrival at a radial distance of $\lambda=0.09763$.

$D_{Q}^{+}=$Duration of positive dynamic pressure $=0.315$

$D_{\Delta_{p}}^{+}=$Duration of positive overpressure $=0.158$

$\tau_{\mathrm{s}}=$ Shock arrival time $=0.003917$

$\Delta p=$ Overpressure $\left[\left(p-p_{0}\right) / p_{0}\right]$

$Q=$ Dynamic pressure $\gamma \eta \beta^{2} / 2$

$\eta=$ Density ratio $\left(\rho / \rho_{0}\right)$

$\theta^{\prime}=$ Temperature ratio $\left(T / T_{0}\right)$

$\beta=$ Porticle velocity $\left(u / c_{0}\right)$

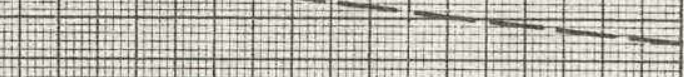
+1

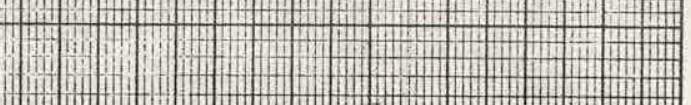
.020 .025 


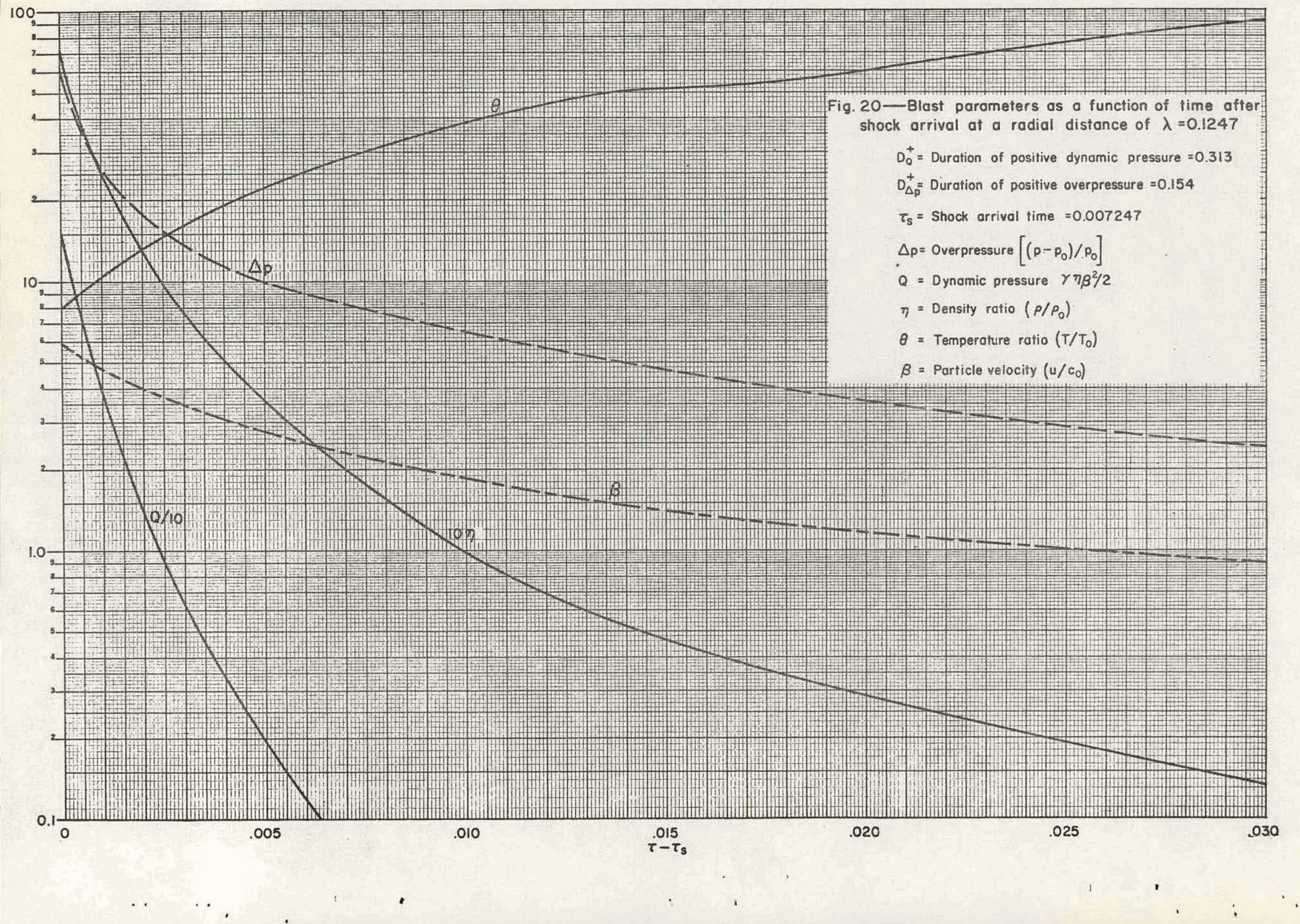




\section{7}

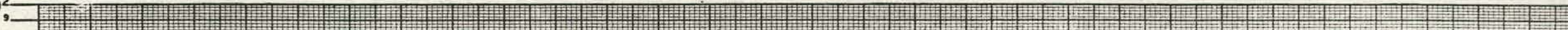
工

r

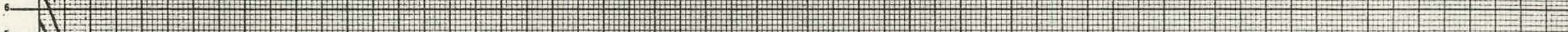

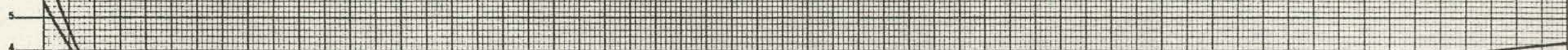

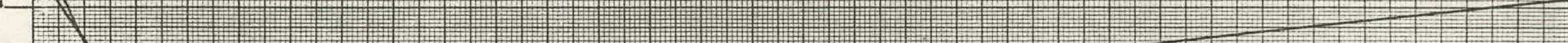

$+2$

X

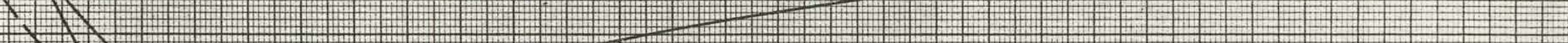
F W

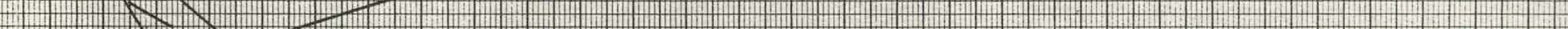

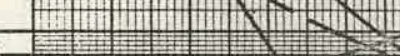

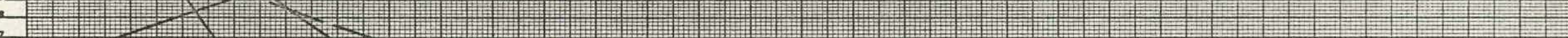

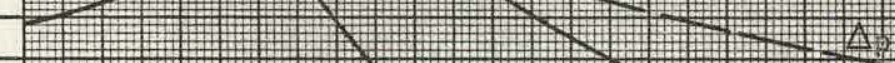

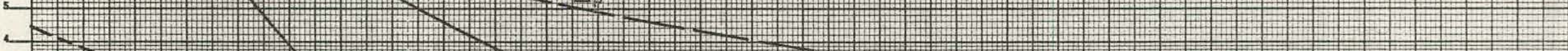

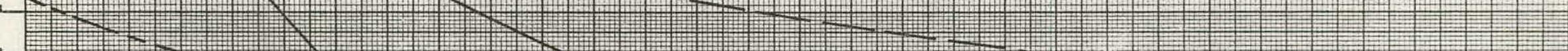

2

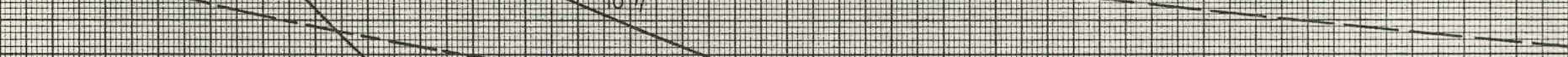

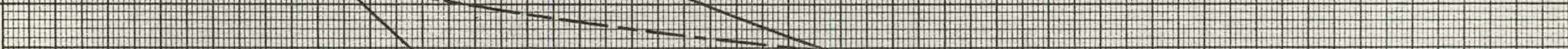
$\mathrm{C}+\mathrm{P}$
$\mathrm{H}$ I I

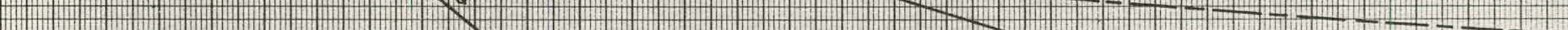

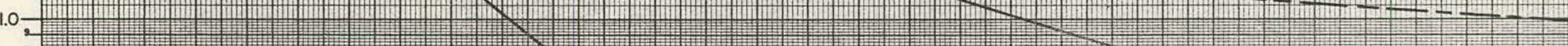

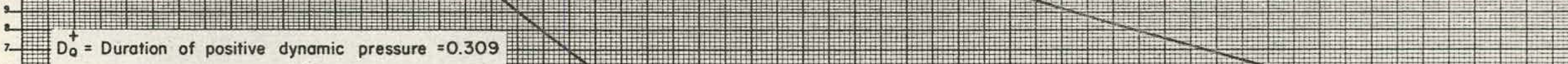

$\mathrm{D}_{\Delta \mathrm{p}}^{+}=$Duration of positive overpressure $=0.149$

$\tau_{s}=$ Shock arrival time $=0.01182$

. $\Delta p=$ Overpressure $\left[\left(p-p_{0}\right) / p_{0}\right]$

$Q=$ Dynamic pressure $\gamma \eta \beta^{2} / 2$

$\eta=$ Density ratio $\left(\rho / P_{0}\right)$

$\theta=$ Temperature ratio $\left(T / T_{0}\right)$

$\beta=$ Particle velocity $\left(u / c_{0}\right)$

$0.1 \frac{0}{0} \quad .005$

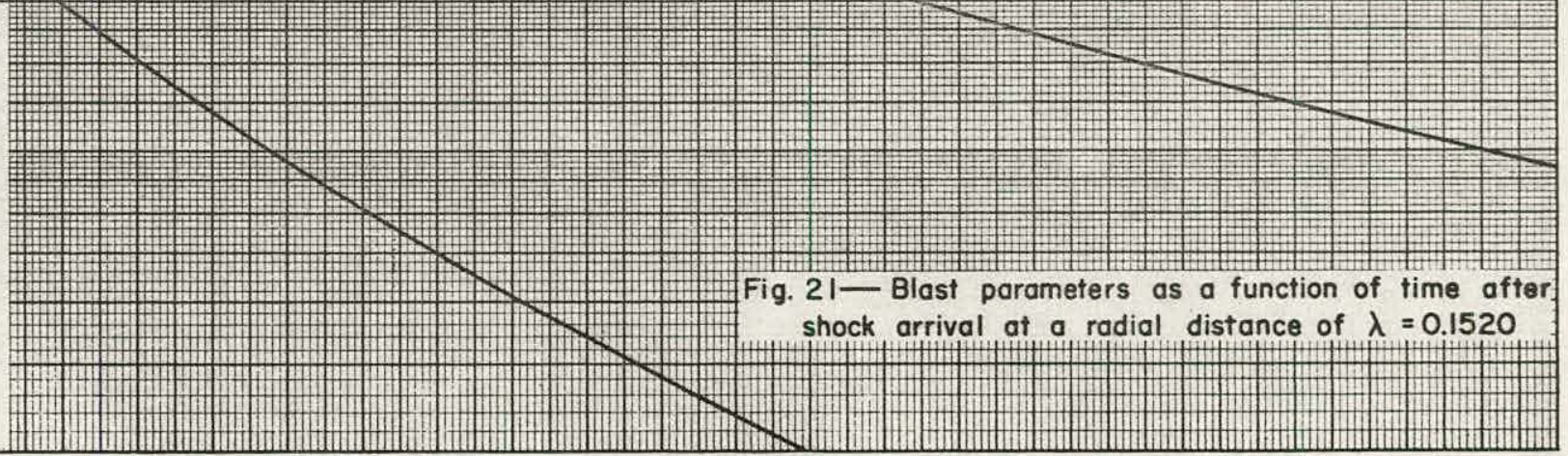




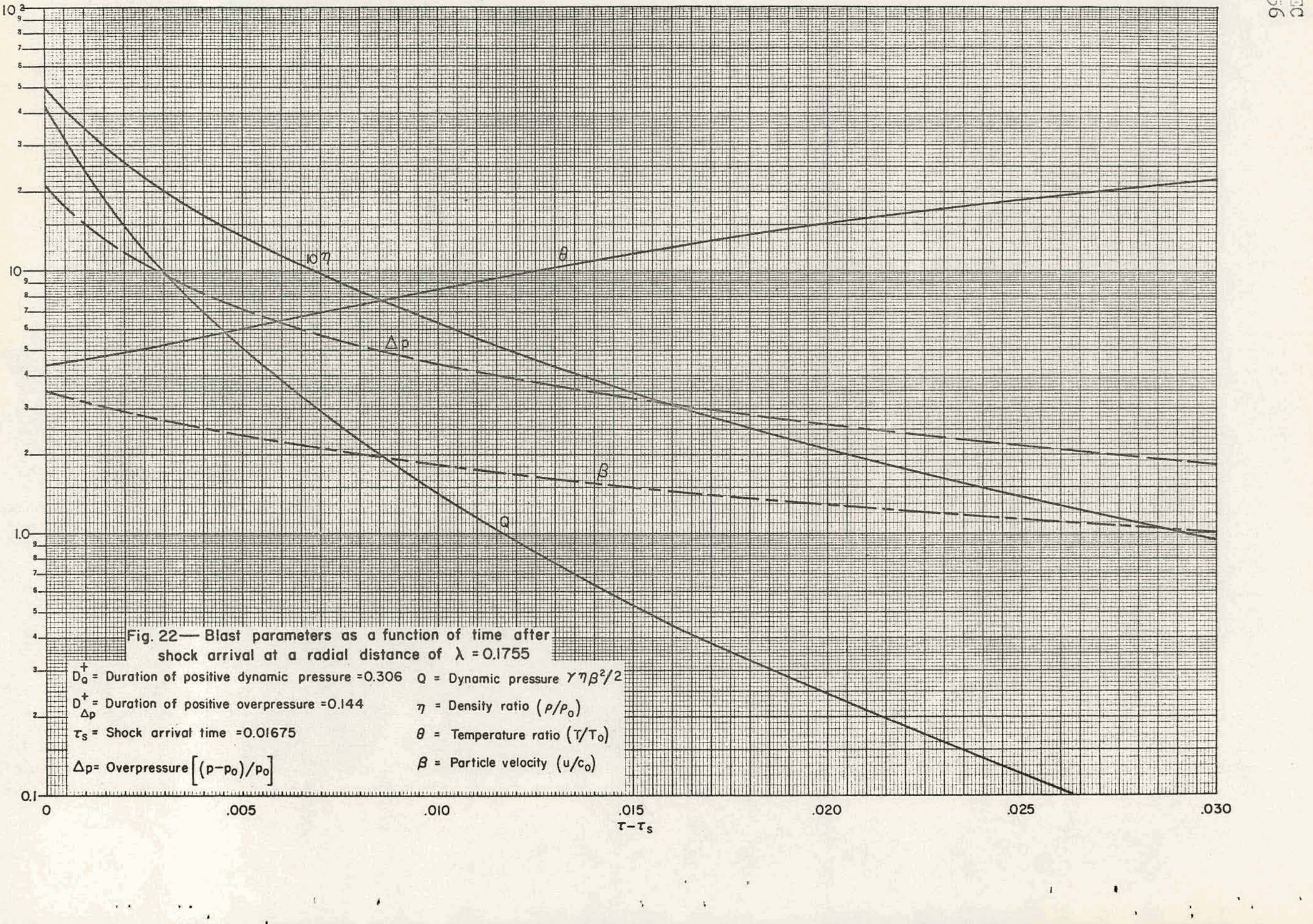




\section{9}

工

-

工

$6 \mathrm{C}$

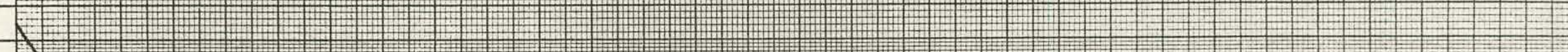

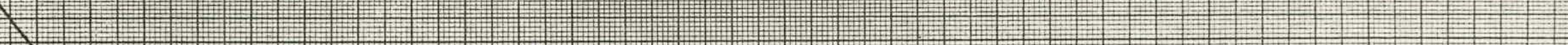
W W

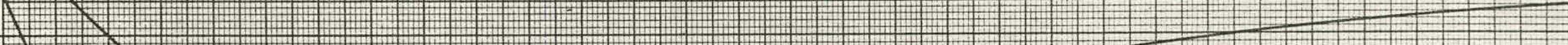

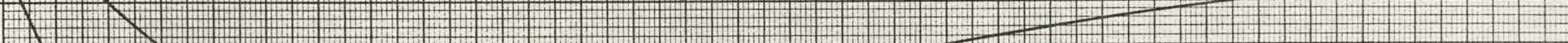

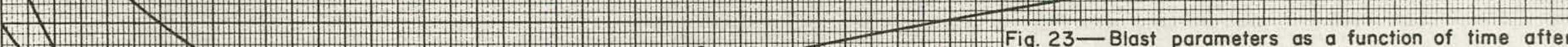
X. shock arrival at a radial distance of $\lambda=0.1970$

10

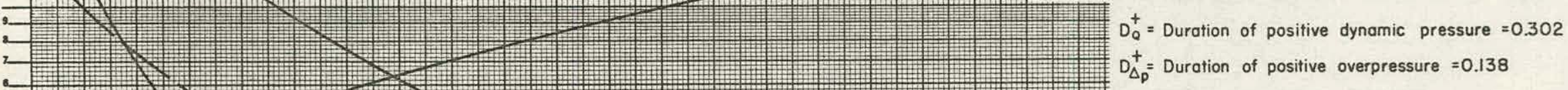

W

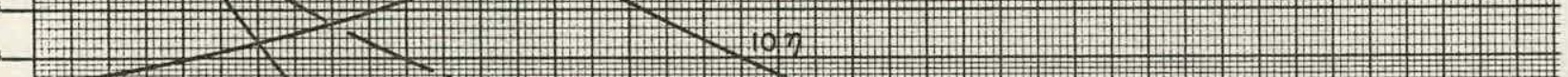
(

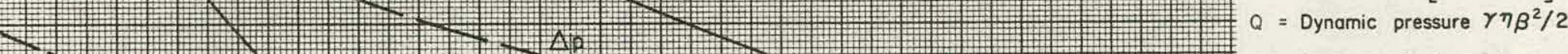

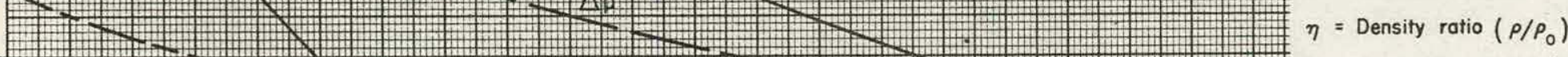

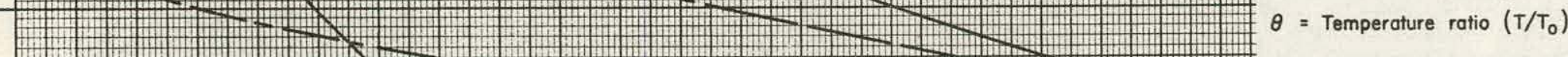

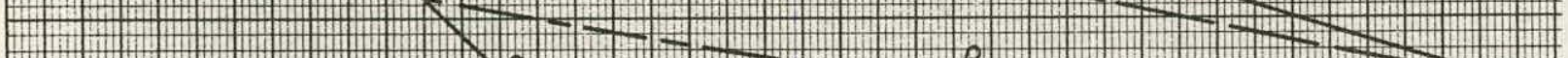

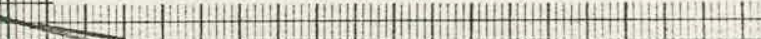
L

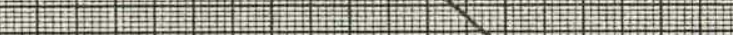

$\Delta p=$ Overpressure $\left[\left(p-p_{0}\right) / p_{0}\right]$

$=$ Temperature ratio $\left(T / T_{0}\right)$ (

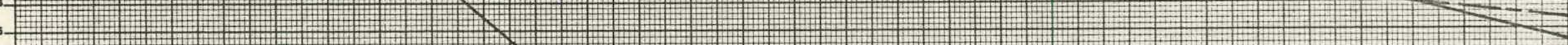

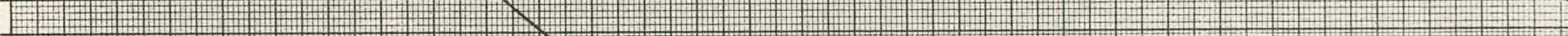

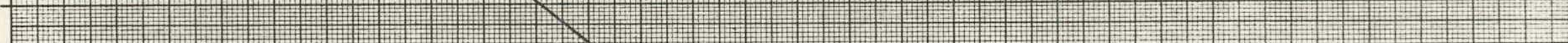

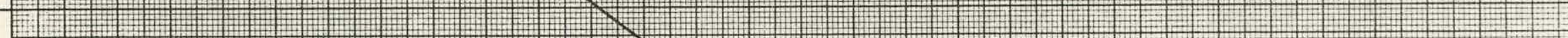

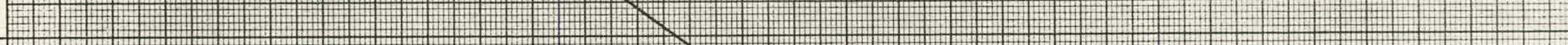

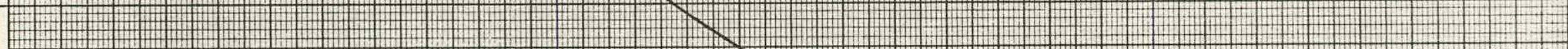

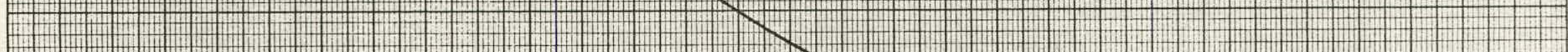




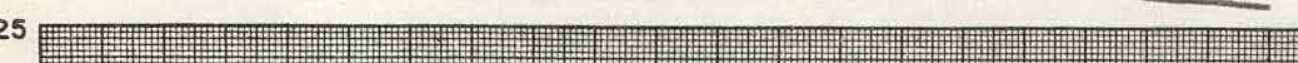

\section{-}

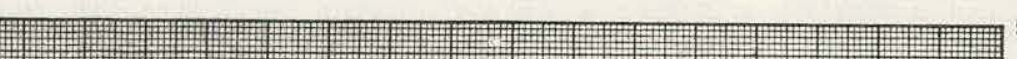

20

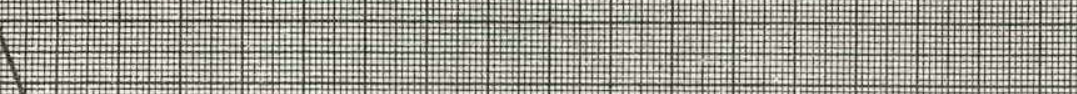

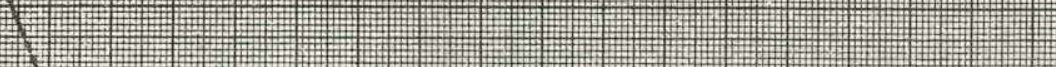

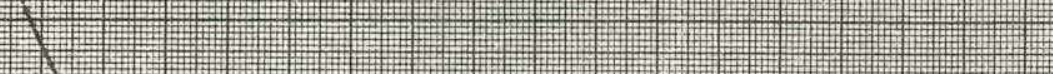

(1) (

-

-

T

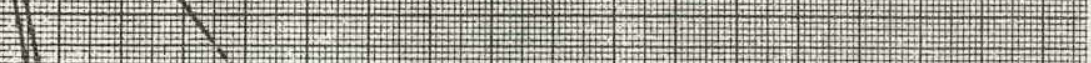

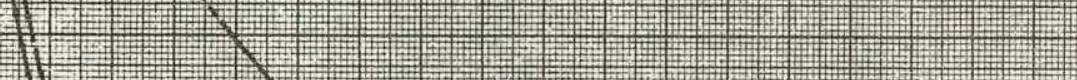

15

T.

il

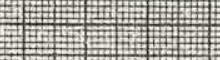

(1) + + + +

Q

10

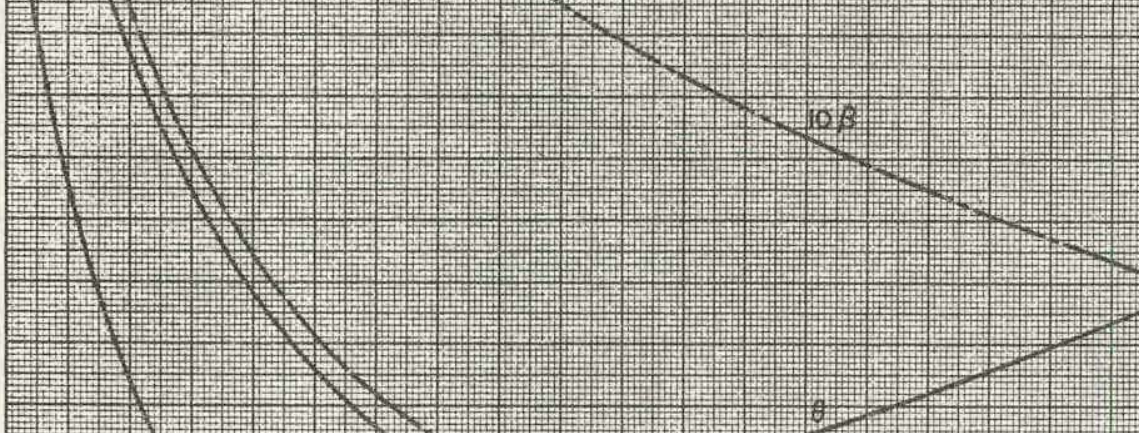

5

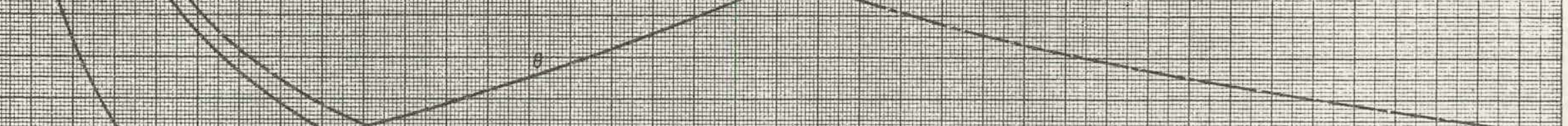

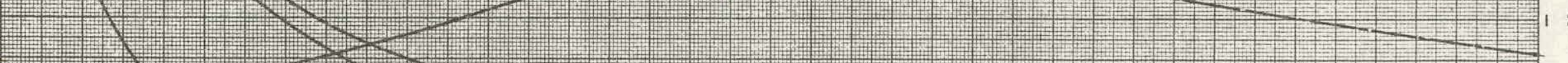

-

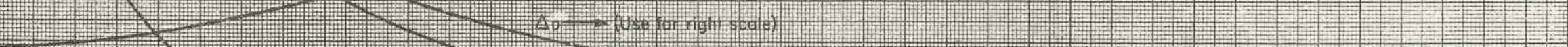
-

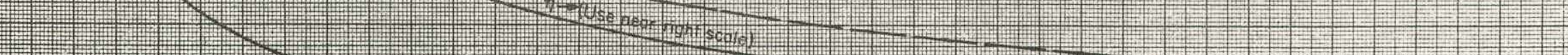

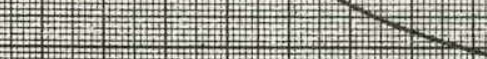

0.01
Fig. 24-Blast parameters as o function of time after shock arrival at a radial distance of $\lambda=0.2231$

$\mathrm{D}_{0}^{+}=$Duration of positive dynamic pressure $=0.300$

$D_{\Delta p}^{+}=$Duration of positive overpressure $=0.131$

$\tau_{s}=$ Shock arrival time $=0.02970$

$\Delta p=$ Overpressure $\left[\left(p-p_{0}\right) / p_{0}\right]$

$Q=$ Dynamic pressure $\gamma \eta \beta^{2 / 2}$

$\eta=$ Density ratio $\left(p / p_{0}\right)$

$\theta=$ Temperature ratio $\left(T / T_{0}\right)$

$\hat{\beta}=$ Particle velocity $\left(u / c_{0}\right)$

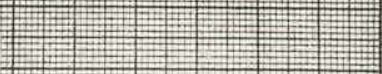

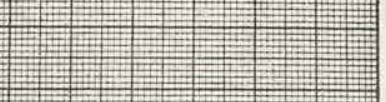

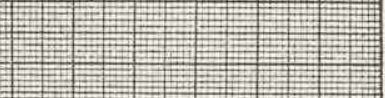
$-4100$

$\tau-\tau_{s}$
0.05

0.06
0.07 


\section{1}

${ }^{10}$

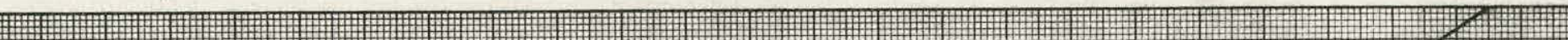

W

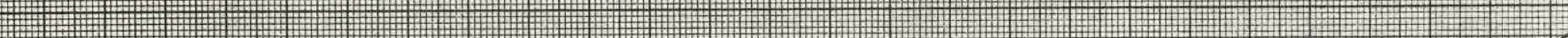

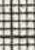

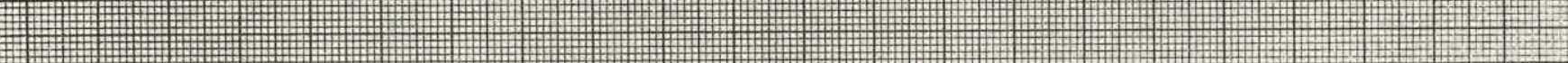

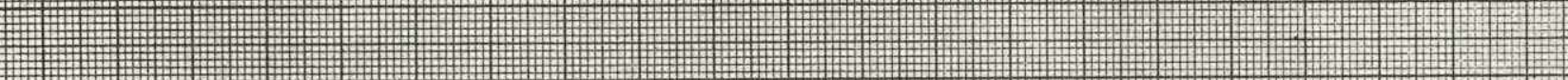

8

I
I

\#\#

(1)

(1)

6 (2)

$\theta$

(

$\theta$ $\ldots$

$\Delta_{P} \ldots$

4 $+1$

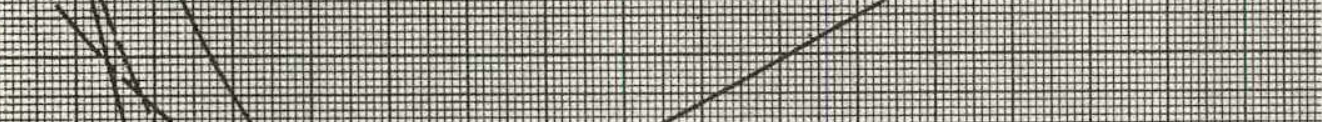
细, , .

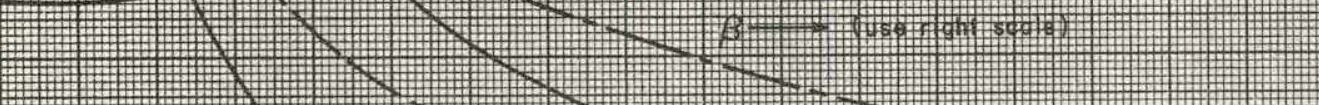

Fig
Fig. 25-Blast parameters as a function of time ofter shock arrival at a radial distance of $\lambda=0.2544$

$D_{Q}^{+}=$Duration of positive dynamic pressure $=0.291$

$D_{\Delta_{p}}^{+}=$Duration of positive overpressure $=0.121$

$\tau_{\mathrm{s}}=$ Shock arrival time $=0.04040$

$\Delta p=$ Overpressure $\left[\left(p-p_{0}\right) / p_{0}\right]$

$Q=$ Dynamic pressure $\gamma \eta \beta^{2} / 2$

$\eta=$ Density ratio $\left(\rho / p_{0}\right)$

$\theta=$ Temperature ratio $\left(T / T_{0}\right)$

$\beta=$ Particle velocity $\left(u / c_{0}\right)$

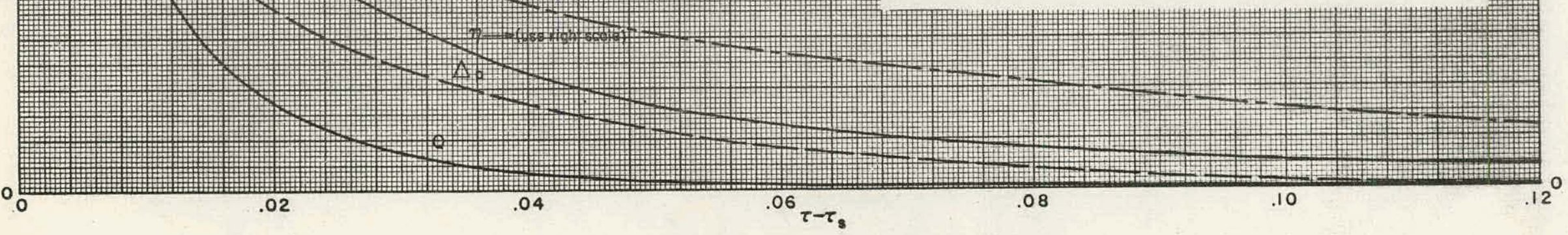

范 gum 


\section{2}

的監

$1, \frac{1}{3}$

สู

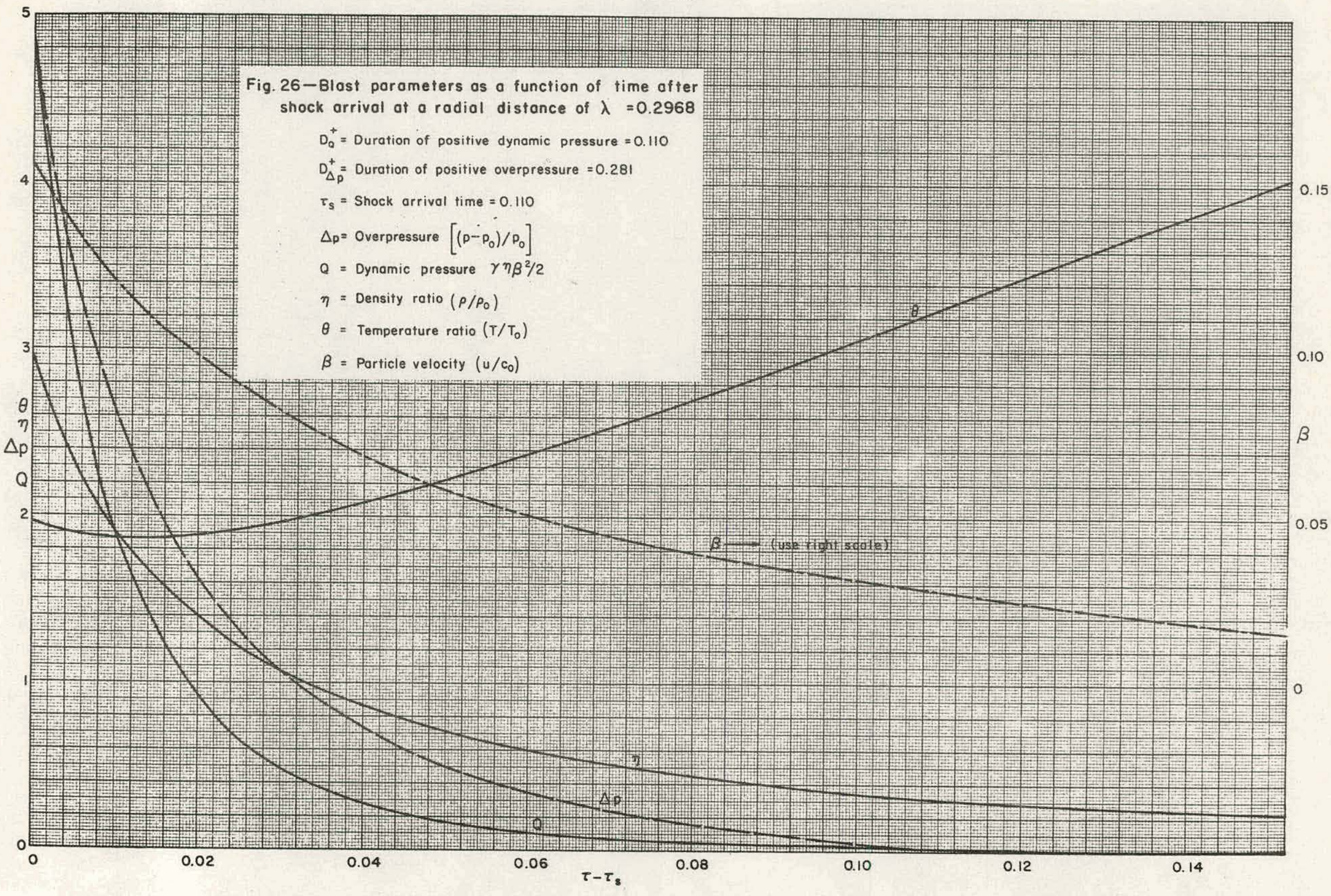




\section{3}

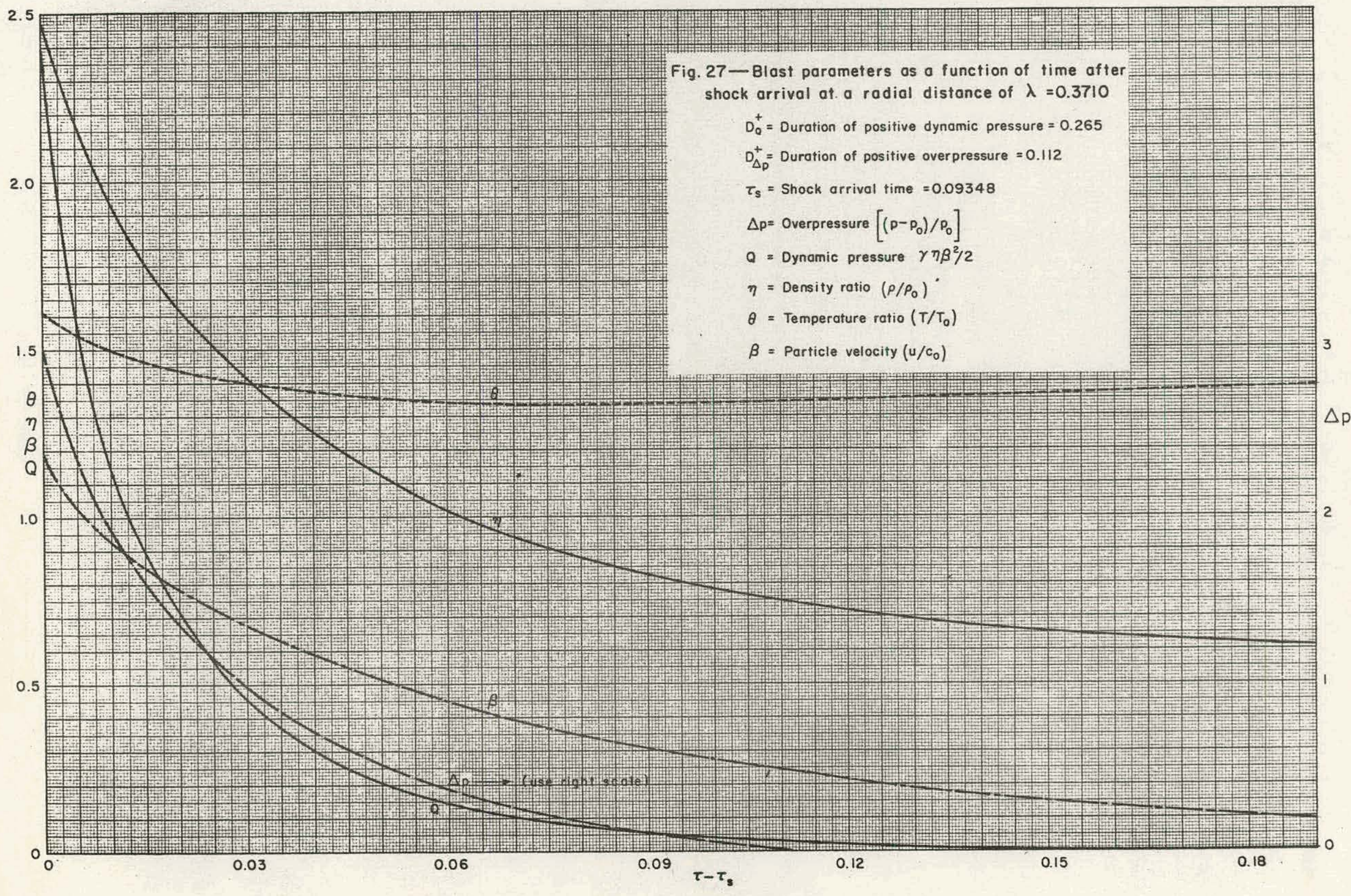

㟧恣

$11 \stackrel{5}{5}$ ow

' 


\section{4}

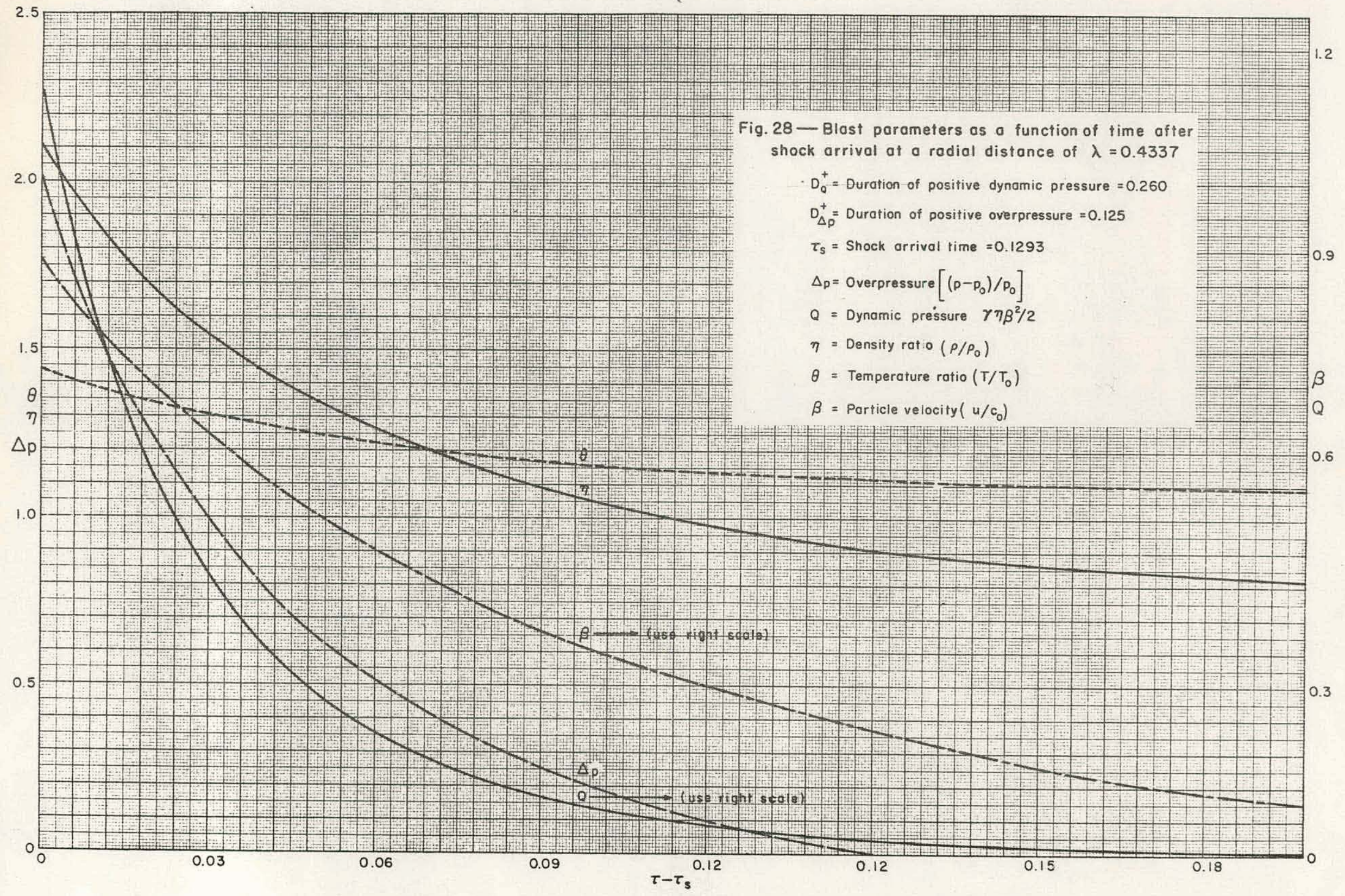

占咨

gW

13

ज招 


\section{5}

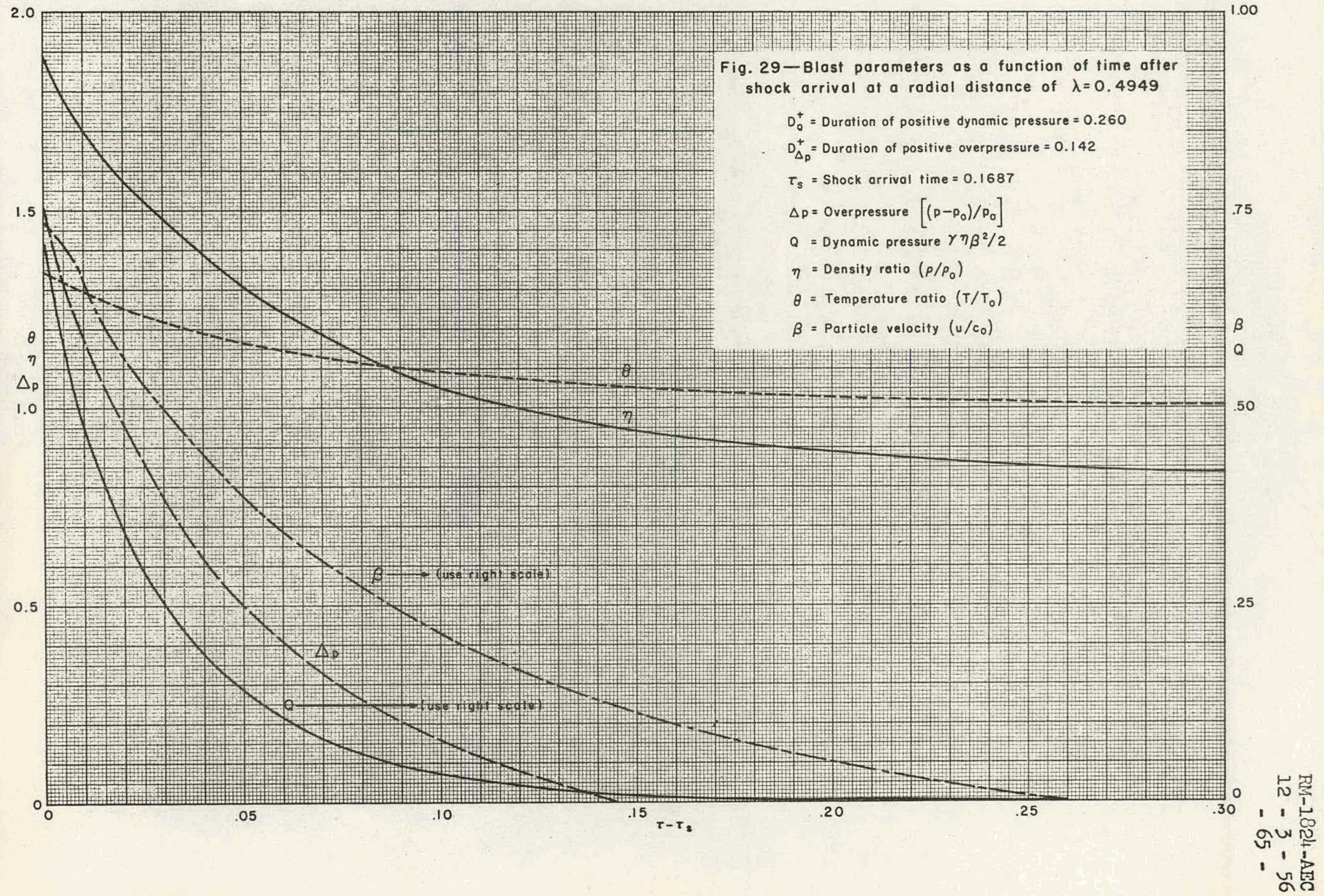




\section{6}

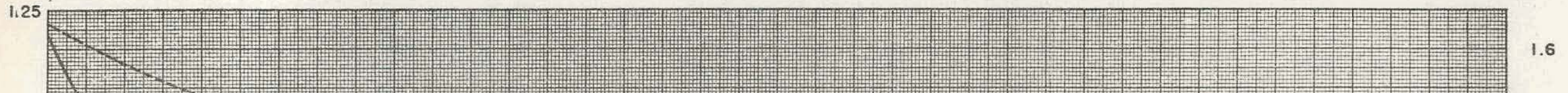

.00 L P n

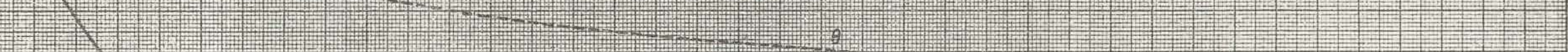

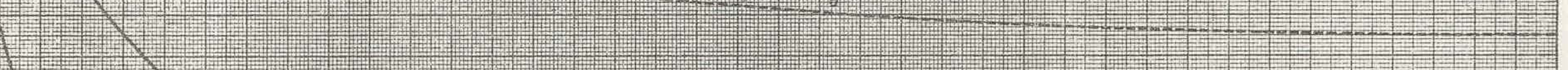

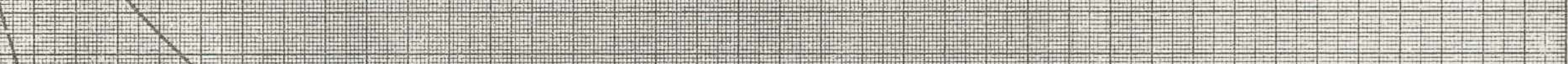
W

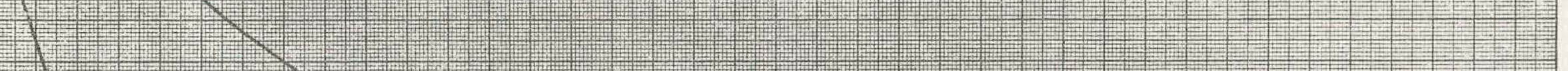

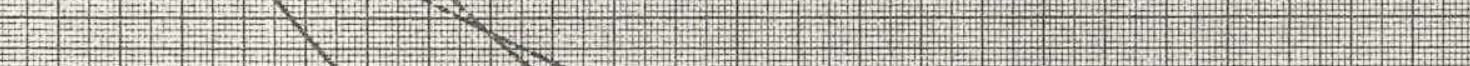

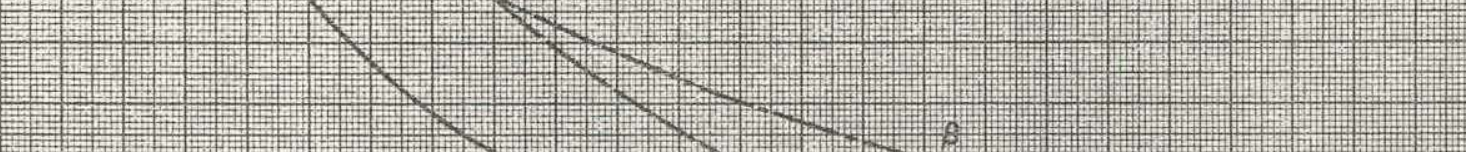

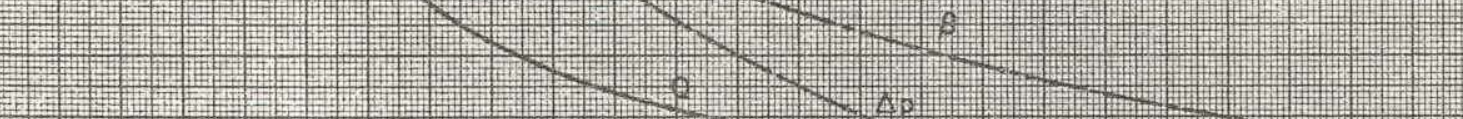

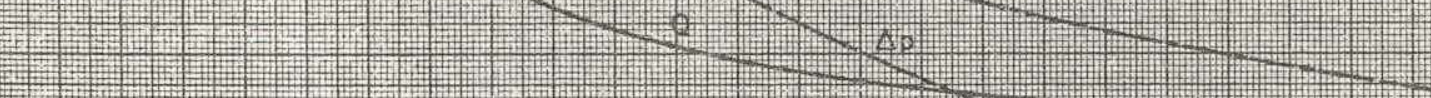
shock arrival at a radial distance of $\lambda=0.6091$ $\mathrm{D}_{a}^{+}=$Duration of positive dynamic pressure $=0.263$

$\mathrm{D}_{\Delta p}^{+}=$Duration of positive oyerpressure $=0.166$

$\tau_{s}=$ Shock orrival time $=0.2493$

$\Delta p=$ Overpressure $\left[\left(p-p_{0}\right) / p_{0}\right]$

$Q=$ Dynamic pressure $\gamma \eta \beta{ }^{2} / 2$

$\eta=$ Density ratio $\left(\rho / P_{0}\right)$

$\theta=$ Temperafure rotio $\left(T / T_{0}\right)$

$\beta=$ Porticle velocity $\left(u / c_{0}\right)$ 


\section{7}

2.0

F

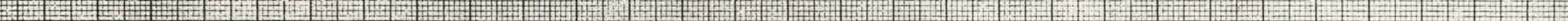
+

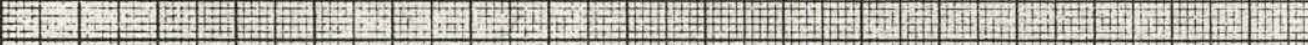

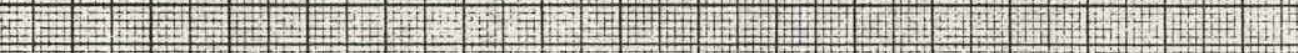
-

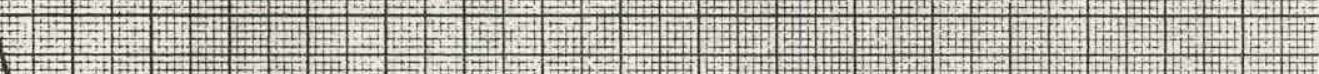

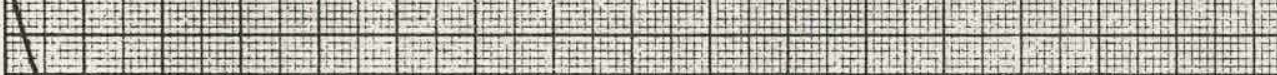
shock arrival at a radial distance of $\lambda=0.7213$

$D_{0}^{+}=$Duration of positive dynamic pressure $=0.272$

$D_{\Delta_{p}}^{+}=$Duration of positive overpressure $=0.185$

$\tau_{\mathrm{s}}=$ Shock orrival time $=0.3353$

$\Delta p=$ Overpressure $\left[\left(p-p_{0}\right) / p_{0}\right]$

$Q=$ Dynamic pressure $\gamma \eta \beta^{2} / 2$

$\eta=$ Density ratio $\left(\rho / \rho_{0}\right)$

$\theta=$ Temperafure ratio $\left(T / T_{0}\right)$

$\beta=$ Particle velocity $\left(u / c_{0}\right)$

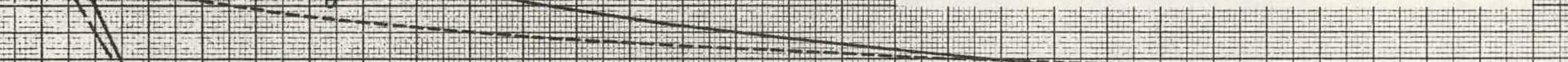

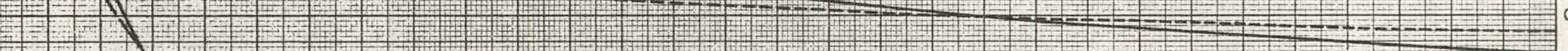

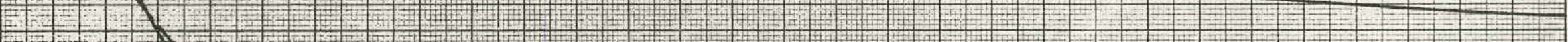

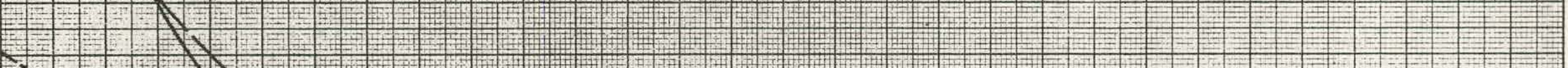

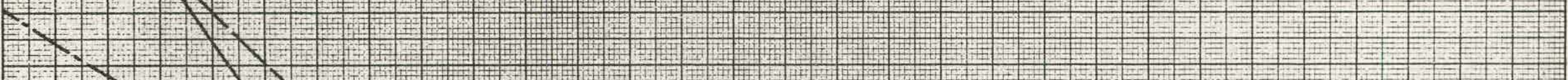

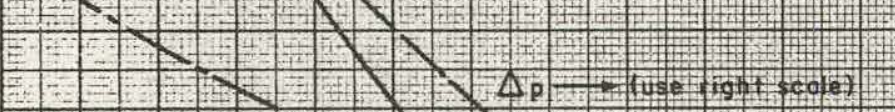

0.5
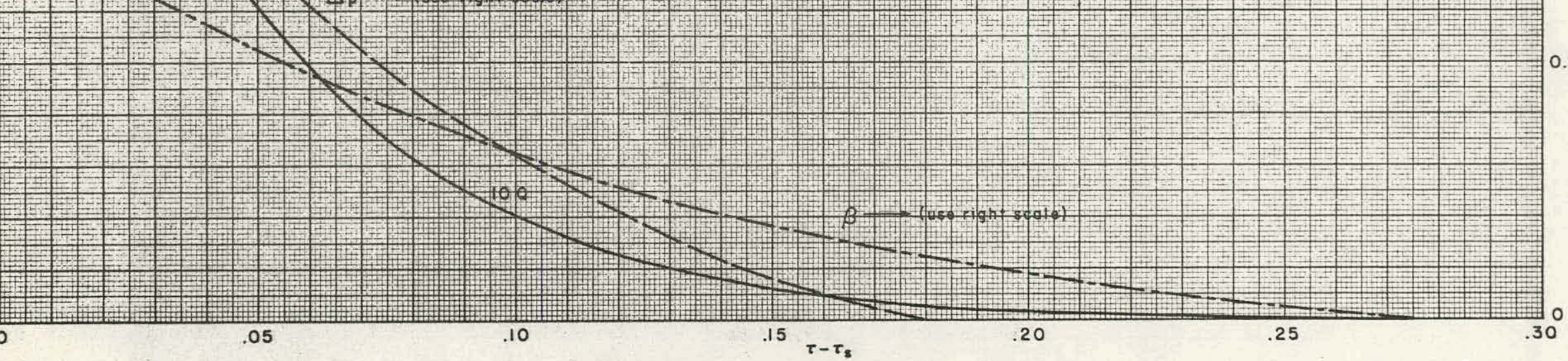
जू

.8

$\Delta_{p}^{Q}$

$\beta$

4

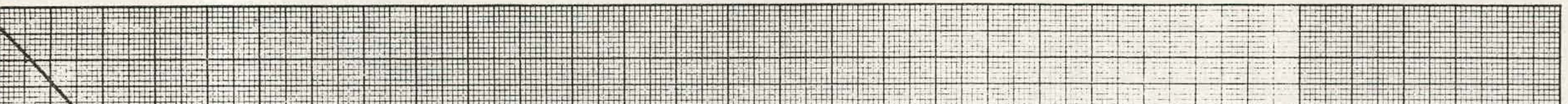
\begin{tabular}{|c|c|c|c|}
\hline \\
\hline
\end{tabular}

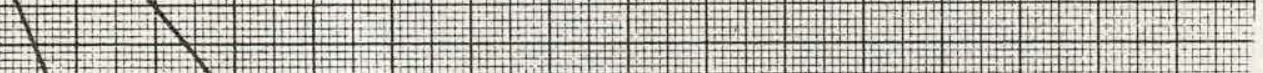

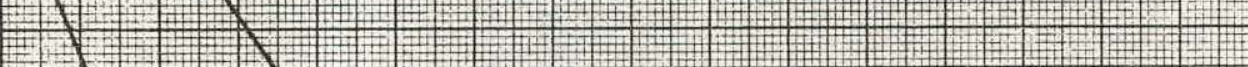
F $+21$

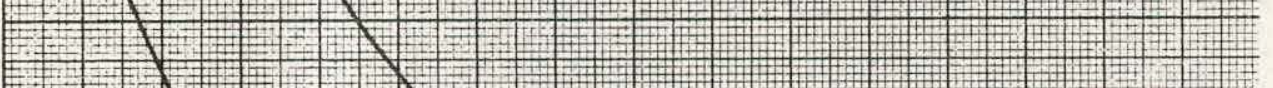

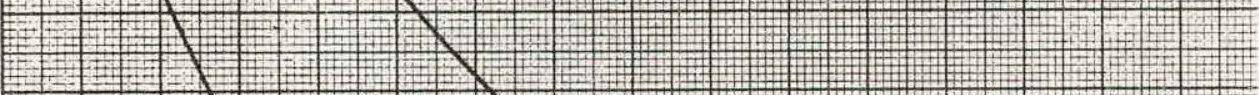
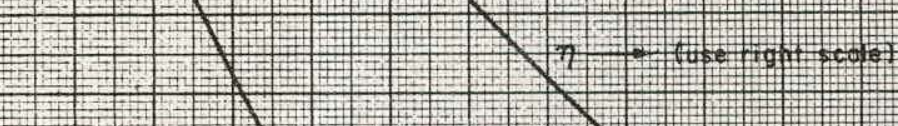

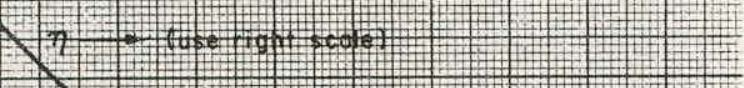

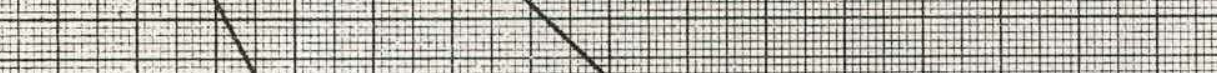

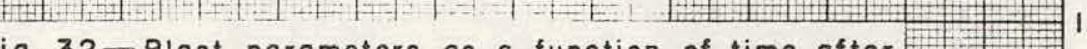
shock arrival at a radial distance of $\lambda=0.8810$

$D_{0}^{+}=$Durotion of positive dynamic pressure $=0.276$

$\mathrm{D}_{\Delta_{p}}^{+}=$Duration of positive overpressure $=0.205$

$\tau_{\mathrm{s}}=$ Shock orrival time $=0.4649$

$\Delta p=$ Overpressure $\left[\left(p-p_{0}\right) / p_{0}\right]$

$Q=$ Dynamic pressure $\gamma \eta \beta^{2} / 2$

$\eta=$ Density ratio $\left(\rho / \rho_{0}\right)$

$\theta=$ Temperature ratic $\left(T / T_{0}\right)$

$\beta=$ Porticle velocity $\left(u / c_{0}\right)$
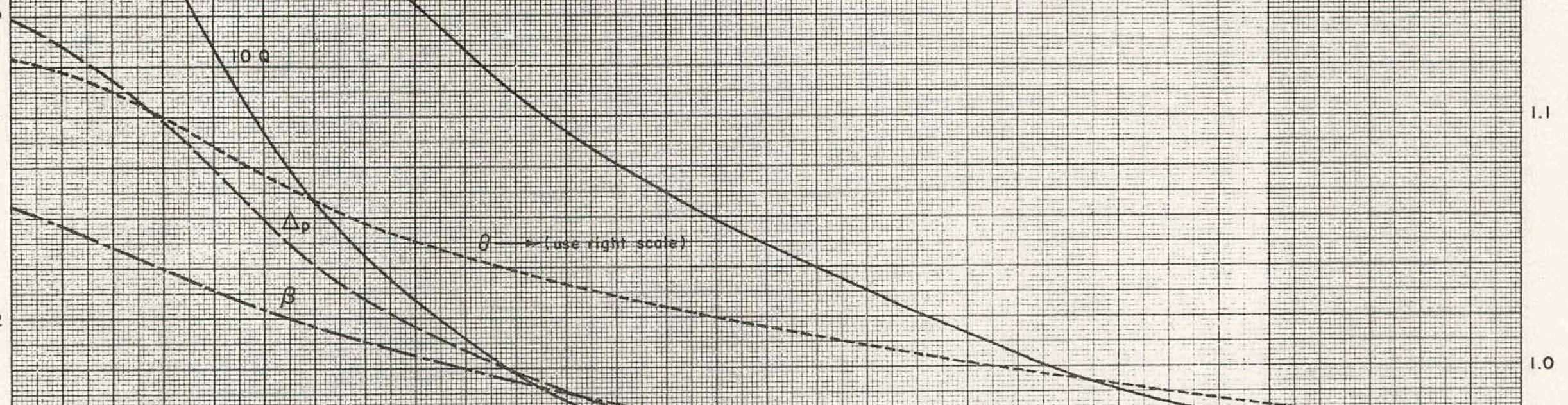

2.

F+

\begin{tabular}{lll}
\hline &
\end{tabular} 


\section{9}

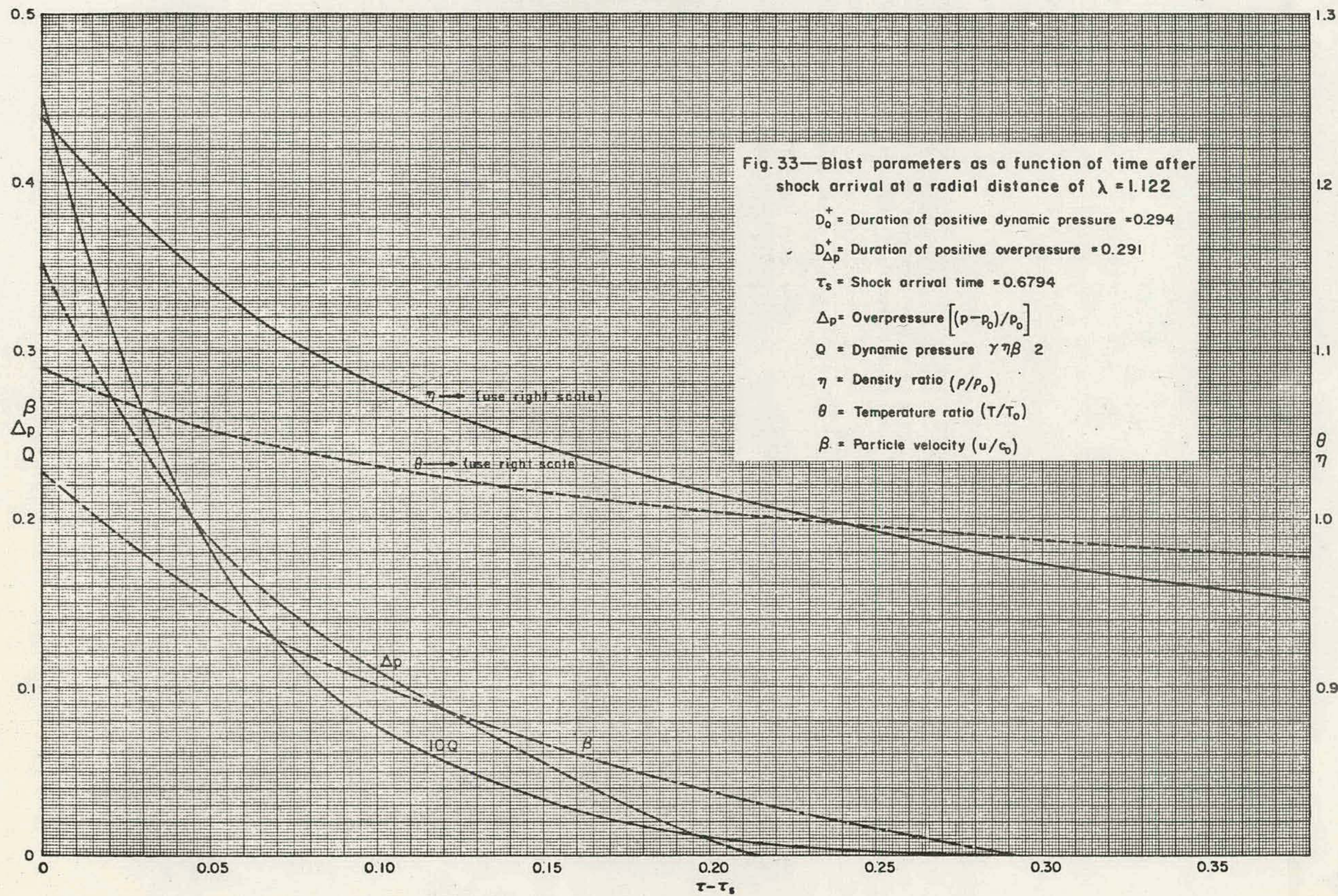


RM-1824-AEC

$12-3-56$

- 70 .
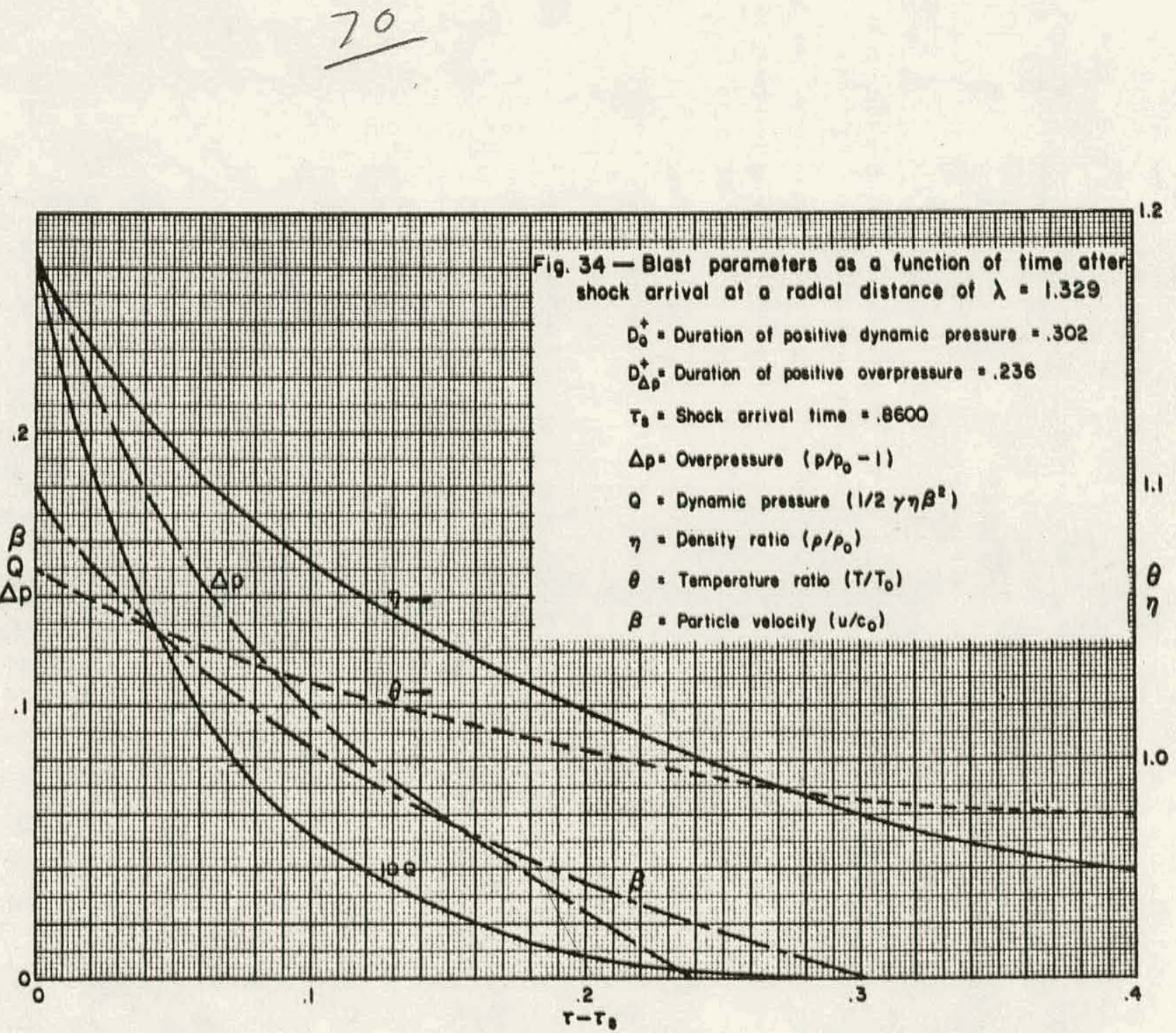


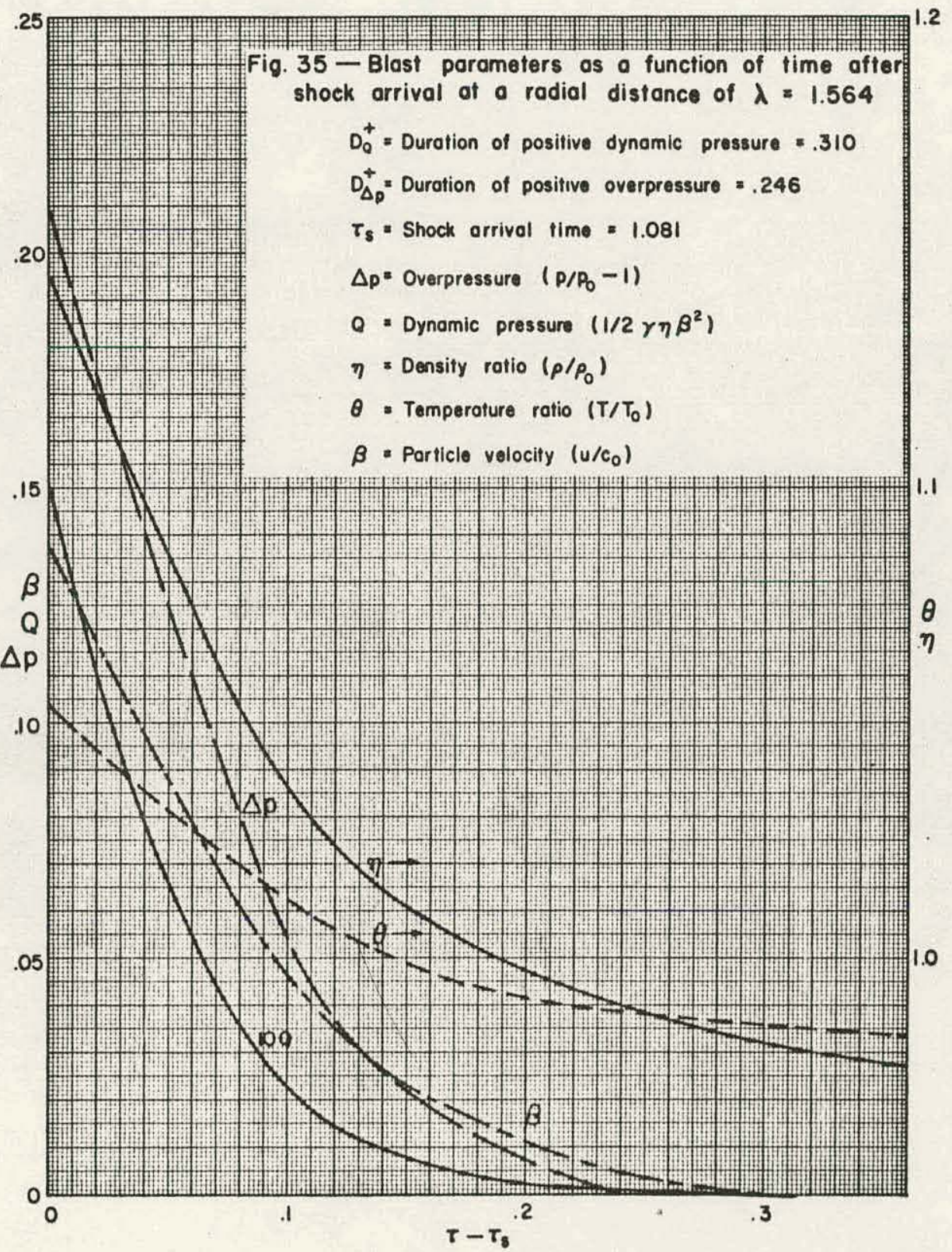


RM-1824-AEC

$12-3-56$

-72 -

72

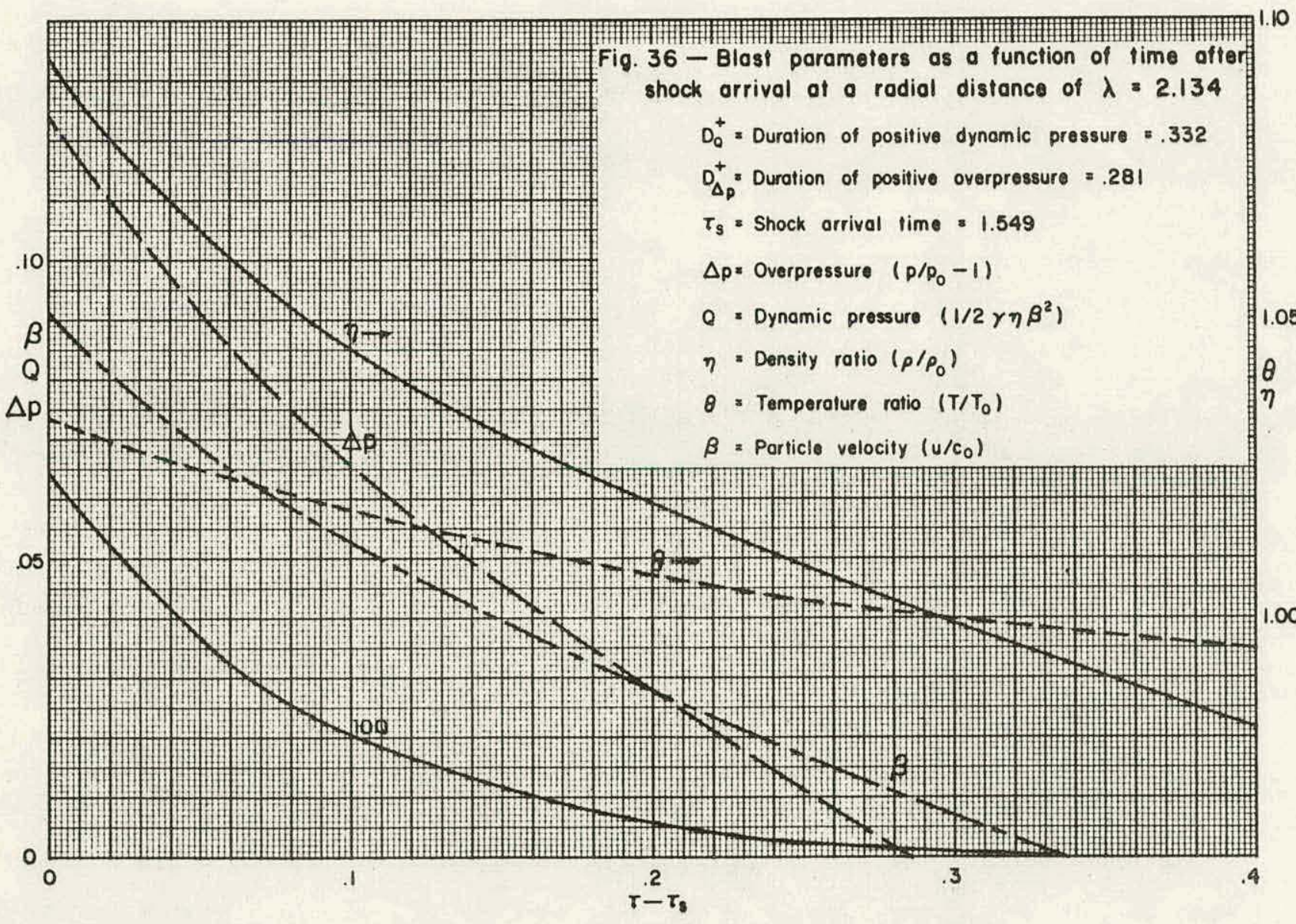


Fig. 37-Blast parameters as a function of time after shock orrival at a radial distance of $\lambda=2.581$

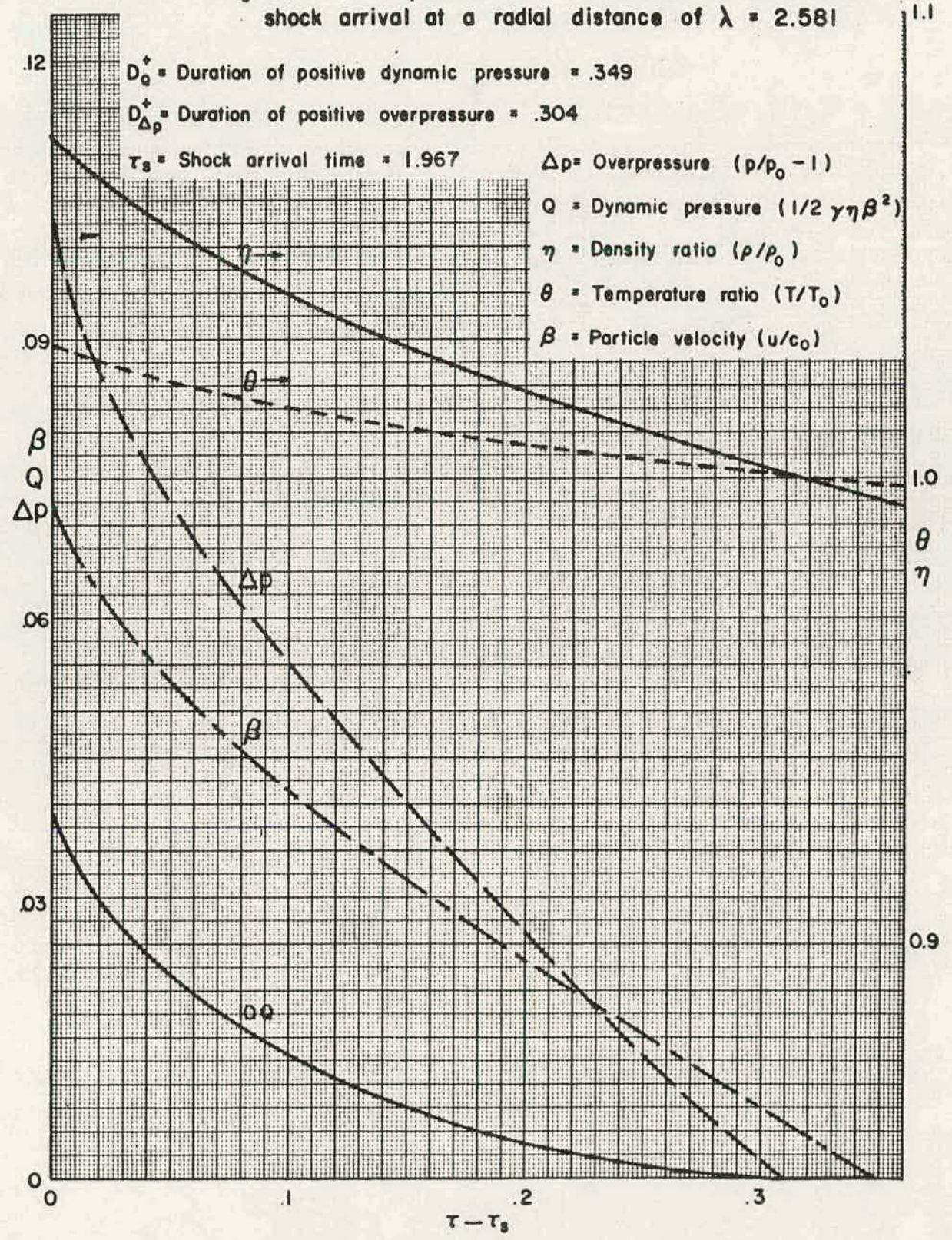


RM-1824-AEC

$12-3-56$

- 74 -

74

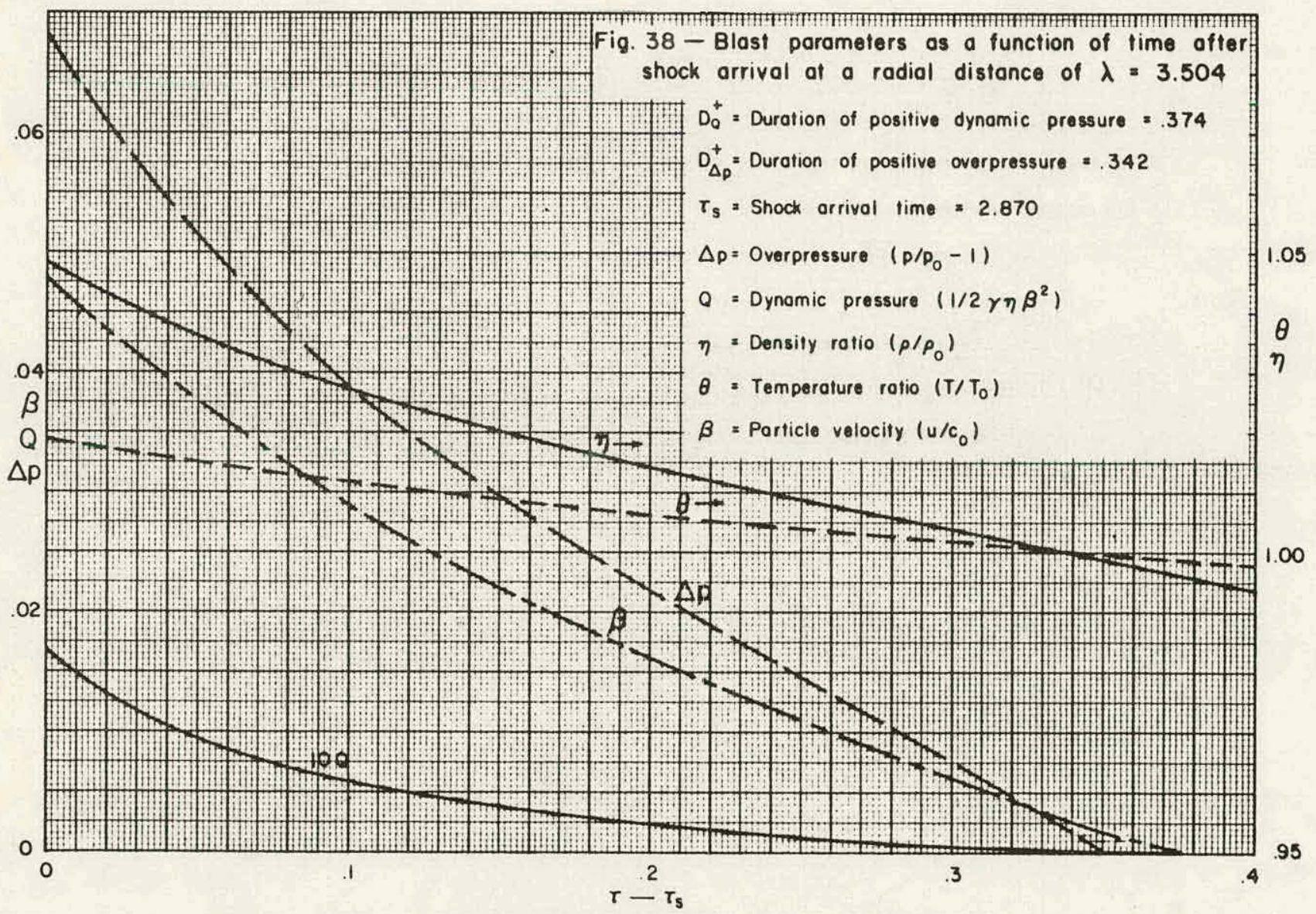




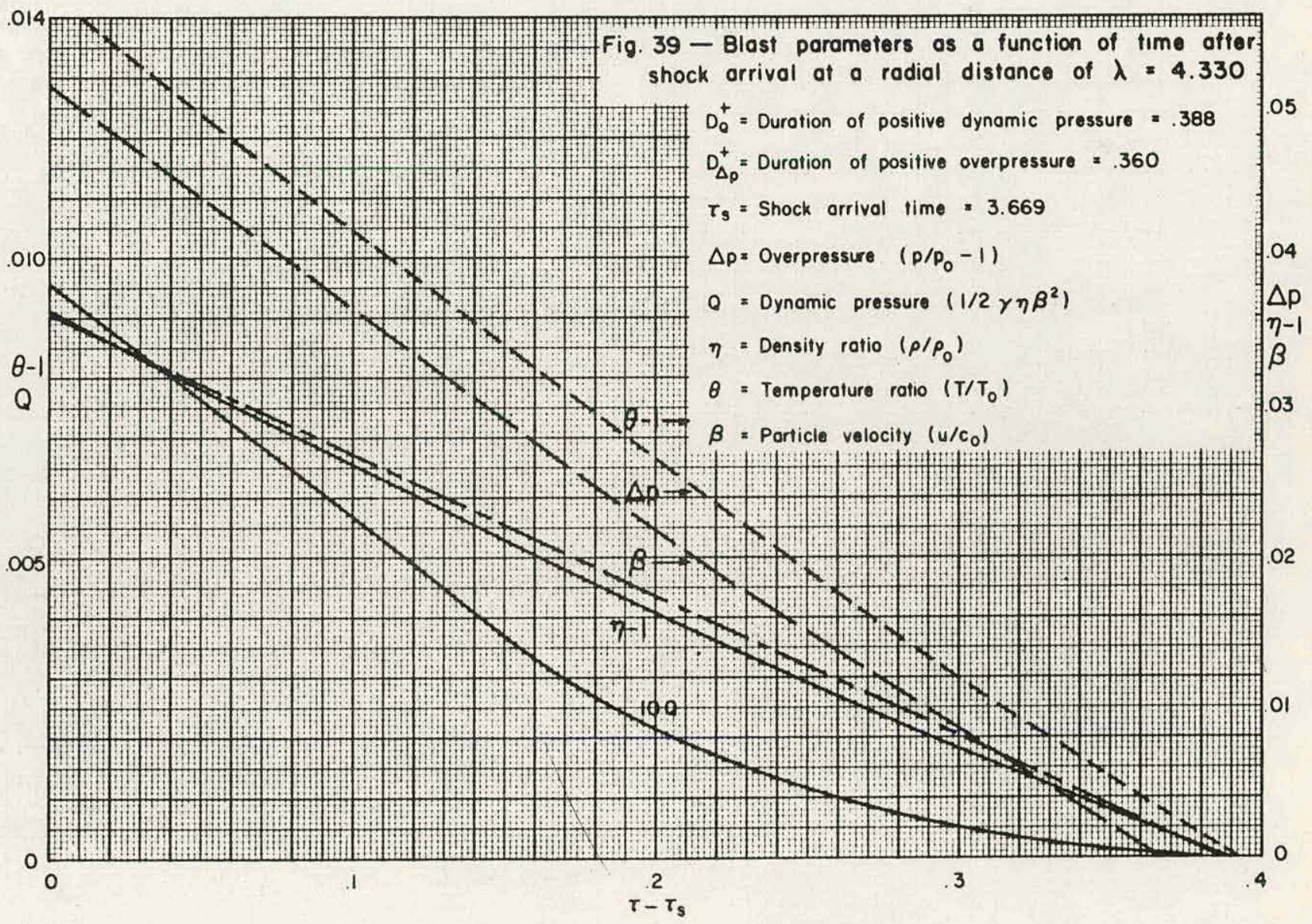


RM-1824-AEC

$12-3-56$

- 76 -

76

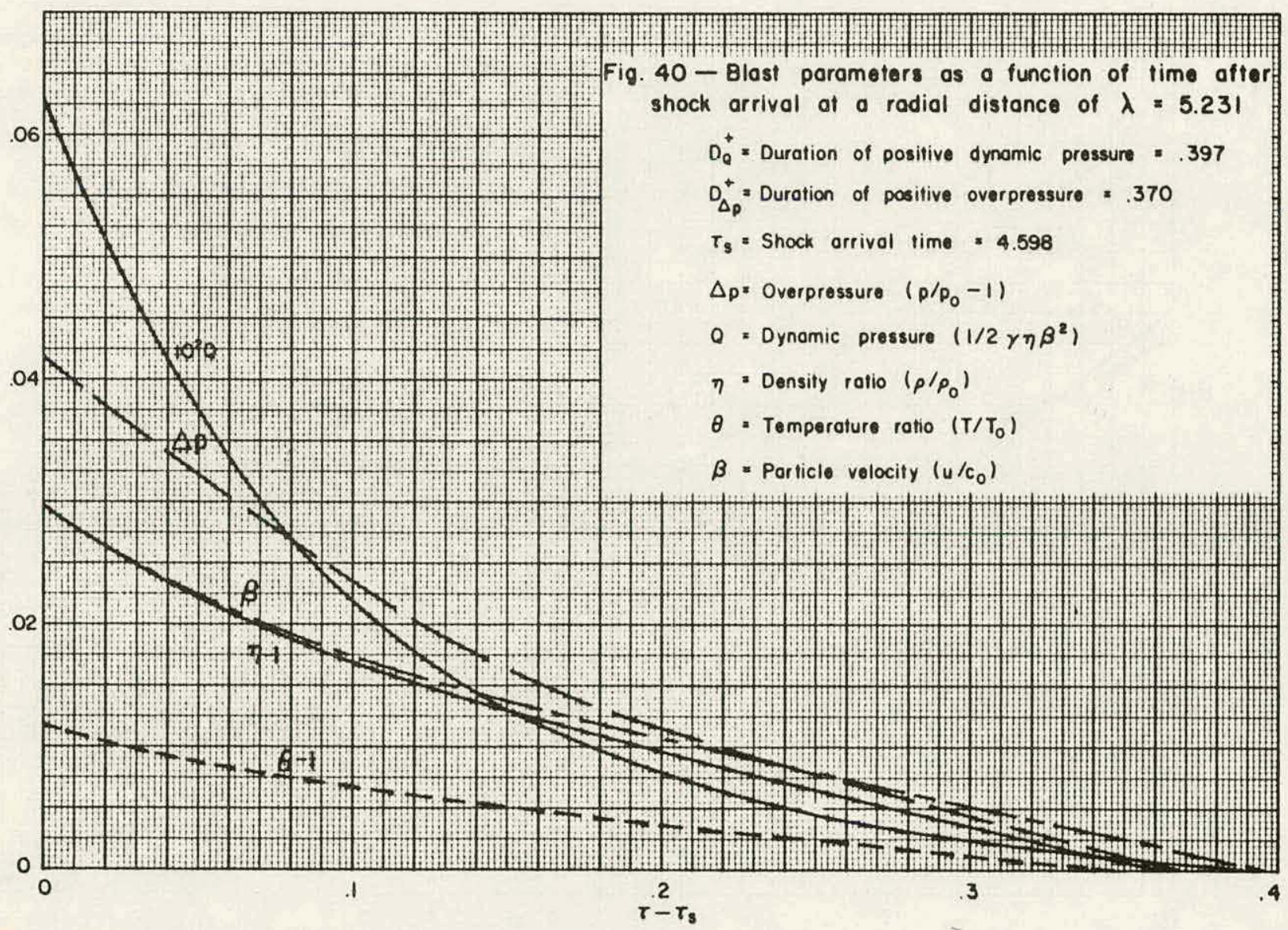




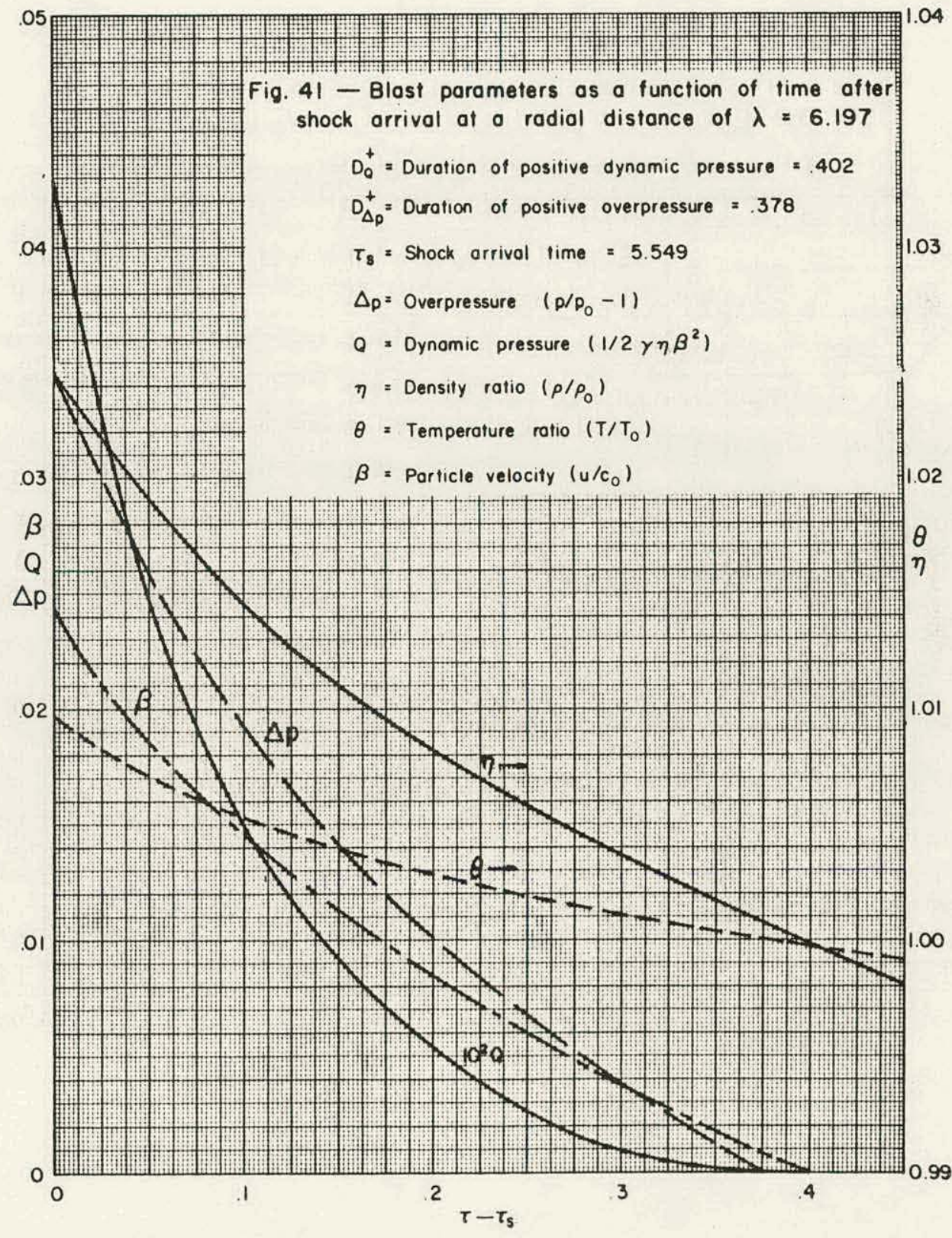


RM-1824-AEC

$12-3-56$

-78 -

78

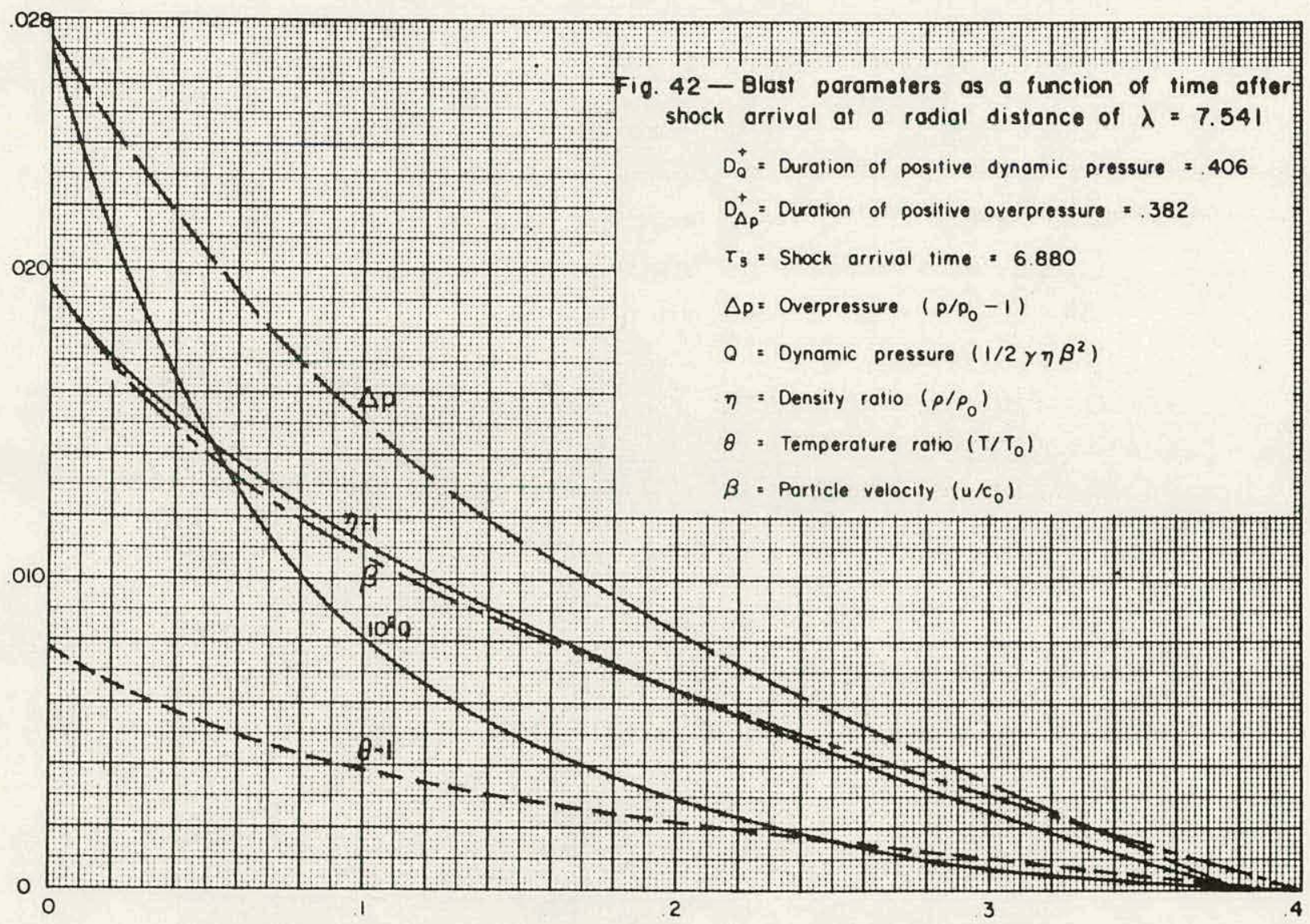




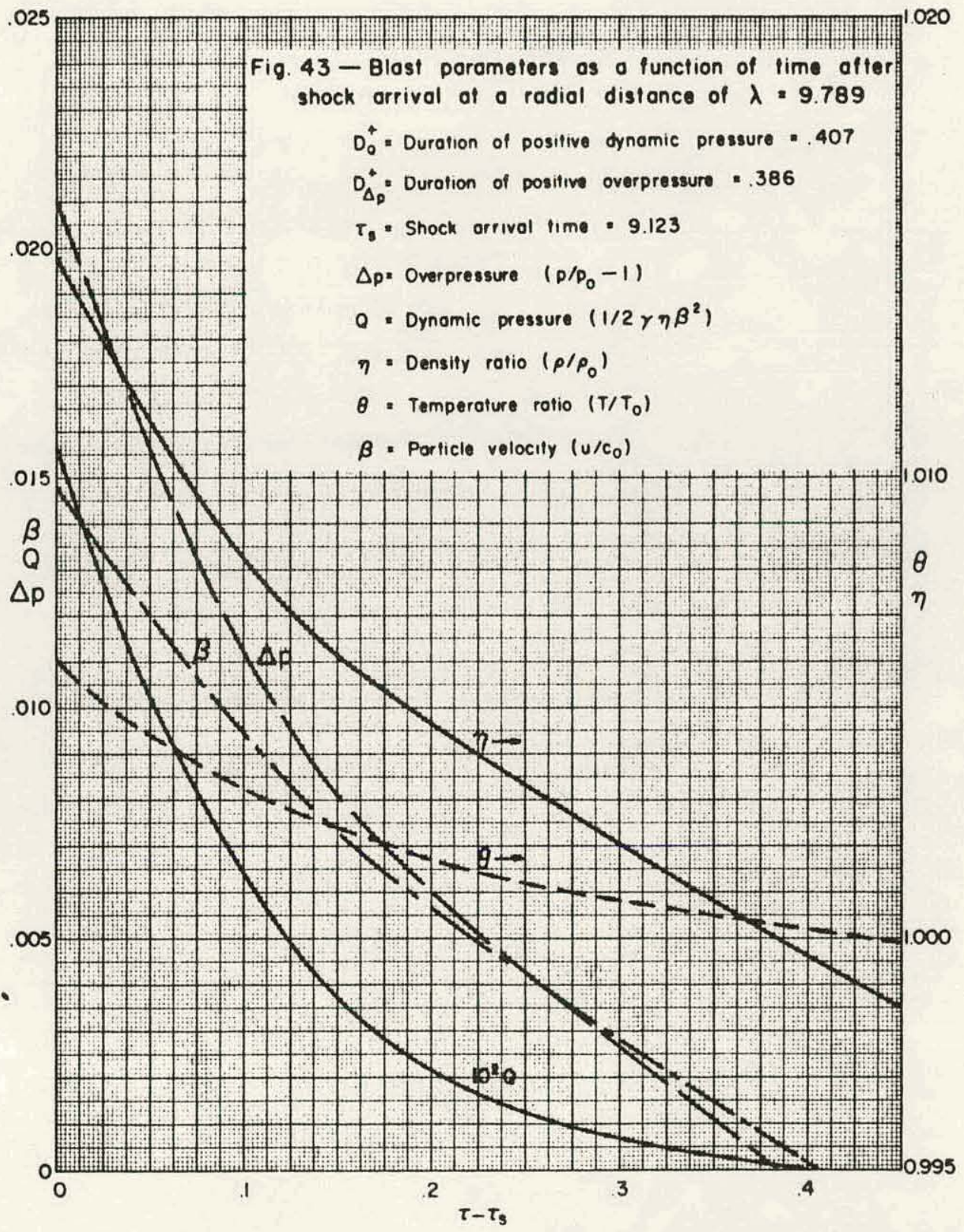


RM-1824-AEC

$12-3-56$

- 80 -
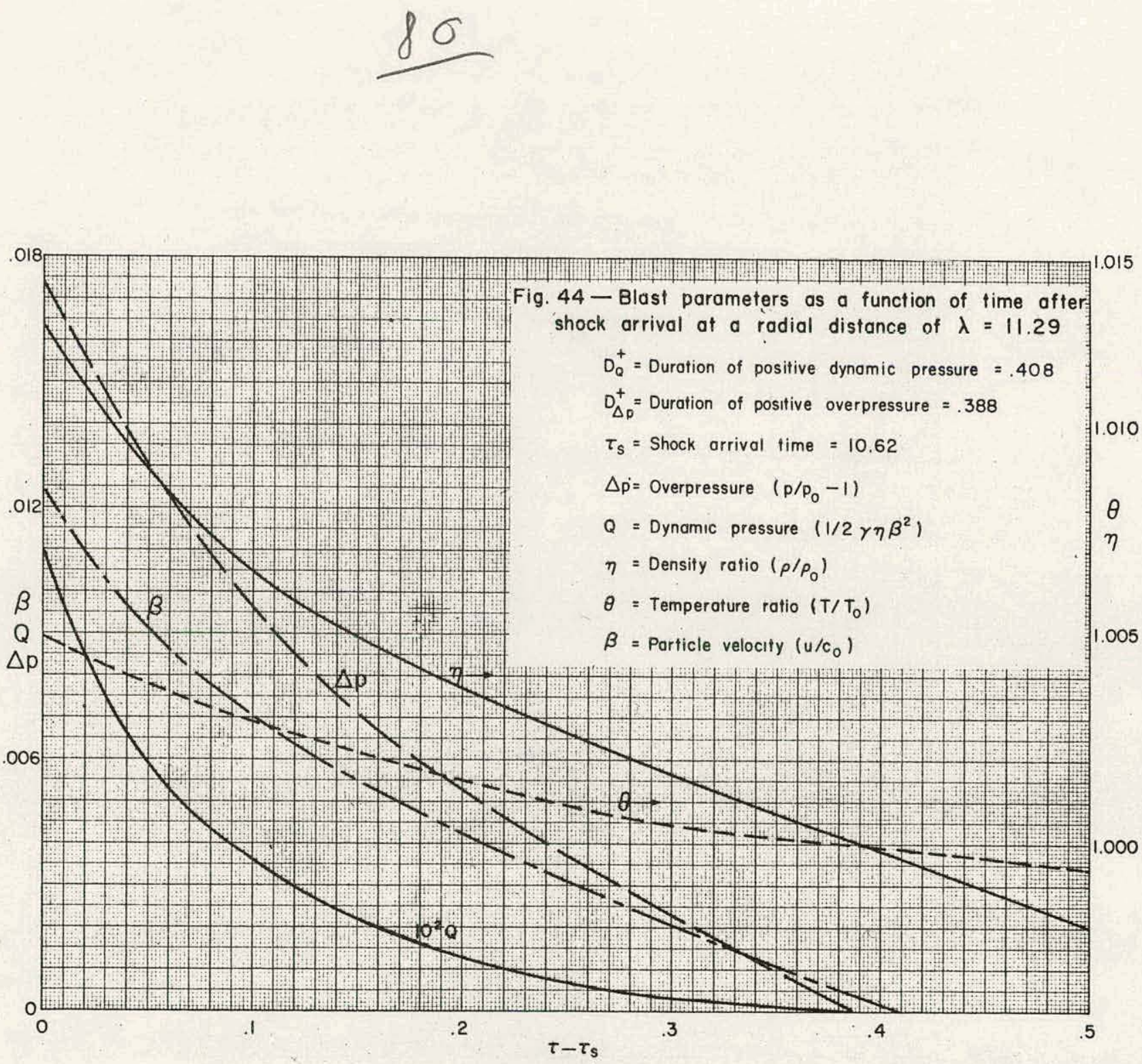


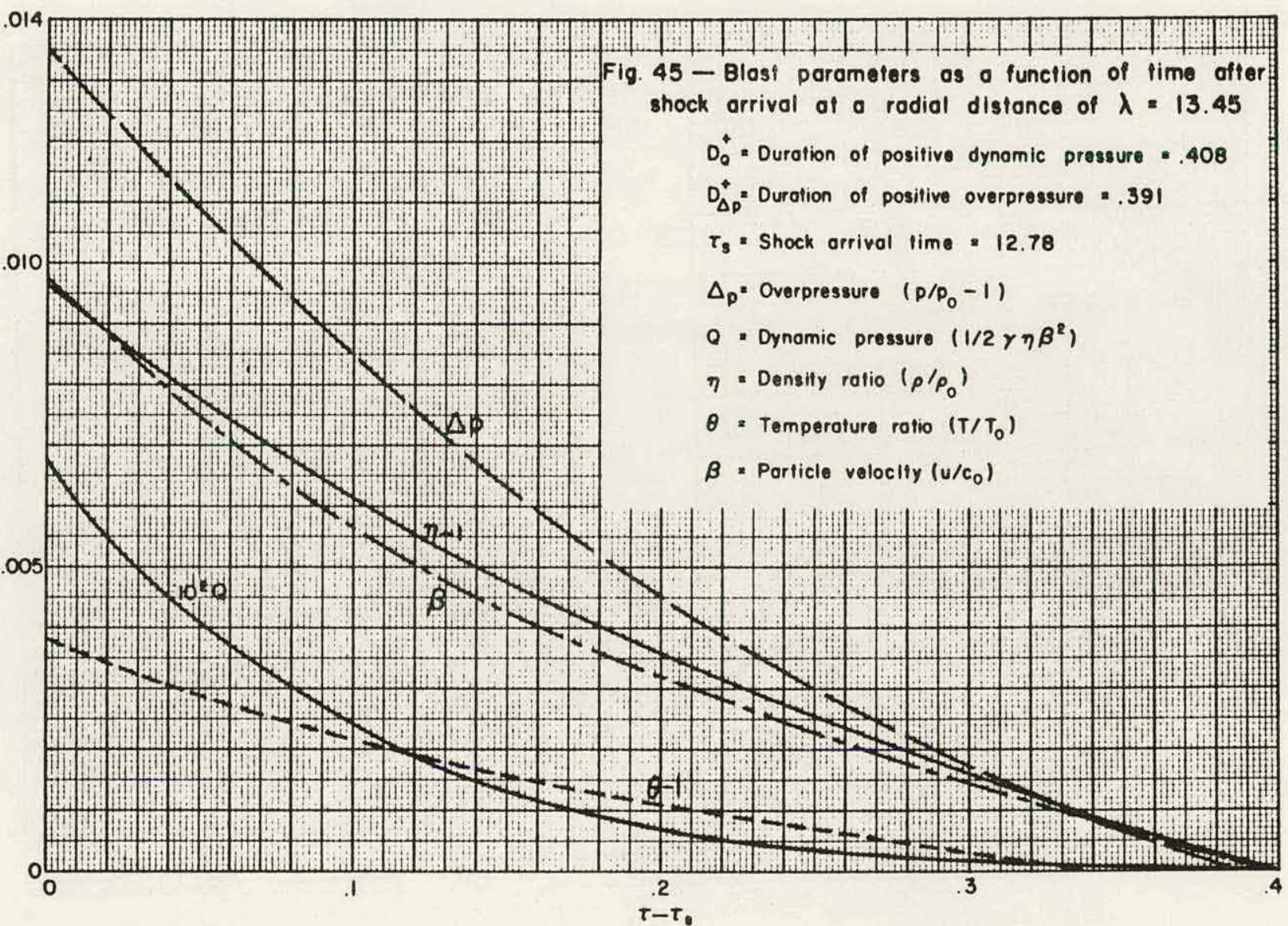


RM-1824-AEC

$12-3-56$

- 82 -

82

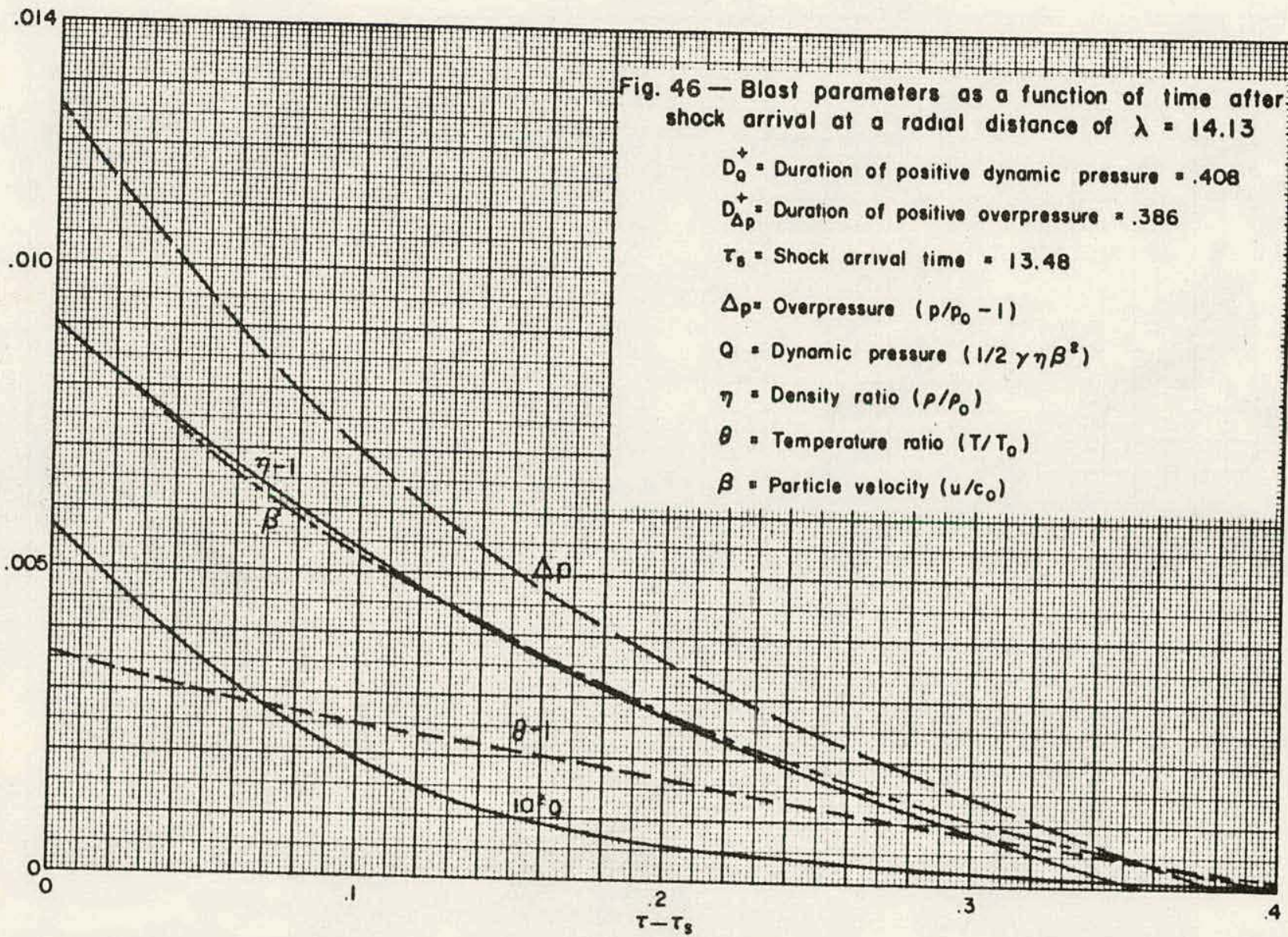

85 
THIS PAGE

\section{WAS INTENTIONALLY LEFT BLANK}

